University of Louisville

ThinkIR: The University of Louisville's Institutional Repository

$12-2010$

\title{
Dimensional relationships between the sphenoid sinus, maxillary sinuses and other craniomaxillofacial structures using cone-beam computed tomography analysis.
}

Richard Michael Halpern

University of Louisville

Follow this and additional works at: https://ir.library.louisville.edu/etd

\section{Recommended Citation}

Halpern, Richard Michael, "Dimensional relationships between the sphenoid sinus, maxillary sinuses and other craniomaxillofacial structures using cone-beam computed tomography analysis." (2010). Electronic Theses and Dissertations. Paper 564.

https://doi.org/10.18297/etd/564

This Master's Thesis is brought to you for free and open access by ThinkIR: The University of Louisville's Institutional Repository. It has been accepted for inclusion in Electronic Theses and Dissertations by an authorized administrator of ThinkIR: The University of Louisville's Institutional Repository. This title appears here courtesy of the author, who has retained all other copyrights. For more information, please contact thinkir@louisville.edu. 


\title{
DIMENSIONAL RELATIONSHIPS BETWEEN THE SPHENOID SINUS, MAXILLARY SINUSES AND OTHER CRANIOMAXILLOFACIAL STRUCTURES USING CONE-BEAM COMPUTED TOMOGRAPHY ANALYSIS
}

\author{
By \\ Richard Michael Halpern \\ B.Sc., Concordia University, 2003 \\ D.M.D., University of Saskatchewan, 2007 \\ A Thesis \\ Submitted to the Graduate Faculty of the \\ School of Medicine of the University of Louisville \\ in Partial Fulfillment of the Requirements \\ for the Degree of
}

Master of Science

Department of Anatomical Sciences and Neurobiology University of Louisville

Louisville, Kentucky

December 2010 
Copyright 2010 by Richard Michael Halpern

All rights reserved 


\title{
DIMENSIONAL RELATIONSHIPS BETWEEN THE SPHENOID SINUS, MAXILLARY SINUSES AND OTHER CRANIOMAXILLOFACIAL STRUCTURES USING CONE-BEAM COMPUTED TOMOGRAPHY ANALYSIS
}

By

\author{
Richard Michael Halpern \\ B.Sc., Concordia University, 2003 \\ D.M.D., University of Saskatchewan, 2007
}

A Thesis Approved on

November 24, 2010

by the following Thesis Committee:

Dr. Allan Farman, Thesis Director

Dr. William C. Scarfe, Thesis Co-Director

$\overline{\text { Dr. Bruce S. Haskell, Committee Member }}$ 


\section{DEDICATION}

This thesis is dedicated to my mother, Gloria. Regardless of the amount of doubt I

have ever had, she has been my biggest fan. Mom, you have been my pillar of strength by providing me with an unlimited amount of relentless, probably undeserving, belief in my ability to achieve anything I set my mind to. The successes I achieve in life are owed to you for your dedication to me.

This thesis is also dedicated to my girlfriend, Rachel Davis, without whom this study would not have happened. Rachel, your constant love, patience and support have become constants I have learned I can count on. The numerous accommodations you made to your life throughout this degree has made this thesis possible. 


\section{ACKNOWLEDGMENTS}

I would like to recognize the following individuals who I am greatly indebted to:

Dr. Allan G. Farman, Thesis Director, for inspiring me to conduct research. His insight and knowledgeable guidance allowed for this study to take place. I appreciate his lessons on advanced radiologic interpretation and for giving me the opportunity to conduct this research under his supervision.

Dr. William C. Scarfe, Thesis Co-Director, for being such a positive individual. His ability to perpetually find practical solutions to any challenge he is presented with make working with him an incomparable experience. I sincerely appreciate the uncountable hours he dedicated to help me design and complete this study and his continued support and encouragement throughout.

Dr. Bruce S. Haskell, Thesis Committee Member, for inspiring me with his excitement for research and the lessons he has granted me with in orthodontics. This world would be a much better place if it was filled with more people who went as far above and beyond what was necessary for the happiness of others as Dr. Haskell does. Gratitude is also deserved to his wife, Joy for supporting the endless hours Dr. Haskell spent working with me on this study. 
Dr. James P. Scheetz, Statistical Mentor, for teaching me and analyzing data during his retirement. The selfless efforts of Dr. Scheetz allowed this study to have reached completion in time. His exceptional ability to clarify statistics with few words define him as one of the most effective teachers I have ever had. His excitement for statistical analyses is contagious and made applying them an enjoyable experience. Appreciation is also merited to his wife, Mikki for supporting her husband's involvement in this project.

The above four mentors, I am deeply grateful to for their patience and devotion to my professional development and to the advancement of science. I am humbled and honoured to have studied and learned from such extraordinary individuals. I look forward to paying the generosity they have given me, "forward", in their honour.

To Mrs. Barbara Mercer, Mrs. Elaine Luckett, Mrs. Lisa Wade and Mrs. Lucinda Perry, radiology technologists for welcoming me, offering their technical expertise and supporting me to ensure my research was conducted as smoothly as possible.

To my Grandparents, Manny and the late Ray Gotlieb for pushing me to place higher education as a nonnegotiable goal in life. You have instilled in me the values of hard work, sacrifice and the desire to succeed. Your unshakable confidence in my educational abilities are one of the reasons I have been able to successfully pursue my lifelong professional goals.

To my Uncle Fred Kamens, I am deeply saddened your untimely passing happened only three months before you could see the completion of this thesis and learn of my acceptance into an orthodontic program. Your passion for dentistry inadvertently inspired me to pursue a career in health care and in dentistry in particular. 


\title{
ABSTRACT \\ DIMENSIONAL RELATIONSHIPS BETWEEN THE SPHENOID SINUS, MAXILLARY SINUSES AND OTHER CRANIOMAXILLOFACIAL STRUCTURES USING CONE-BEAM COMPUTED TOMOGRAPHY ANALYSIS
}

\author{
Richard Michael Halpern
}

November 24, 2010

Introduction: The study investigated dimensional relationships between the sphenoid and maxillary sinuses and other selected craniomaxillofacial structures by using traditional cephalometric and volumetric procedures based on cone beam computed tomographic (CBCT) data.

Methods and Materials: A retrospective three-dimensional (volumetric) and twodimensional (conventional cephalometric) analyses were conducted on CBCT datasets of 27 subjects who met the inclusional criteria from a sampled database of 2,290 individuals. Subjects were divided into 3 groups: (1) pre-fused spheno-occipital synchondrosis $<18$ years $(n=8)$, (2) fused spheno-occipital synchondrosis $<18$ years $(n=9)$, and $(3) \geq 18$ years with fused spheno-occipital synchondosis $(n=10)$.

Results: Differences between studied groups were found for linear and angular measurement. Specific correlations were found between certain topographic and internal measurements, and some sinus dimensions and other selected craniomaxillofacial structures. 
Conclusion: Dimensional correlations exist between the sphenoid and maxillary sinuses and development of other selected craniomaxillofacial structures.

Keywords: Cephalometry; Computed tomography, cone-beam, x-ray; Development, maxillofacial; Malocclusion, dental; Sinus, maxillary; Sinus, paranasal; Sinus, sphenoid; 


\section{TABLE OF CONTENTS}

PAGE

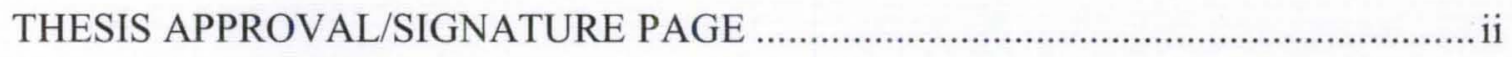

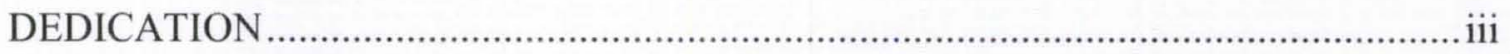

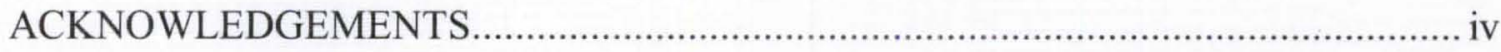

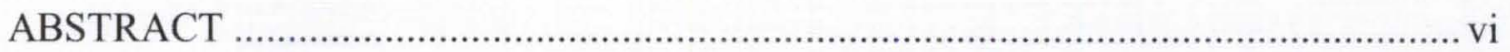

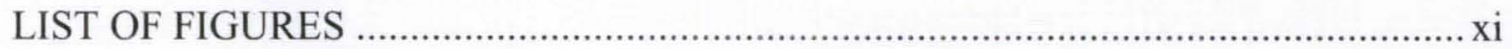

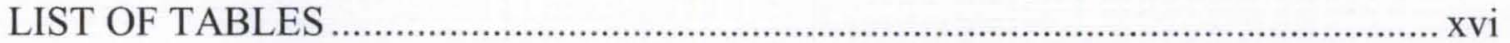

CHAPTER

I. INTRODUCTION AND LITURATURE REVIEW ........................................... 1

II. STATEMENT OF OBJECTIVES AND HYPOTHESIS …….............................. 8

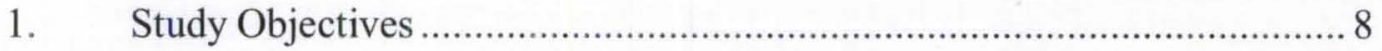

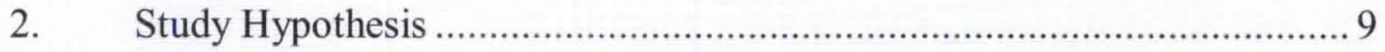

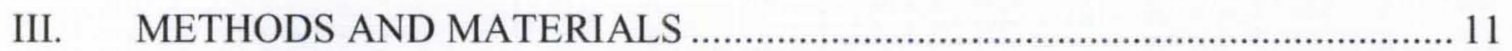

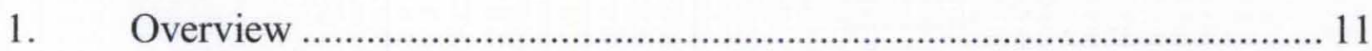

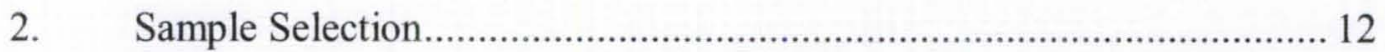

viii 


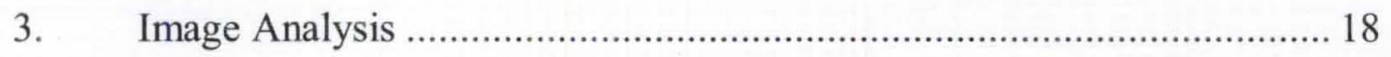

4. Determination of Stage of Sphenoidal Development ............................... 19

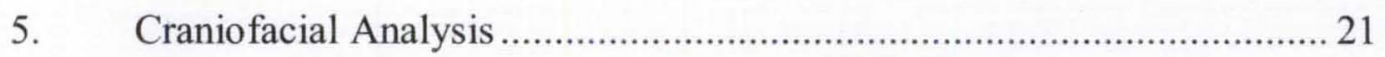

6. Three Dimensional Standardization........................................................ 21

7. Linear and Angular Measurement …………............................................ 24

8. Linear and Angular Measurements ......................................................... 29

9. Volumetric Measurement Procedures and Description.............................. 33

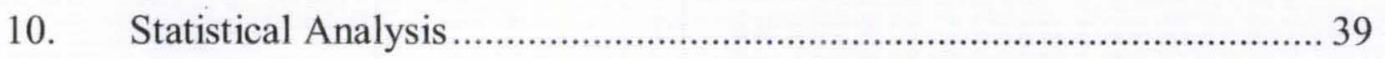

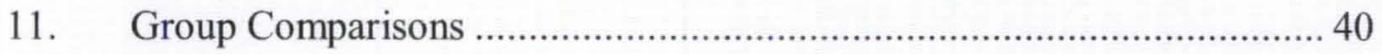

12. Intra-Observer Reliability and Repeatability ............................................ 41

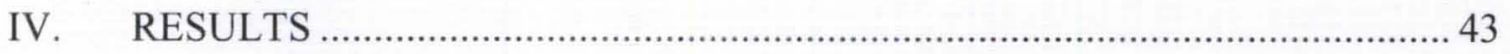

1. Variation in Measurements Between Groups......................................... 48

2. Relationship Between Linear, Angular and Volumetric Relationship of the Sinuses and Other Selected Craniomaxillofacial Dimensions......... 50

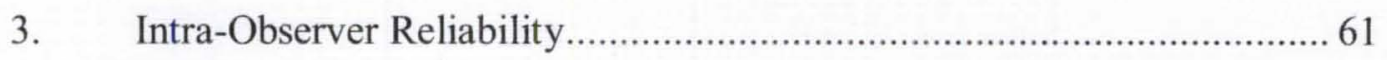

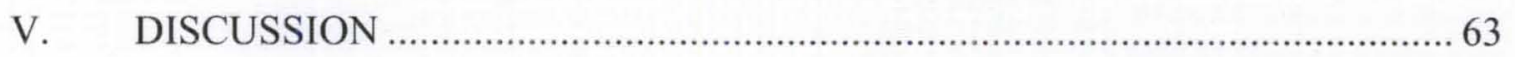

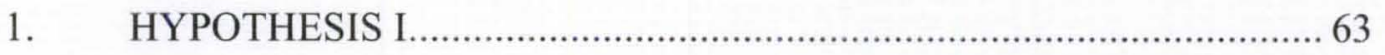

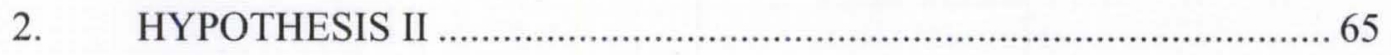

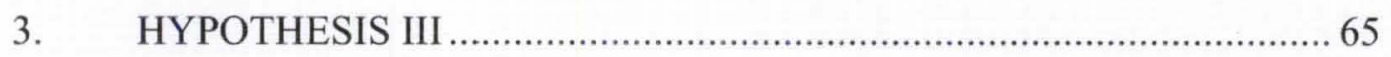

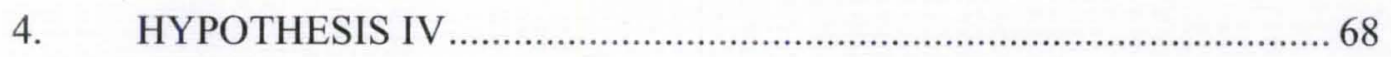




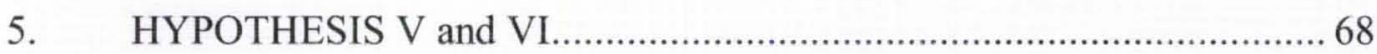

6. LIMITATIONS AND FUTURE STUDIES....................................... 69

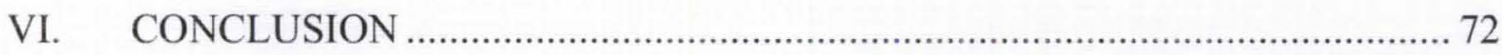

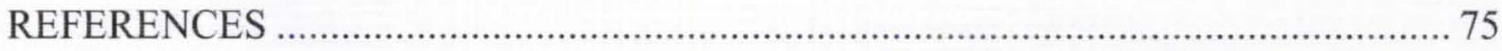

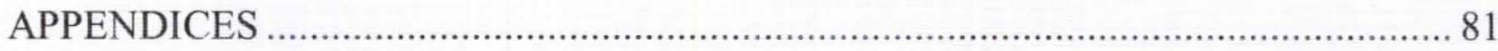

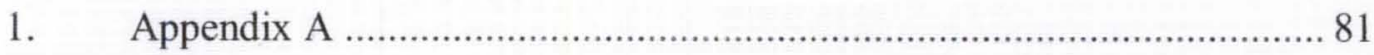

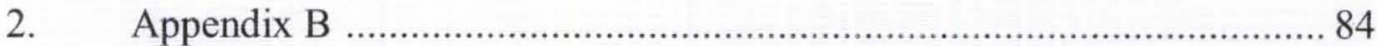

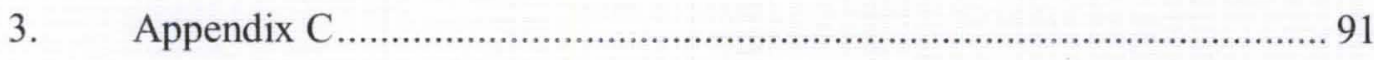

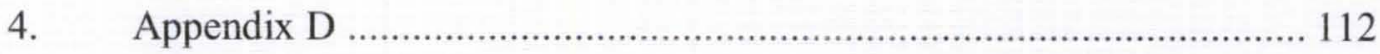

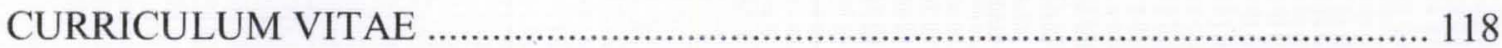




\section{LIST OF FIGURES}

FIGURE

PAGE

1. Records Exclusion Flowchart Part 1 of 2 ................................................... 14

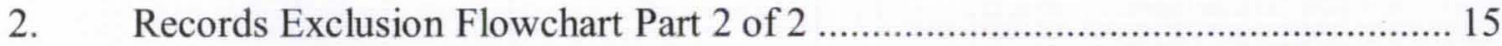

3. Second attempt at increasing sample size of subjects under 20 years old imaged after initial database was assessed................................................... 17

4. Third attempt at increasing sample size by using Orthodontic Database ............ 18

5. Screen capture of segment of Dolphin 3D display demonstrating location and selection of 3D option (a) and options available (b) and subsequent loading

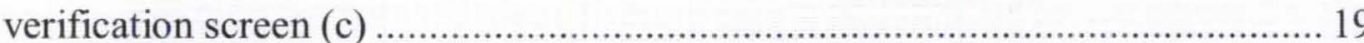

6. Cropped screen capture of Dolphin 3D Imaging software demonstrating selection of 4-Equal Layout option (a) and resultant screen display (b) 20

7. Cropped sagittal image of a 12 year old subject prior to fusion of the spheno-occipital synchondrosis representative of subjects within Group 1 (a). Cropped sagittal image of a 14 year old subject demonstrating fusion of the spheno-occipital synchondrosis representative of subjects

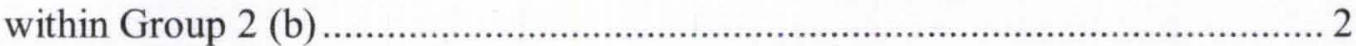

8. Axial orientation using the ANS and PNS landmarks ................................... 22 
9. Coronal orientation using the left (a) and right (b) EAM landmark in the sagittal view 23

10. Sagittal orientation using the right (a) and left (b) Orbitale landmark 24

11. Screen capture of Dolphin 3D Imaging software demonstrating location of initial access to measurement screen window. 24

12. 3D Digitize/Measurement window for adding lines (a), 2D-Lateral

Digitize/Measurement window for Steiner/SM analysis (b), and 3D

Digitize/Measurement window for adding angles (c) 26

13. Image of coronal and sagittal slice demonstrating differences in display with a slice thickness of $0.5 \mathrm{~mm}$ (a) and $5.0 \mathrm{~mm}$ (b) 27

14. Sequence of coronal images demonstrating the effect of altering brightness and contrast. (a) Initial auto-adjusted brightness and contrast, (b) decreased contrast and, (c) increased brightness 28

15. Cropped coronal images of the right maxillary sinus (a), demonstrating the effect of increasing magnification (b) and further magnification increase used to enlarge the view of the inferior margin of the sinus (c) 28

16. Screen capture of Dolphin 3D Imaging software display indicating location of Sinus/Airway option

17. Screen capture of Dolphin 3D Imaging software displaying Sinus/Airway

Window 
18. Cropped mid-sagittal image demonstrating outlining of the borders of the sphenoid sinus (a). Lateral sagittal image plane with sinus dimension larger than initial tracing (b). Magnified image shown in (b) demonstrating borders after adjustment allowing for entire containment of sinus (c) .......................... 36

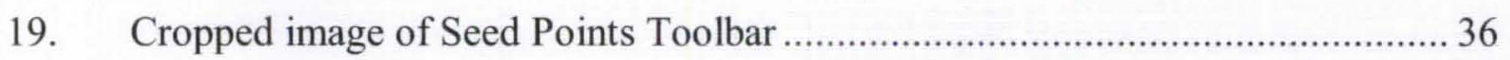

20. Magnified cropped image demonstrating initial placement of seed point within sinus colorizing values within a specific voxel range (a), lateral sagittal slice showing non-inclusion of a part of the sinus (b) and addition of secondary seed point including volume within this separated region (c) ......... 37

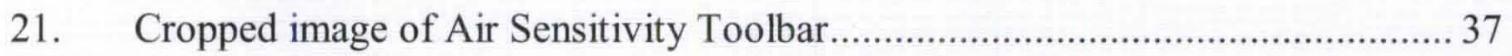

22. Maximum seed sensitivity without extending to non-representative area (a) and excessive seed sensitivity that has extended to non-representative

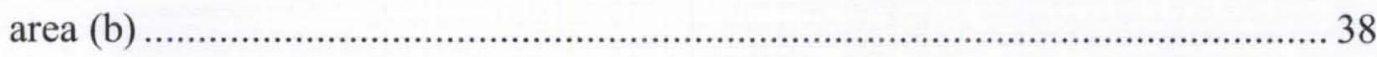

23. Cropped image of Update Airway Volume Toolbar ....................................... 38

24. Screen capture of Dolphin 3D Imaging software display indicating airway volume 39

25. Random sequence generator used to determine which subjects to remeasure (a), resultant random numbers generated (b)

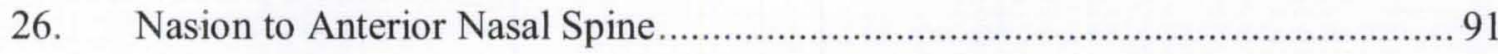

27. Anterior Nasal Spine to Upper and Lower Incisor Tip................................ 92

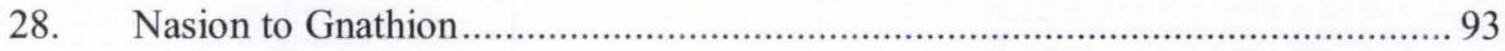

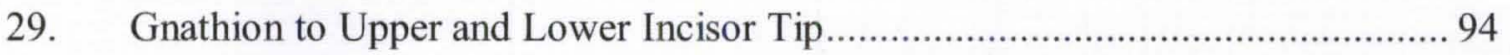

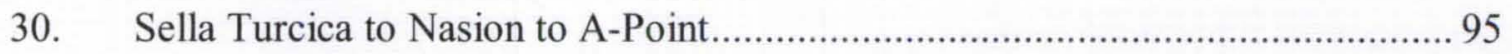




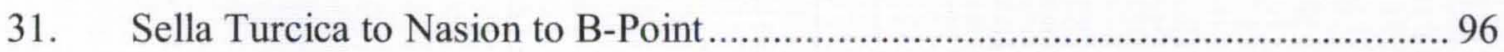

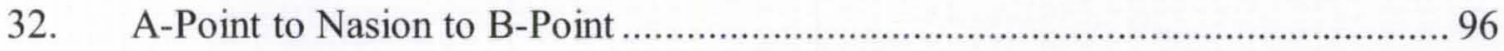

33. Sella Turcica to Posterior Nasal Spine ............................................................ 97

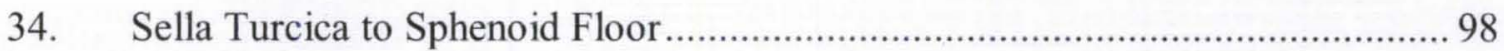

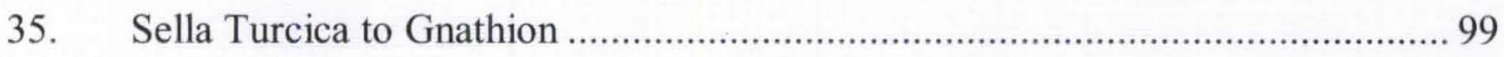

36. Sella Turcica to Posterior Nasal Spine to Gnathion ...................................... 100

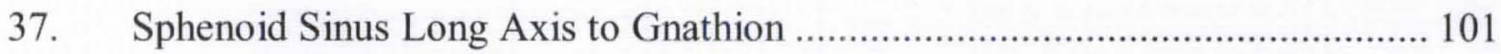

38. Maximal Sphenoid Sinus Posterior-Anterior Length in lateral sagittal slice (a), and in a different lateral sagittal slice measured at

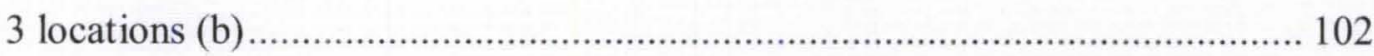

39. Maximal Right Maxillary Sinus Posterior-Anterior Length ............................. 102

40. XY Axis Angle (Nasion to Basion with Sella Turcica to Gnathion) ................. 103

41. Intersection of crosshairs over Sella Turcica in midsagittal view (a), measurement from crosshairs to Gonion in sagittal view (b), coronal view

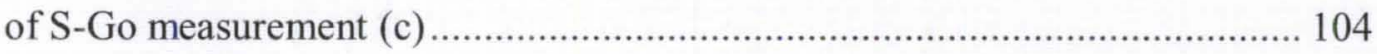

42. Midsagittal plane with markings placed at Sella Turcica, Nasion and Gnathion (a), and in a lateral sagittal plane with marking placed at Gonion (b) 105

43. Maximal Sphenoid Sinus Superior-Inferior Height ................................... 106

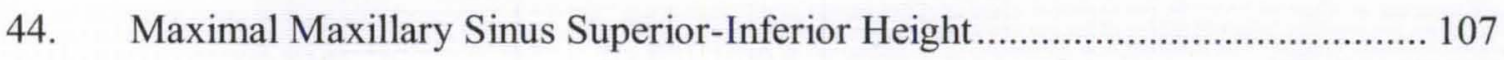

45. Maximal Lateral Orbital Distance. Crosshair alignment over Nasion (a), Maximal Lateral-Lateral Width (b) 108 
46. Maximal Sphenoid Sinus Medial-Lateral Width in coronal slice (a), Maximal Sphenoid Sinus Medial-Lateral Width measured in another coronal slice (b)

47. Maximal Left Maxillary Sinus Medial-Lateral Width ... 109

48. Maximal Outer and Minimal Inner Right to Left Maxillary Sinus

Medial-Lateral Width 110 


\section{LIST OF TABLES}

TABLE

PAGE

1. Midline and Bilateral Topographic Points Used as Landmarks for the Measurements .... 30

2. Definition of Sagittal Linear Dimensions Measurements

3. Coronal Linear Dimensions Measurements....................................................... 32

4. Sagittal Angular Dimensions Measurements......................................................... 33

5. Group Sample Size .............................................................................................. 43

6. Comparison of Mean Linear Measurements ( \pm standard deviation) for Craniofacial

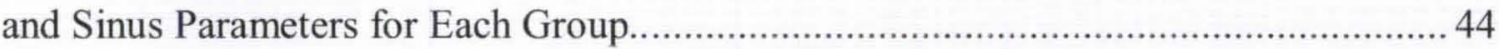

Comparison of Mean Linear Measurements ( \pm standard deviation) for Craniofacial and Sinus Parameters for Each Group (Continued) ….......................................... 45

7. Comparison of Mean Angular Measurements ( \pm standard deviation) for Craniofacial

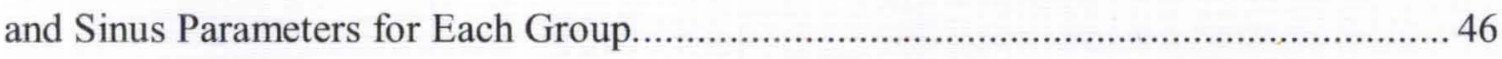

8. Comparison of Mean Volumetric Measurements ( \pm standard deviation) for Sinus

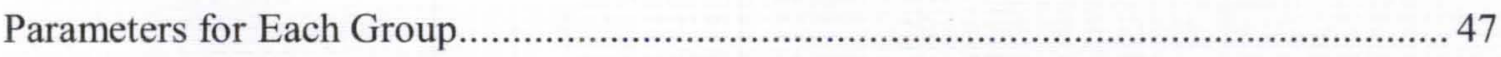

9. Summary of ANOVA Comparisons Between all Groups ....................................... 48

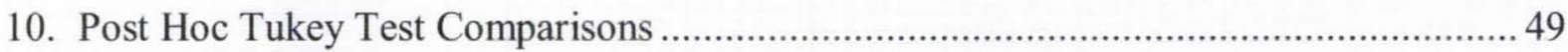

11. Bivariate Pearson Correlations Between Sinus and Craniomaxillofacial Dimensions ( $\mathrm{R}$ (p value)) 
12. Bivariate Pearson Correlation Between Sphenoid Sinus and Craniomaxillofacial Dimensions ( $\mathrm{R}(\mathrm{p}$ value $)$ )

13. Bivariate Pearson Correlations Between Craniomaxillofacial Dimensions

( $\mathrm{R}$ ( $\mathrm{p}$ value))

14. Bivariate Pearson Correlations Between Craniomaxillofacial Dimensions

( $\mathrm{R}$ ( $\mathrm{p}$ value))

15. Bivariate Pearson Correlations Between Craniomaxillofacial Dimensions

( $\mathrm{R}$ ( $\mathrm{p}$ value) $)$

16. Bivariate Pearson Correlations Between Craniomaxillofacial Dimensions

( $\mathrm{R}$ ( $\mathrm{p}$ value) $)$

17. Sphenoid Sinus Width Multiple Regression with Predictor Variables Lat Orb

Distance, Outer Mx Sinus and Inner Mx Sinus.

18. Sphenoid Sinus Hgt Multiple Regression with Predictor Variables S-PNS and

Post Facial Hgt.

19. Sphenoid Sinus Vol Multiple Regression with Predictor Variables Sph Sin Hgt, Sph Sin Width and S-PNS

20. Sphenoid Sinus Vol Multiple Regression with Predictor Variables Sph Sin Hgt and Sph Sin Width.

21. Sphenoid Sinus Vol Multiple Regression with Predictor Variables Lat Orb Distance, Outer Mx Sinus and Inner Mx Sinus. 58

22. Mx Sin Width* Multiple Regression with Predictor Variables Lat Orb Distance, Outer Mx Sinus and Inner Mx Sinus. 58

xvii 
23. Mx Sin Vol* Multiple Regression with Predictor Variables Lat Orb Distance, Outer Mx Sinus and Inner Mx Sinus.

24. Mx Sin Vol* Multiple Regression with Predictor Variables Mx Sin PA Length*, Mx Sin Hgt*, Mx Sin Width* and Inner Mx Sinus.

25. Mx Sin Vol* Multiple Regression with Predictor Variables Mx Sin PA Length*, Mx Sin $\mathrm{Hgt}^{*}$ and Mx Sin Width* 60

26. N-ANS Multiple Regression with Predictor Variables Mx Sin Vol*, Mx Sin Width*, Mx Sin $\mathrm{Hgt}^{*}$ and Mx Sin PA Length*

27. N-ANS Multiple Regression with Predictor Variable Mx Sin PA Length*.... 61

28. T-Test Results of Remeasured Values. 61

29. Intraclass Correlation Coefficient. 62 


\section{CHAPTER I INTRODUCTION AND LITERATURE REVIEW}

The field of Orthodontics has relied on three dimensional (3D) structures being represented by two dimensional (2D) projections for over half a century (Farman and Scarfe, 2006). In 1972 Godfrey Hounsfield introduced the Computed Tomography (CT) scanner based on his findings with Allan MacLeod Cormack (Hounsfield, 1980). CT imaging uses ionizing radiation to produce representations of certain biologic structures to be viewed in 3D. Initially CT scanners were large, costly and emitted high radiation doses. Adhering to the ALARA principle, ('as low as reasonably achievable') and analysing the cost/ benefit ratio, CT imaging was rarely used in dentistry (Farman and Scarfe, 2006).

In the late 1990's Cone-Beam Computed Tomography (CBCT) machines began to become commercially available with the first introduced in the United States market in 2001. CBCT scanners are much smaller, cheaper and emit less radiation compared to comparable CT units (Schulze, et al., 2004). CBCT allows for better spatial appreciation than $2 \mathrm{D}$ radiography. Clinicians had previously relied on interpreting the relative positions of $3 \mathrm{D}$ structures from multiple 2D images. For these reasons, CBCT machines began to grow in popularity and are becoming more common place in dentistry.

Consequently, software companies have begun to develop user-friendly applications to serve the imaging needs of the general dentist and dental specialist alike. 
Today, CBCT is being used in Orthodontics to assist in diagnosis, treatment planning and predicting growth and assessing treatment therapy. Orthodontists have used CBCT for assessing: tooth morphology, position of impacted teeth, and spatial relationship of teeth to adjacent structures. CBCT images sometimes can allow for more precise discernment of supernumerary teeth, pathoses, temporomandibular joints and airway volumes than is possible with $2 \mathrm{D}$ images. Applications have been created for orthodontists to use virtual dento-alveolar models, super-impose hard and soft tissues before and after various treatments such as orthognathic surgery as well as to view thin slices or half the face without overlap. DICOM (Digital Imaging and Communications in Medicine) compatible software allows the practitioner to assess facial symmetry, bone defects in cleft-palate patients, and sites for temporary orthodontic mini-implants. 3D imaging can also facilitate better patient-practitioner and practitioner-practitioner communication (Hechler, 2008; Chenin, et al., 2009; Mah, et al., 2010).

Orthodontists treat patients in all three dimensions while continually trying to find final stable dental positions that will not relapse (Hahn, 1944). A 3D radiologic image allows the practitioner an enhanced appreciation of facial form and in some select instances may help reduce the amount of relapse that occurs. 3D orthodontic analyses are being developed and are gaining popularity in use for diagnosis, treatment planning and predicting prognoses.

Unfortunately, CBCT has become such a popular treatment modality in certain regions and the West Coast of the United States that questions arise about practitioners balancing patient dose to ionizing radiation with diagnostic necessity and analysing the financial cost/benefit ratio (Scarfe, et al., 2006). The American Association of 
Orthodontists (AAO) does not support CBCT as routine for orthodontic radiography. (American Association of Orthodontists, www.aaomembers.org/Resources/Publications/ebulletin-05-06-10.cfm, 2010). A joint effort is in progress between the American Academy of Oral and Maxillofacial Radiology (AAOMR) and the American Association of Orthodontists (AAO) to establish guidelines for use of diagnostic imaging including $\mathrm{CBCT}$ in Orthodontics. The co-chairs of this activity are William C. Scarfe (AAOMR) and Carla Evans (AAO) (Farman, 2010). In the future orthodontics will likely complete a 3D assessment for patients where CBCT imaging is indicated and will continue to use $2 \mathrm{D}$ assessments for patients where CBCT is not indicated.

Respiratory patterns affect the way craniofacial growth occurs (McNamara, 1981; Harari, et al., 2010). A case presented by Basdra, et al., (1998) presented a case report of abnormal bone growth in the maxillary sinus with unknown etiology. Examination revealed that the contralateral maxillary sinus had expanded to compensate, and the asymmetric maxilla, which was transversely wide, was matched by a non-pathologic unilateral mandibular asymmetry. Hence, the maxillary sinus pathosis during growth is believed to be the cause of this craniofacial morphologic abnormality in both jaws.

Leclerc and Leclerc (2009) compared 23 non-syndromic patients with choanal atresia to controls found a significant decrease in zygomatic width, despite normal maxillary and sphenoid sinus widths in patients with this condition. This study was not able to measure volumes, and was limited by not being able to have a common orientation between patient images because only axial and coronal CT printed slices were available. 
Recently, there has been attention in the literature about airway measurements as they pertain to sleep apnea and posterior skeletal crossbite (Haskell, et al., 2009; Pirelli, et al., 2010). Prior to the current study focus had not been placed on the effects of sinus dimensions on each other and on other craniomaxillofacial structures. It is suspected that this was due to $\mathrm{CBCT}$ not being common in Dentistry, difficulty in measuring these structures and the lack of technology.

Orthodontists, pediatricians, otorhinolaryngologists, allergists and speech physiologists all have concerns about the effects of respiratory patterns on craniofacial growth (McNamara, 1981). Establishing normative values of paranasal sinuses improves the understanding of diseases such as chronic sinusitis, cystic fibrosis, eosinophilic granuloma, neurofibromatosis, fibrous dysplasia, and sickle cell anemia on sinus development (Kim, et al., 1997; Barghouth, et al., 2002).

Several authors have also stressed the importance of knowledge of paranasal sinus anatomy and anatomical variations for sinus operation. These normative values are important in preoperative staging of complex craniofacial malformations, bone dysplasias, craniomaxillofacial tumours by maxilla-facial surgeons and neurosurgeons and in surgical approaches of the pituitary gland through the sphenoid sinus and for functional endoscopy of the sinuses by otorhinolaryngologists. Precise anatomic knowledge is especially important to minimize complications in operating in growing children as sinus pneumatisation and facial growth could be compromised without it. Trauma, infection surgical intervention and irradiation have all been described as causes of sinus hypoplasia (Elwany, et al., 1983; Wolf, et al., 1993; Mair, et al., 1995; Kosko, et al., 1996; Spaeth, et al., 1997; Barghouth, et al., 2002). 
Attempts have been made to associate sinus dimension with malocclusions. With limited technologic capability, attempts like that of Oktay (1992) of trying to associate maxillary sinus area on panoramic radiographs with malocclusions were innovative. One early attempt to assess sinus volume involved using physical craniomaxillofacial measurements of skulls in three dimensions and multiplying these values to estimate volume size (Shea, 1977). Others have used a more complex ellipsoid formula to calculate volume from 2D dimensions measurements found by the researcher (Barghouth, et al., 2002).

Calculating volumes have also been done by using the Cavalieri principle. This technique requires the researcher to overlay sequential CT scans with a sheet of positive symbols spread out evenly over the page. The number of positive symbols found overlaying the area in the sinus is added to the number of those in sequential scans (Emirzeolgu, et al., 2007).

The most common technique of computing sinus volume, until recently, has been computer summation of areas measured from sequential CT slices. Uchida, et al., (1998) printed CT scans and digitised them by tracing the sinus borders prior to the computer summating these areas. Other authors have traced outlines in the proprietary software and relied on the computer program to summate the areas of each slices (Fernandes, 2007; Kim, et al., 2007).

The spectrum of reporting methodology includes failing to mention how reported volumes were calculated (Yonetsu, et al., 2000), reporting methodology for acquiring volumetric measurements but omitting to mention which software program was used (Kim, et al., 2007) and not providing adequate detail on the technique used (Rae, et al., 
2003). This makes it difficult to repeat previous techniques for future studies and to compare the reported volumes.

Software now exists to define borders and isolate segments of airway space for volumetric analysis. Parameters can be controlled by the user to adjust the limits of opacity required in order to incorporate each voxel, (smallest volumetric unit in the CT scan) into volumetric summation (Primer, et al., 2009).

A recent study reported that the software program they used, while the CT dataset was being reconstructed, was simultaneously "automatically" calculating airway volumes (Park, et al.,2010).

Advances in CT software applications is making it seemingly easier to measure airway volumes with less user-dependant involvement for selecting borders, opacities or eliminating the need for complex summative formulas. As technology, "advances," it is important to examine the findings of a recent study. El and Palomo (2010) examined 30 random subjects CBCT images with four different software programs, each with airway volume calculation capabilities. Their findings showed that repeat volumetric measurements, of the same airway, with the same software program, reported values which were consistent between measurements. However, values of the same airways, measured by different volumetric software, were statistically significantly different. Therefore, it is prudent to consider which software package was used when objective volumetric airway values are reported. For this reason, the current study will place its focus on dimensional relationships. 
Throughout the past thirty years, there has been an absence of correlation between paranasal sinuses despite the ease with which we can now evaluate such structures (Brichard, et al., 1979; Emirzeoglu, et al., 2007; Park, et al., 2010). Studies have proposed that maxillary sinus dimensions may be responsible for anterior cranial base length, maxilla position and specific malocclusions, (Rothstein \& Yoon-Tarlie, 2000) while others have found no conclusive correlation between maxillary sinus volume and malocclusions when considering both sexes together (Oktay, 1992). The present study, however, is the first study that will attempt to correlate the sizes of the sphenoid sinus, maxillary sinuses and other selected craniomaxillofacial structures with one another.

The goal of this research is to seek statistical trends from the data and find relationship between metrics of the sinuses and other selected craniomaxillofacial structure. Correlations found may assist orthodontists, surgeons and other health care professionals in their increased understanding of biologically natural relationships between the dimensions of these structures relative to one another. Perhaps these findings will also be useful in clinical planning of medical or surgical interventions of the paranasal sinuses. The positive findings will ultimately yield better treatment planning by the practitioner and improved care for the patient. 


\section{CHAPTER II}

\section{STATEMENT OF OBJECTIVES AND HYPTOHESES}

\section{Study Objectives}

The purpose of this of this study is to investigate relationships between the sphenoid and maxillary sinus dimensions and other selected craniomaxillofacial measurements with cone-beam computed tomography (CBCT) analysis. The subject sample will be derived from a retrospective audit of the radiologic database of patients referred to oral and maxillofacial faculty practice at the University of Louisville School of Dentistry. The determination of these relationships may increase our understanding the influence of the development of the sinuses on craniofacial dimensions and aid surgical treatment planning for orthognathic patients.

The specific aims of the study were to:

1. assess potential difference in craniomaxillofacial measurements between age groups for subjects in three developmental groups based on age and fusion of the spheno-occipital synchondrosis.

2. describe potential relationships between external topographic measurements and internal measurements of the craniomaxillofacial complex. 
3. describe potential relationships between volumetric and linear dimensions of the sphenoid and maxillary sinus and other selected craniomaxillofacial dimensions.

4. describe potential relationships between vertical, antero-posterior and transverse craniomaxillofacial dimensions.

5. assess potential differences between initial and repeat measurements for a sample of representative volumetric and linear dimensions.

6. assess intra-observer reliability of repeat measurements as measured by the interclass correlation coefficient (ICC).

\section{Study Hypothesis}

Null Hypotheses $\left(H_{o}\right)$

1. There is no statistically significant difference between craniomaxillofacial measurements for subjects in three developmental groups based on age and fusion of the spheno-occipital synchondrosis.

2. There is no statistically significant relationship between external topographic measurements and internal measurements of the craniomaxillofacial complex.

3. There is no statistically significant relationship between volumetric and linear dimensions of the sphenoid and maxillary sinus and other selected craniomaxillofacial dimensions.

4. There is no statistically significant relationship between vertical, antero-posterior and transverse craniomaxillofacial dimensions. 
5. There is a statistically significant difference between repeat and initial measurements for a sample of representative volumetric and linear dimensions.

6. The measures of intra-observer reliability of repeat measurements, as measured by the ICC, do not differ from 0 .

Alternate Hypotheses $\left(H_{l}\right)$

1. There is a statistically significant difference between craniomaxillofacial measurements for subjects in three developmental groups based on age and fusion of the spheno-occipital synchondrosis.

2. There is a statistically significant relationship between external topographic measurements and internal measurements of the craniomaxillofacial complex.

3. There is a statistically significant relationship between volumetric and linear dimensions of the sphenoid and maxillary sinus and other selected craniomaxillofacial dimensions.

4. There is a statistically significant relationship between vertical, antero-posterior and transverse craniomaxillofacial dimensions.

5. There is no statistically significant difference between repeat and initial measurements for a sample of representative volumetric and linear dimensions.

6. The measures of intra-observer reliability of repeat measurements, as measured by the ICC, differ from 0 . 


\section{CHAPTER III}

\section{METHODS AND MATERIALS}

\section{Overview}

This observational research involved cone-beam computed tomography (CBCT) datasets previously collected for clinical diagnostic purposes. The study design was approved through an expedited review by the Institutional Review Board (IRB), of the University of Louisville on March 16, 2010 (IRB \#10.0093) (Appendix A).

This study involved a retrospective audit of CBCT report records within a radiologic interpretation database (Filemaker Pro v.8, FileMaker Inc., Santa Clara, CA) held within the Radiology and Imaging Science Division, Department of Surgical/Hospital Dentistry, The University of Louisville School of Dentistry, Louisville, Kentucky. Subjects were grouped according to age: Child (included individuals prior to and approximating the fusion of the spheno-occipital synchondrosis), Adolescent (post fusion of the Sphenoid-occipital synchondrosis until age 18 years) and, Adult (over 18 years of age). A single observer made linear, angular and volumetric measurements of craniofacial structures from DICOM format images imported into a proprietary cephalometric software program. Two months later, repeated measurements on a subset of the sample were recorded and compared to determine intra-observer reliability. Group differences were analyzed using ANOVA testing, and associations explored with bivariate correlations and multiple regression analyses using statistical software (PASW 
Statistics v. 18.0, SPSS Inc., Chicago, IL). All tests were set at an á priori level of significance set at $\alpha \leq 0.05$.

\section{Sample Selection}

Four specific data fields from reports in the $\mathrm{CBCT}$ radiologic interpretation database for the period May 13, 2004 (installation of the CBCT equipment) to a convenience date (December 8, 2009) were exported to a spreadsheet (Excel, Microsoft Corp., Redmond, WA) representing all subjects in the database within this period. A total of 2,290 radiographic reports were available. The specific data fields included:

1) Age. Age in whole years at the time of presentation for the radiologic examination.

2) Field of View. Categorical structured text categorizing the procedure of $\mathrm{CBCT}$ scan used. Categories included: $8 \mathrm{~cm}$ (maxillofacial), Consultation, Extended (maxillofacial), Extended FOV (22 $\mathrm{cm} \times 16 \mathrm{~cm})$ both arches, Extended Full (maxillofacial), Extended view CBCT, Full (both jaws), Full (craniofacial), Full (maxillofacial), Full (maxillofacial)/Anterior Calvarium, Full extended FOV (Restricted $6 \mathrm{~cm}$ ), Limited area (Mx/Md), Mandible $8 \mathrm{~cm}$ FOV, Second Opinion Consultation, Supplemental report: TMJ only.

3) Reason for referral. Categorical structured text categorizing the reason that the subject was referred for a CBCT scan. Categories included: Hand Wrist, Implant CBCT, Pathology CBCT, Fracture CBCT, TMJ CBCT, TMJ Tomography, Trauma CBCT, Cleft Lip/Palate, Ortho CBCT, Third Molar 
CBCT, Cephalometric, Sleep Apnea, Dento/Craniofacial, Impaction CBCT, Surgical follow-up - plates/graft, Surgical follow up - recurrence, Surgical follow up - trauma, Consultation.

4) Radiologic Impression. Narrative text data summarizing the primary and synchronous imaging findings.

Records were sorted by the field of view data field, age of the subject then reason for referral respectively.

Numerous exclusion criteria were applied to each of the fields within the radiographic reports (Figures 1 and 2).

1. Field of View - Subjects whose scans potentially did not include three essential anatomic landmarks (Nasion (Na), Gnathion ( $\mathrm{Gn}$ ) and the external auditory meatus (EAM) bilaterally) necessary for orthodontic analysis were excluded such as: maxilla, mandible, maxilla/mandible or hand wrist. In addition CBCT data sets with ambiguous field of view inclusions were viewed with proprietary acquisition software (Xorancat, Imaging Sciences International, Hatfield, PA, USA). These included: $8 \mathrm{~cm}$ (maxillofacial), extended full, extended view, full (both jaws), limited area scan, full (maxillofacial), limited (Mx/Md), full (Craniofacial) and those records without a procedure entry in the database. 


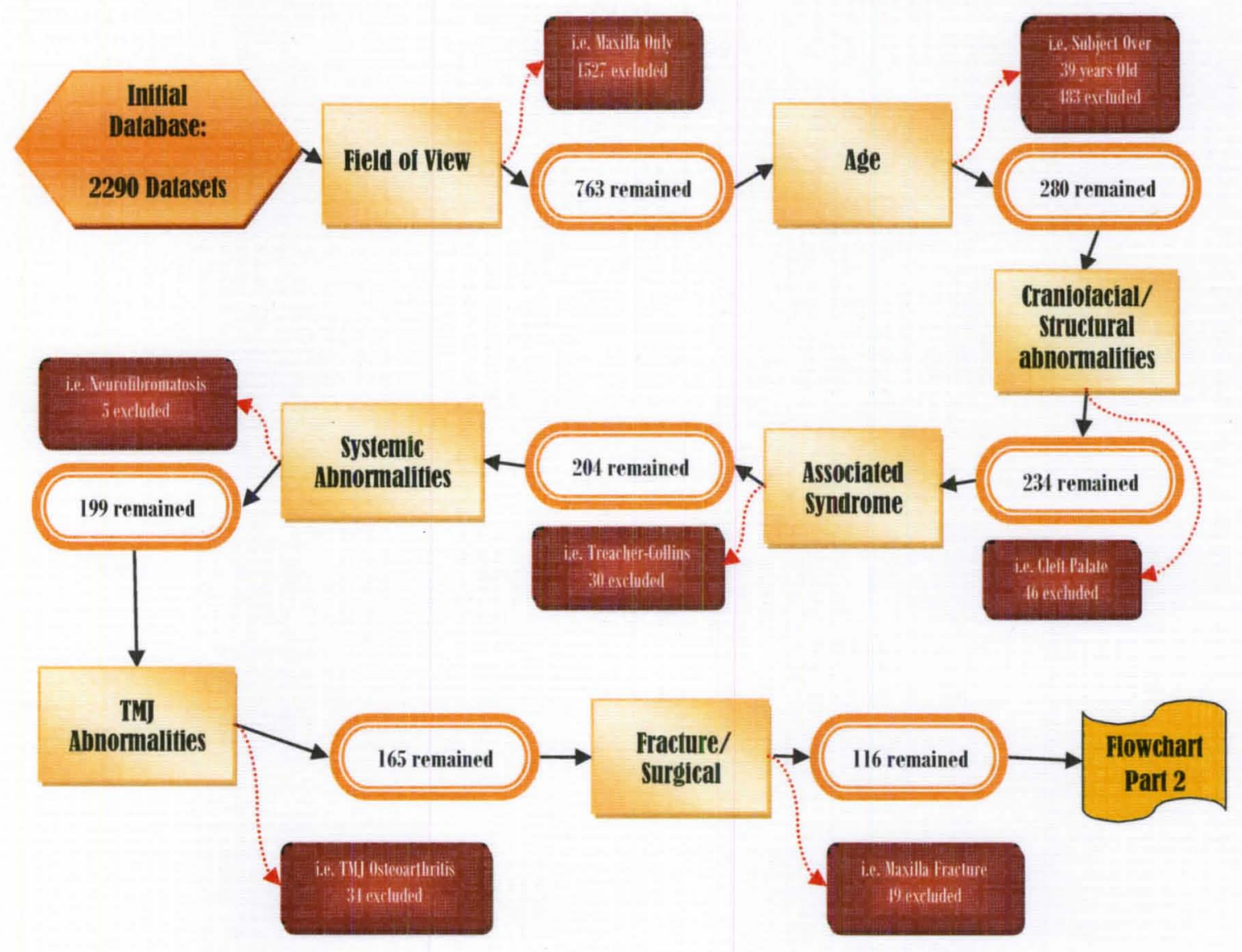

Figure 1. Records Exclusion Flowchart Part 1 of 2. 


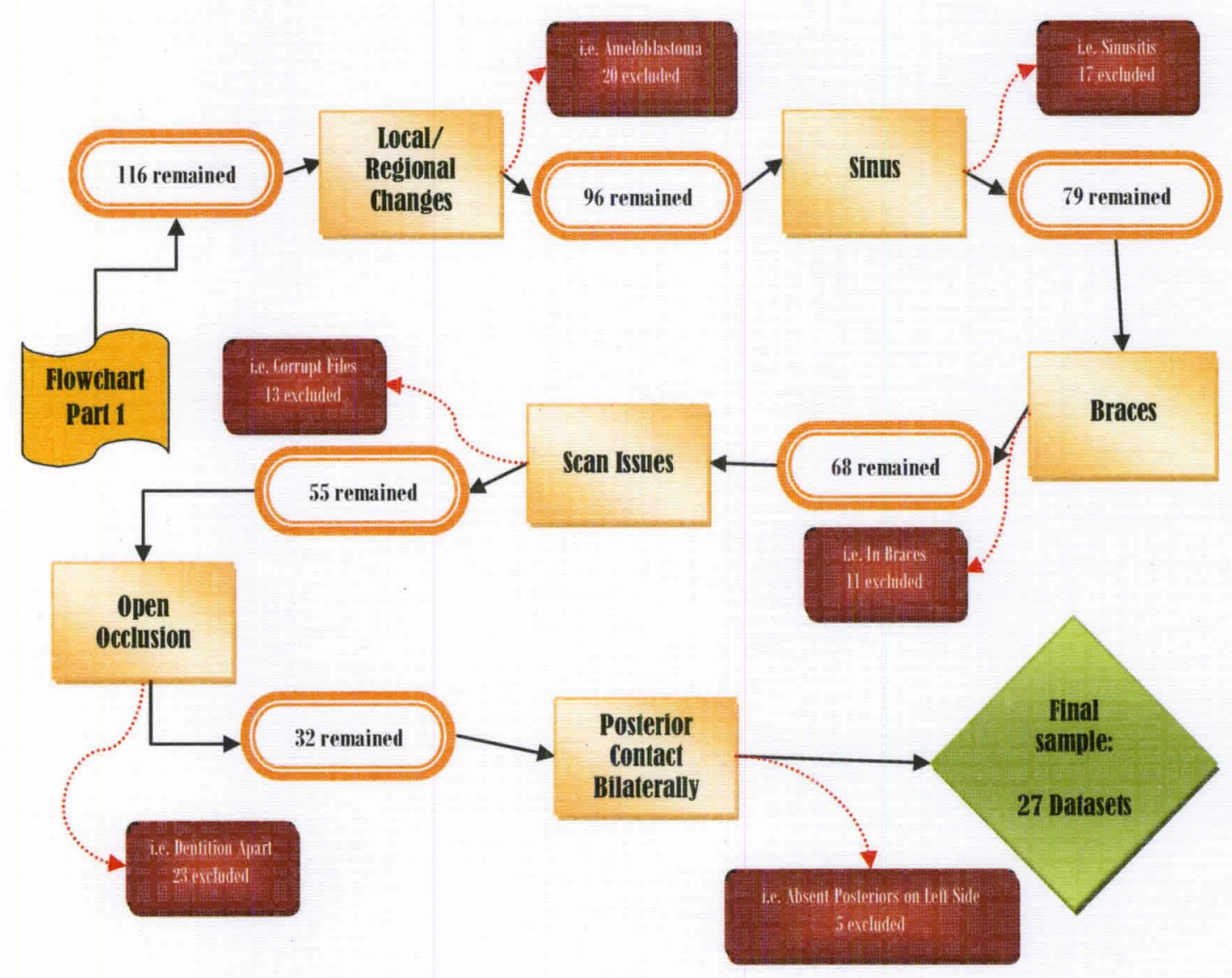

Figure 2. Records Exclusion Flowchart Part 2 of 2.

2. Age - Subjects listed in the database as 40 years old and older were excluded based on the assumption that these individuals' occlusion and craniofacial morphologic characteristics could have been altered due to restorative intervention and/or loss of teeth.

3. Report Type - Subjects having been imaged for sleep apnea were identified and excluded.

4. Radiologic Impression - Pathologic and implant impressions were reviewed in detail. Records were excluded when craniofacial/structural abnormalities, 
associated syndromes, systemic abnormalities, temporomandibular joint abnormalities, fractures, surgical stabilization plates, orthognathic surgery, local or regional changes or sinus issues were known or suspected. Subjects in or known to have had braces were excluded. Subjects with deviated septum, Haller cells, concha bullosa, ethmo bullosa, alveolar atrophy, alveolar fracture, socket sclerosis/enostosis and bifid mandibular canal were not excluded.

5. Scan Issues - Subjects with corrupt or missing images were excluded.

6. Open Occlusion - Using the proprietary acquisition software, datasets were examined to determine whether subjects' teeth were separated or in occlusion during imaging and those whose dentitions were not intercuspated were excluded.

7. Posterior Contact on Each Side - Subjects who did not have at least one posterior contact on each side were excluded. This observation was made with the primary acquisition software.

Twenty seven subjects were determined to fulfill all exclusion criteria for the study. A list of each exclusion was recorded (Appendix B). This was considered as a low sample size, particularly in the target populations under consideration (subjects who demonstrated pre-fused spheno-occipital synchondrosis and those whose spheno-occipital synchondrosis had fused but were less than 18 years old (Coben, 1998) (See

Determination of Stage of Sphenoid Development later). Therefore 2 further attempts were made to increase sample size. The first attempt involved expanding the search dates of the primary radiologic database from December 8, 2009 to April 26, 2010. While this provided a further 194 subjects, application of the exclusion criteria resulted in no further recruitment of individuals (Figure 3). A much smaller separate database CBCT radiologic 
interpretive database was also available for patients who had presented with specific orthodontic imaging (e.g. impacted canines, asymmetry, etc.). The orthodontic database was created on November 2, 2009 and on April 26, 2010 consisted of 17 subjects. Application of the exclusion criteria resulted in no further recruitment of individuals (Figure 4).

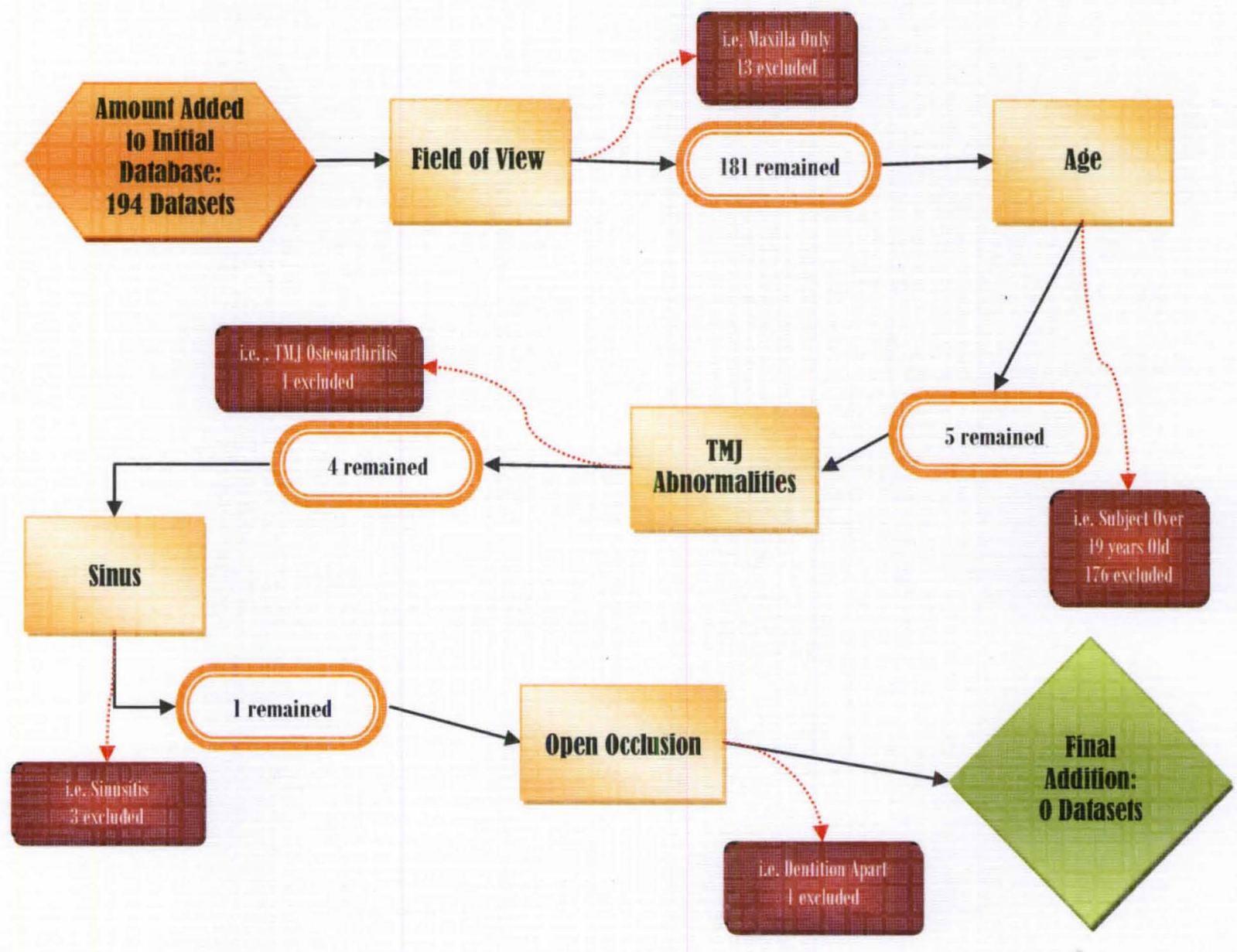

Figure 3. Second attempt at increasing sample size of subjects under 20 years old imaged after initial database was assessed. 


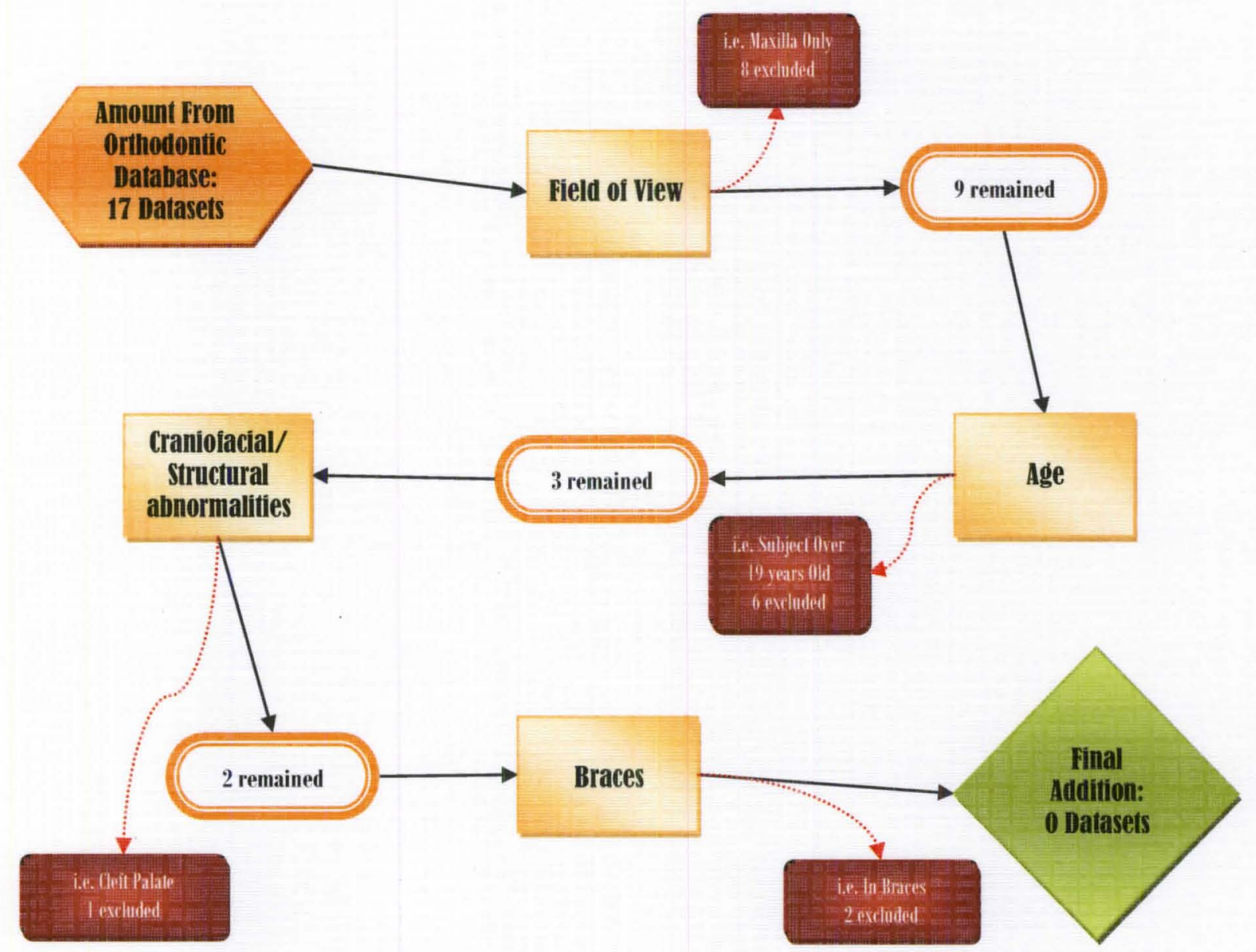

Figure 4. Third attempt at increasing sample size by using Orthodontic Database.

Subjects within each group were categorized into and saved as coded files. Subject waivers were not necessary, as all subject identifiers were stripped from the data set and files were made anonymous.

\section{Image Analysis}

Twenty seven subjects were determined to fulfill all exclusion criteria for the study. Their CBCT datasets were then exported as a DICOM files. These files were then imported into a proprietary orthodontic analysis software program (Dolphin 3D Imaging 
Premium, v.11.0, Dolphin Imaging, Chatsworth, CA) with a new subject entry. One examiner preformed all image manipulations and analysis.

\section{Determination of Stage of Sphenoid Development}

For each subject, the CBCT data was initially visualized to determine the stage of development of the spheno-occipital synchondrosis.

First the "3D" option was selected and "Edit" was selected which initiated loading of the CBCT dataset (Figure 5). The "4-Equal Layout" option was selected which displayed the three planes and a reconstructed image (Figure 6).

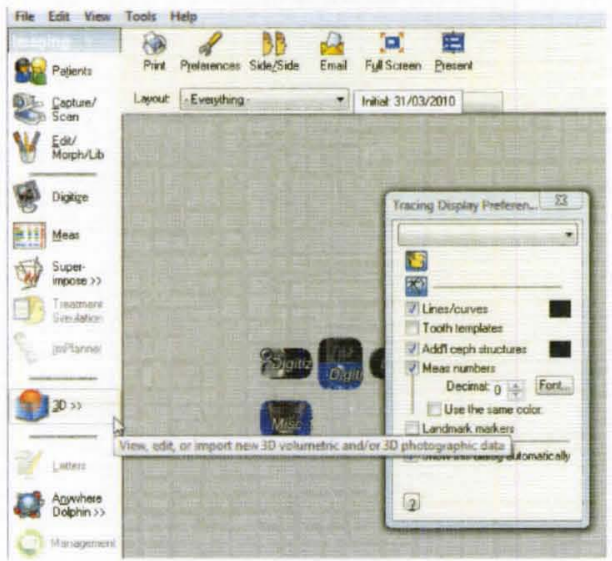

(a)

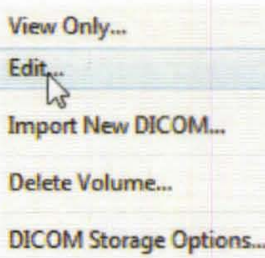

(b)

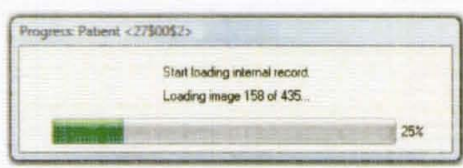

(c)

Figure 5. Screen capture of segment of Dolphin 3D display demonstrating location and selection of 3D option (a) and options available (b) and subsequent loading verification screen (c). 


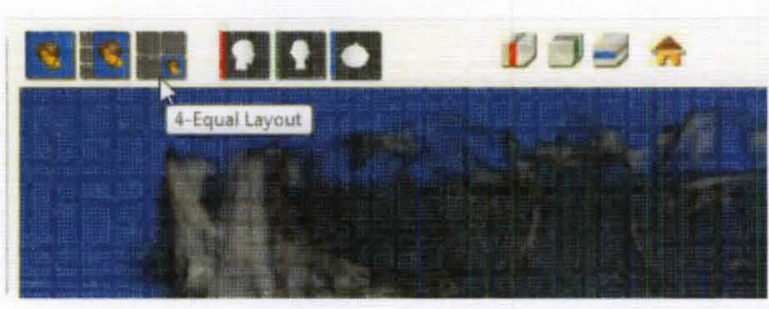

(a)

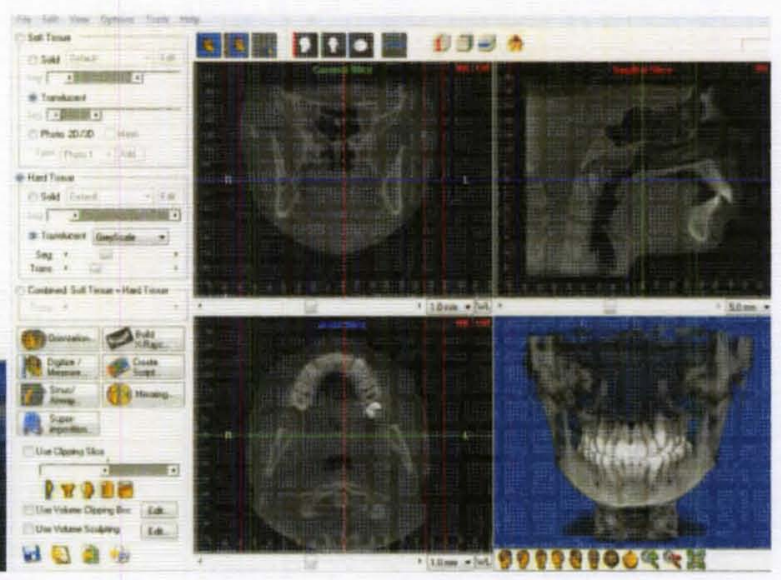

(b)

Figure 6. Cropped screen capture of Dolphin 3D Imaging software demonstrating selection of 4-Equal Layout option (a) and resultant screen display (b).

All subjects under the age of 18 were analysed for fusion of the spheno-occipital synchondrosis in the sagittal view in the midsagittal plane (Figure 7). Based on these observations on the presence or absence of the spheno-occipital synchondrosis, subjects were assigned to one of three groups. Group 1, consisted of the youngest sample of images who demonstrated pre-fusion of the spheno-occipital synchondrosis (Akhlaghi, et al., 2008). Group 2 comprised subjects who had fusion of the spheno-occipital synchondrosis but were 17 years or younger (Fudalej, et al., 2007). Group 3 comprised subjects who demonstrated fusion of the spheno-occipital synchondrosis and were 18 years or older. 


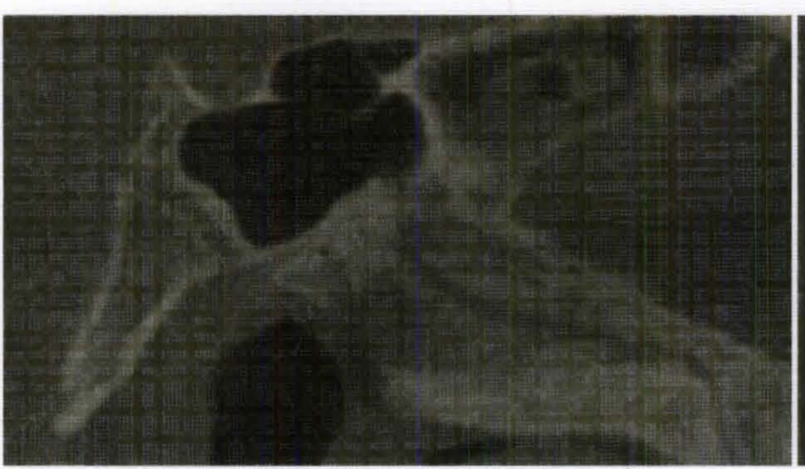

(a)

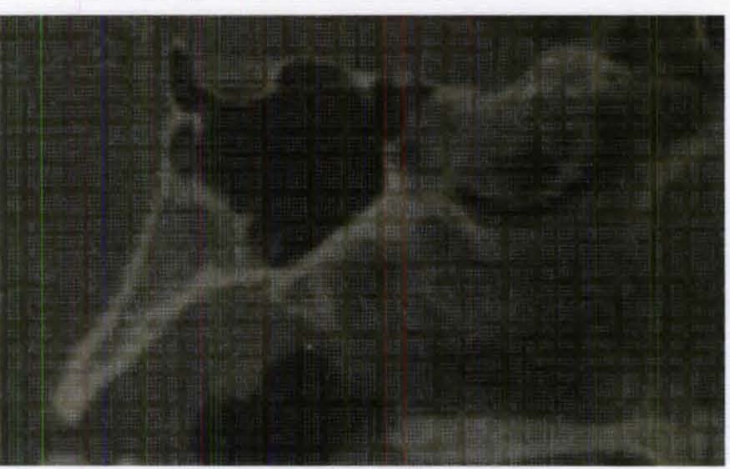

(b)

Figure 7. Cropped sagittal image of a 12 year old subject prior to fusion of the sphenooccipital synchondrosis representative of subjects within Group 1 (a). Cropped sagittal image of a 14 year old subject demonstrating fusion of the spheno-occipital synchondrosis representative of subjects within Group 2 (b).

\section{Craniofacial Analysis}

\section{Three Dimensional Standardization}

Each CBCT dataset was retrieved (Figures 5 and 6) and re-oriented to provide a standard reference display prior to recording any linear or angular measurements. The following scheme was used:

1. The anterior-posterior crosshair for the coronal view was placed along the palate. The image was rotated along this plane to ensure the crosshair was covering the middle of the Anterior and Posterior Nasal Spines (Figure 8) (Appendix C). 


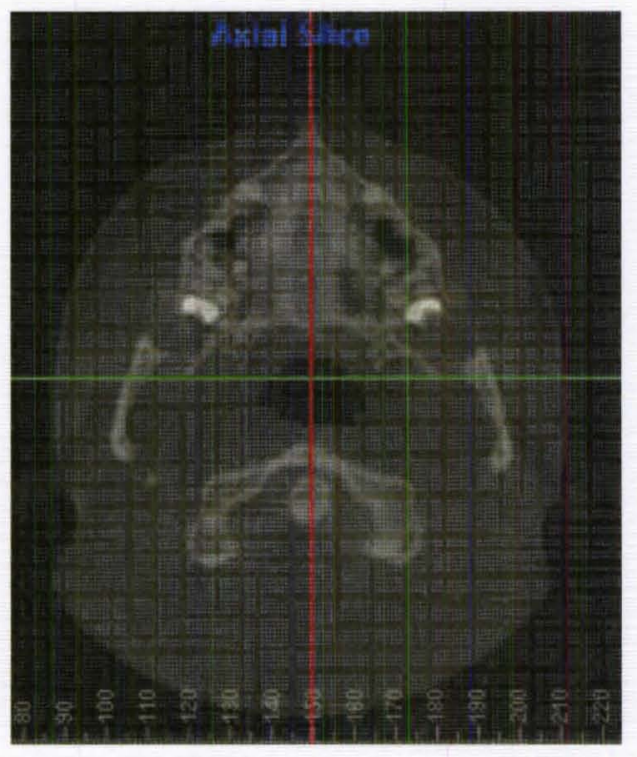

Figure 8. Axial orientation using the ANS and PNS landmarks.

2. The sagittal view was moved medially until the external auditory meatus (EAM) was as posterior and superior and nearest the temporal bone while still being in a plane lateral to that where the temporal bone beginning to encircle the EAM. The anterior-posterior crosshair of the sagittal view was placed directly superior to the EAM on the superior margin of the EAM along the temporal bone (Figure 9). Where one EAM was found to be more superior to the other relative to this crosshair, the coronal view was rotated to allow this crosshair to lie over the most inferior aspect of the temporal bone superior to the EAM bilaterally. This plane assisted in orienting the first two landmarks of the mid-sagittal plane and with the Nasion made up the midsagittal plane. 


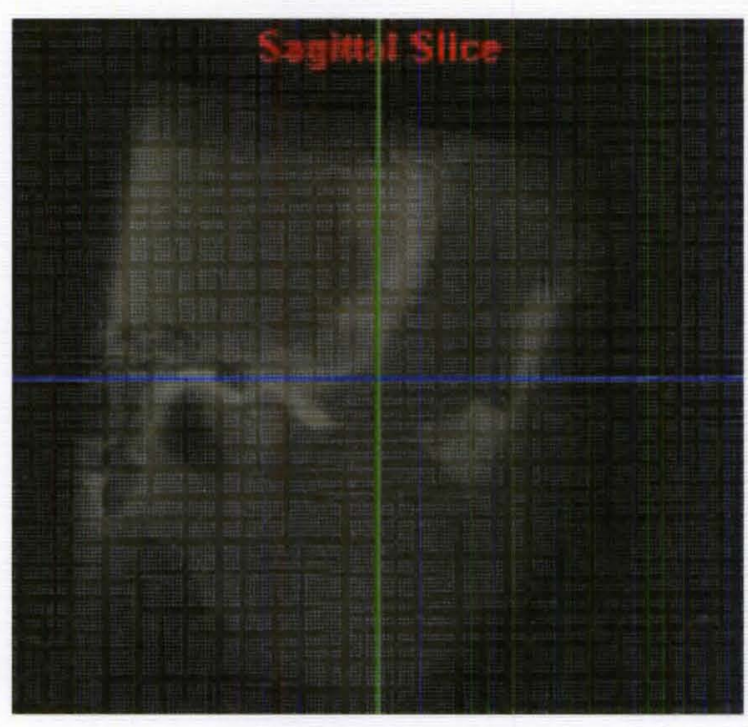

(a)

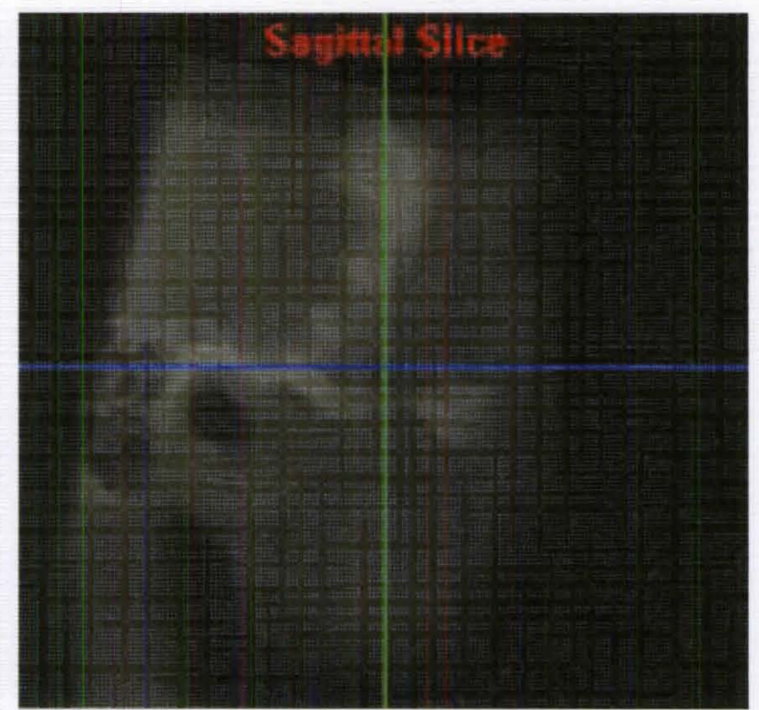

(b)

Figure 9. Coronal orientation using the left (a) and right (b) EAM landmark in the sagittal view.

3. The superior-inferior crosshair in the coronal view was then adjusted to rest over the most lateral inferior aspect of the margin of the orbit (Orbitale). The sagittal view was rotated and the anterior-posterior crosshair adjusted to ensure it lay on the inferior portion of the temporal bone directly superior to the EAM, as previously described, and the most inferior aspect of the orbit bilaterally (Figure 10). This plane was used as the Frankfort Horizontal Plane for orientation purposes (Seward, et al., 1968). 


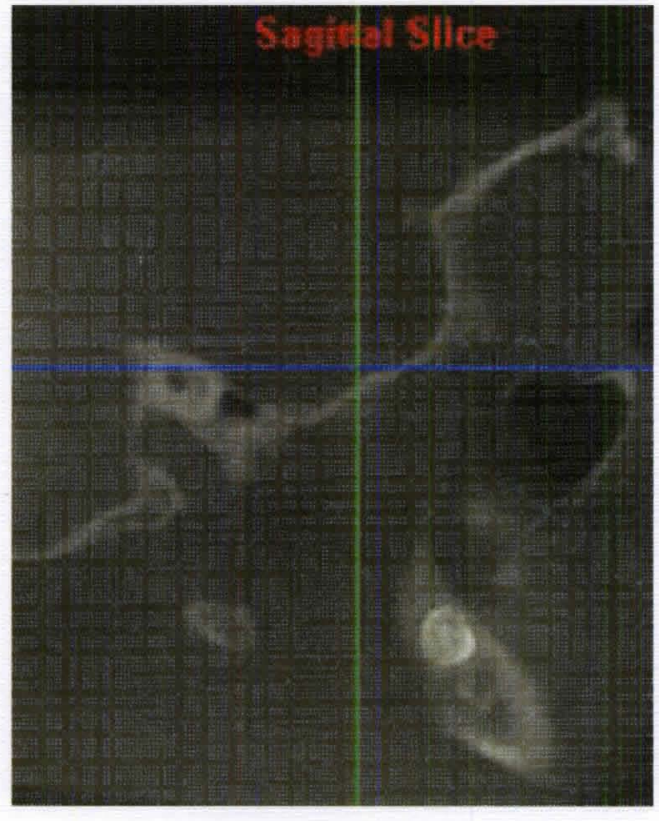

(a)

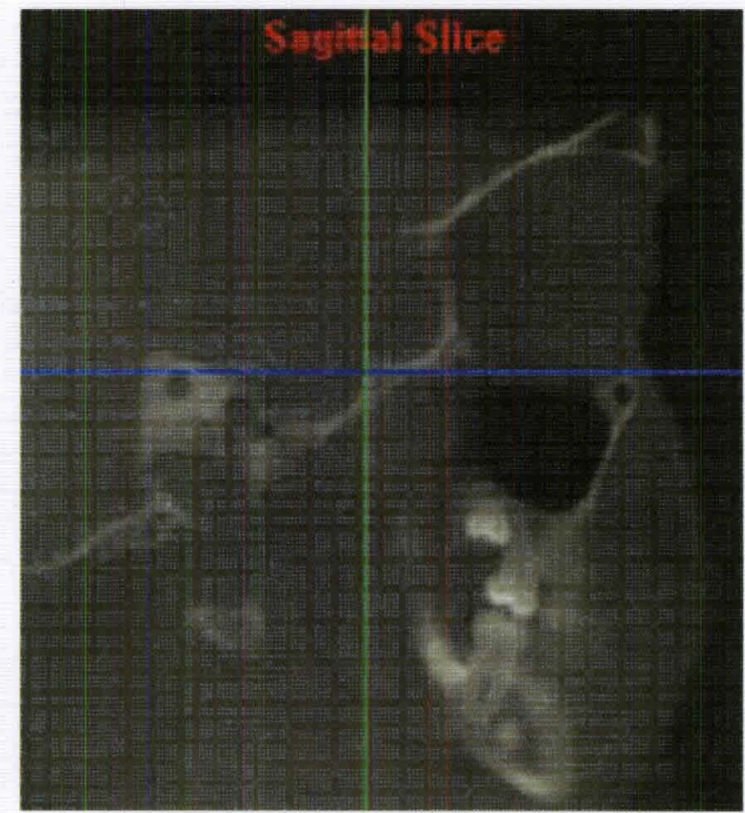

(b)

Figure 10. Sagittal orientation using the right (a) and left (b) Orbitale landmark.

\section{Linear and Angular Measurement}

Following orientation, the Digitize/Measure option was selected on left toolbar

(Figure 11) and used to measure all angles and lines that follow.

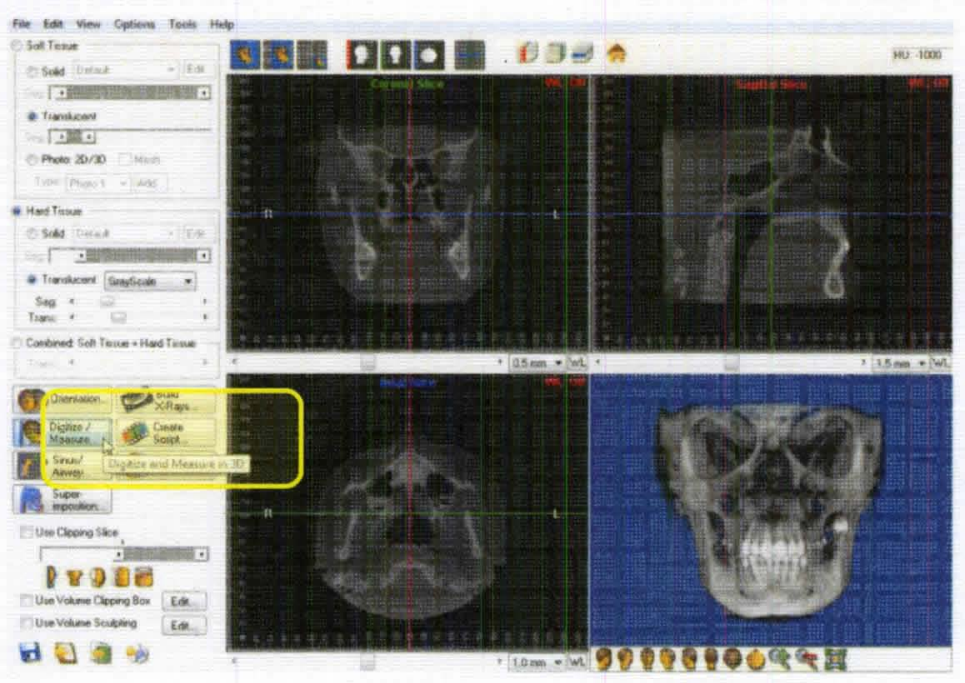

Figure 11. Screen capture of Dolphin 3D Imaging software demonstrating location of initial access to measurement screen window. 
In the Digitise/Measurement window, the view "drop down" box would be selected and all lines and angles measured (Figure 12). With the view selection as "3D," all linear and angular measurements were made by selecting the "Line" or "Angle" tab respectively and clicking on the first, then second point; and third point when angles were measured. After the points were repositioned to ensure they were on the accurate locations, measurement values appeared next to the line or angle and in the Digitise/Measurement window (Figure 12). These measurements were transferred into the data analysis spreadsheet (Excel, Microsoft Corp., Redmond, WA). (Appendix D)

For the Sella-Nasion to Gonion-Gnathion angle only, the view was changed to "2D-Lateral." The analysis was changed to "[Steiner/SM]". The "Landmark" tab was selected and the landmark "Nasion" was highlighted from the options and then placed over the corresponding landmark in the sagittal view. The same process was repeated for "Gonion", "Sella" and "Anatomical Gnathion." The "Measurements" tab was then selected and the value of $\mathrm{SN}-\mathrm{GoGn}$ recorded. 


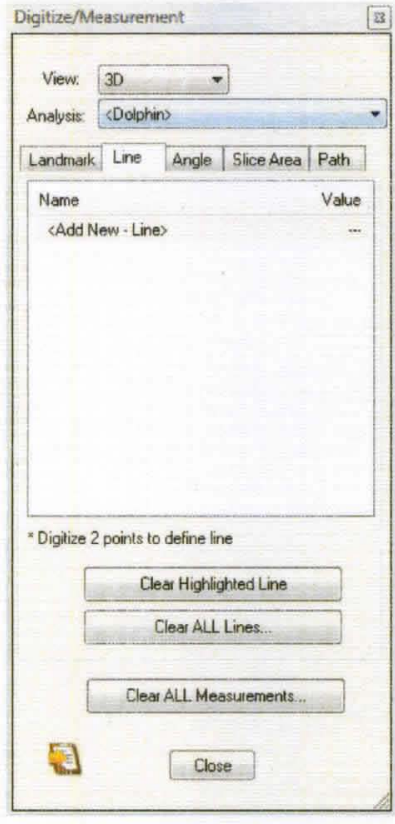

(a)

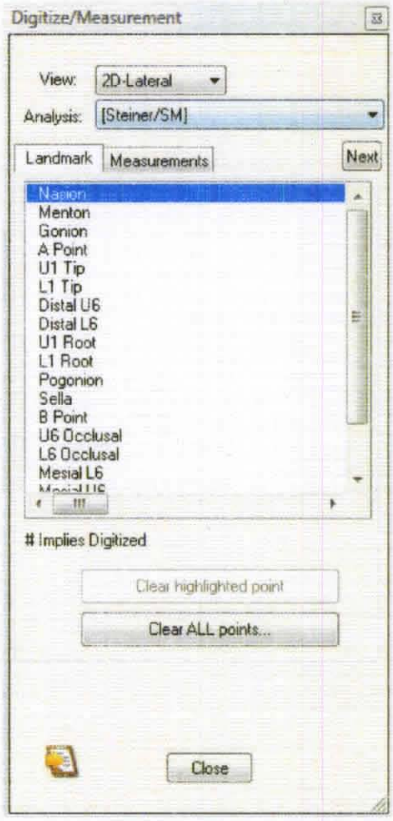

(b)

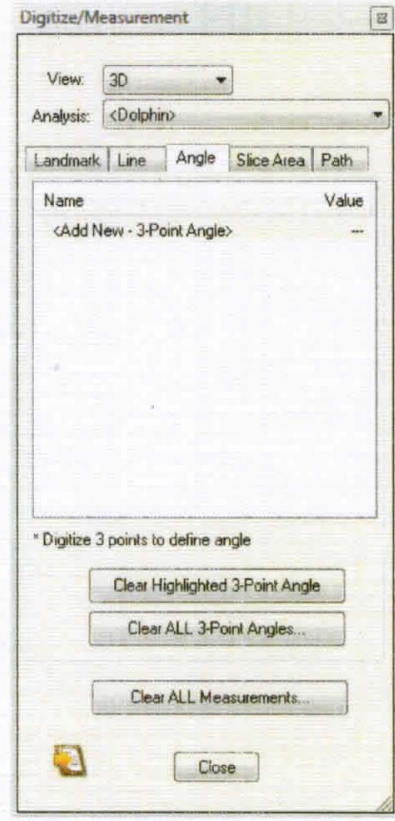

(c)

Figure 12. 3D Digitize/Measurement window for adding lines (a), 2D-Lateral

Digitize/Measurement window for Steiner/SM analysis (b), and 3D Digitize/Measurement window for adding angles (c).

Several image adjustment properties were available.

1) Image Slice thickness. This option allows adjustment of slice thickness between the $0.5 \mathrm{~mm}$ to $5.0 \mathrm{~mm}$. For each measurement, slice thickness was often assessed on each thickness to determine which would provide the best image, except where specified (Figure 13). 


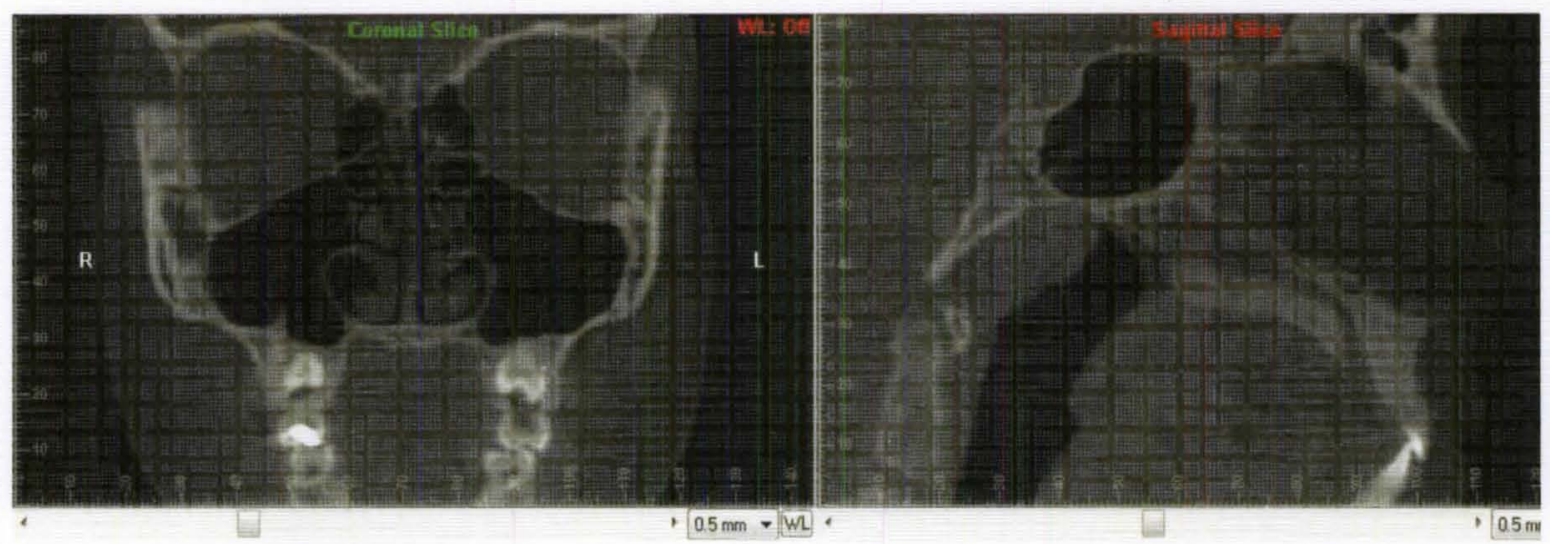

(a)

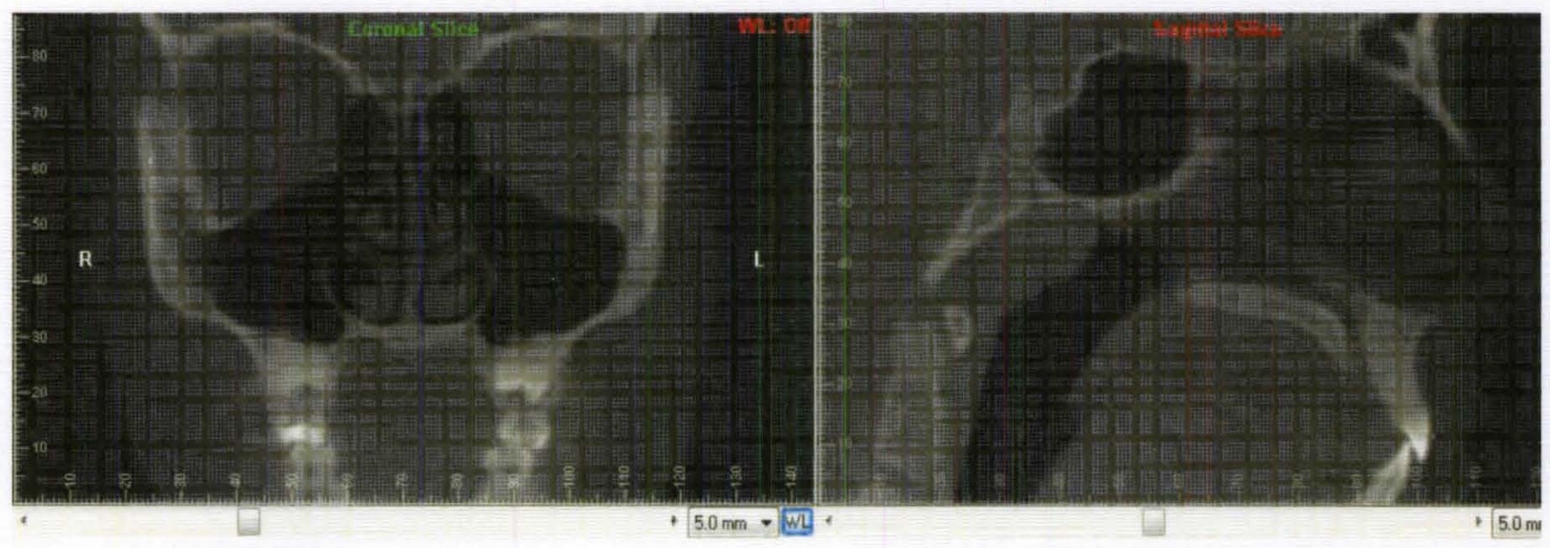

(b)

Figure 13. Image of coronal and sagittal slice demonstrating differences in display with a slice thickness of $0.5 \mathrm{~mm}$ (a) and $5.0 \mathrm{~mm}$ (b).

2) Contrast and Brightness. Contrast and brightness were also adjusted as required to allow appropriate landmarks to appear clearest (Figure 14). 


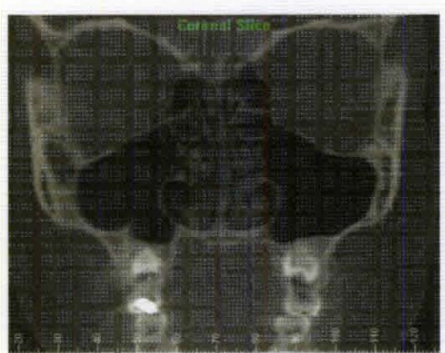

(a)

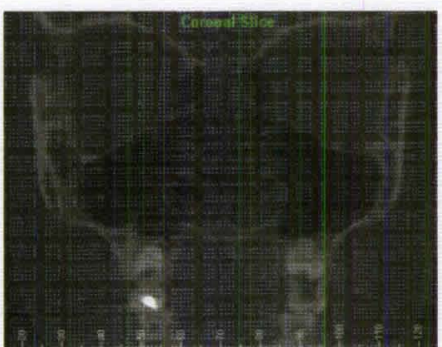

(b)

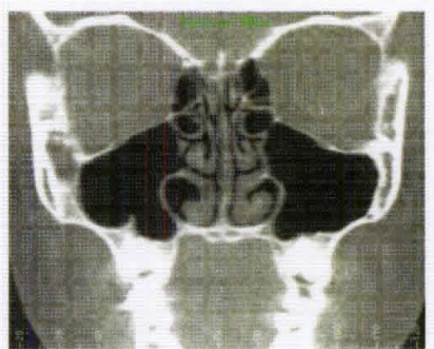

(c)

Figure 14. Sequence of coronal images demonstrating the effect of altering brightness and contrast. (a) Initial auto-adjusted brightness and contrast, (b) decreased contrast and, (c) increased brightness.

3) Magnification. Magnification capability was used to aid in precisely placing the required points on the desired locations for more accurate measurements (Figure 15).

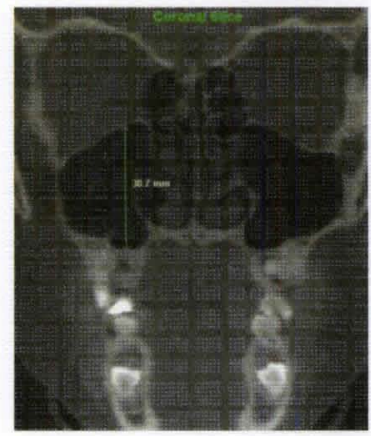

(a)

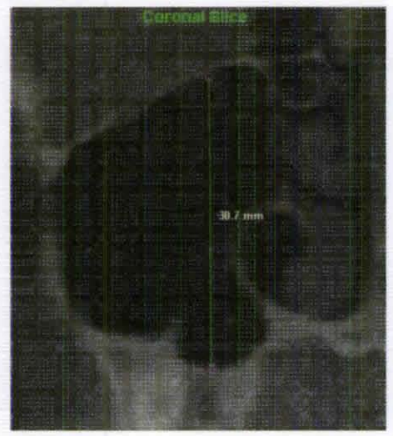

(b)

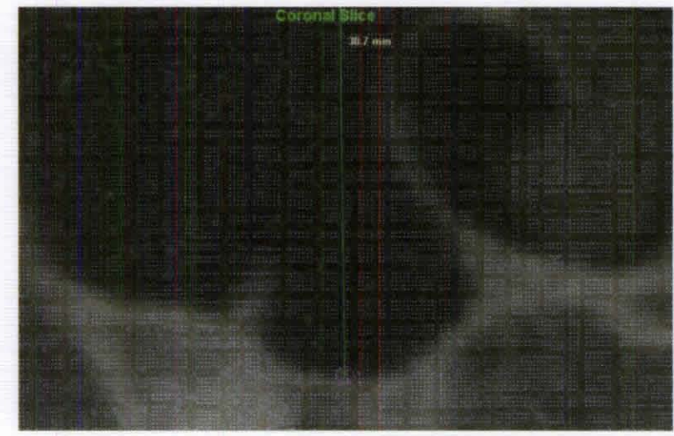

(c)

Figure 15. Cropped coronal images of the right maxillary sinus (a), demonstrating the effect of increasing magnification (b) and further magnification increase used to enlarge the view of the inferior margin of the sinus (c). 


\section{Linear and Angular Measurements:}

Table 1 shows the 12 mid-sagittal and two bilateral anthropometric and/or cephalometric points identified on the correlated orthogonal images (Table 1). Operational definitions of these landmarks were developed considering the variety of established definitions and the ability to repeatedly identify them on a CT image.

Eighteen sagittal and nine coronal linear measurements were recorded as described in Tables 2 and 3. Nine sagittal angular measurements were recorded as described in Table 4 (Appendix C). 
Table 1. Midline and Bilateral Topographic Points Used as Landmarks for the Measurements.

\begin{tabular}{|c|c|c|}
\hline Landmark & Abbreviation & Definition \\
\hline \multicolumn{3}{|l|}{ MID-LINE } \\
\hline A Point & A & $\begin{array}{l}\text { The deepest posterior depression in the } \\
\text { anterior border of the maxilla between the } \\
\text { anterior nasal spine and maxillary alveolar } \\
\text { bone }\end{array}$ \\
\hline Anterior Nasal Spine & ANS & $\begin{array}{l}\text { The most anterior portion of the maxilla } \\
\text { superior to the alveolar bone of the maxilla } \\
\text { and inferior to the inferior nasal conchae }\end{array}$ \\
\hline B Point & B & $\begin{array}{l}\text { The deepest posterior depression in the } \\
\text { anterior border of the mandible between the } \\
\text { chin and the mandibular alveolar bone }\end{array}$ \\
\hline Basion & $\mathrm{Ba}$ & $\begin{array}{l}\text { The most anterior aspect of the anterior } \\
\text { margin of the foramen magnum }\end{array}$ \\
\hline Gnathion & $\mathrm{Gn}$ & The most inferior location of the mandible \\
\hline Incisal Plane & IP & $\begin{array}{l}\text { Mathematically derived geographic plane } \\
\text { halfway between the lower incisor tip and } \\
\text { upper incisor tip parallel to the Frankfort } \\
\text { horizontal }\end{array}$ \\
\hline Lower Incisor Tip & LIT & $\begin{array}{l}\text { The most superior portion of the mandibular } \\
\text { central incisor }\end{array}$ \\
\hline Nasion & $\mathrm{N}$ & Junction of the frontal and nasal bones \\
\hline Posterior Nasal Spine & PNS & $\begin{array}{l}\text { The most posterior aspect of the palatine } \\
\text { bone }\end{array}$ \\
\hline Sella Turcica & $\mathrm{S}$ & $\begin{array}{l}\text { The center of the Sella Turcica based on } \\
\text { inspection }\end{array}$ \\
\hline Sphenoid Floor & Sph Floor & $\begin{array}{l}\text { The inferior surface of the outer cortex of the } \\
\text { body of the sphenoid bone at the junction of } \\
\text { the vomer along a line from the Sella Turcica } \\
\text { to the Posterior Nasal Spine }\end{array}$ \\
\hline Upper Incisor Tip & UIT & $\begin{array}{l}\text { The most inferior portion of the maxillary } \\
\text { central incisor }\end{array}$ \\
\hline $\begin{array}{l}\text { BILATERAL } \\
\text { External Auditory } \\
\text { Meatus }\end{array}$ & EAM & $\begin{array}{l}\text { The radiolucent foramen connecting the outer } \\
\text { and middle ear }\end{array}$ \\
\hline Gonion & Go & $\begin{array}{l}\text { The most posterior inferior location of the } \\
\text { angle of the mandible }\end{array}$ \\
\hline
\end{tabular}


Table 2. Definition of Sagittal Linear Dimensions Measurements.

\begin{tabular}{|c|c|c|}
\hline Measurement & Abbreviation & Definition \\
\hline Nasion to Anterior Nasal Spine & N-ANS & Superior Facial Height. \\
\hline $\begin{array}{l}\text { Anterior Nasal Spine to Upper } \\
\text { Incisor Tip }\end{array}$ & ANS-UIT & $\begin{array}{l}\text { Superior Facial Height Including } \\
\text { Maxillary Dental Complex }\end{array}$ \\
\hline $\begin{array}{l}\text { Anterior Nasal Spine to Lower } \\
\text { Incisor Tip }\end{array}$ & ANS-LIT & Portion of Superior Facial Height \\
\hline $\begin{array}{l}\text { Anterior Nasal Spine to Incisal } \\
\text { Plane }\end{array}$ & ANS-IP & $\begin{array}{l}\text { Mathematically Derived Superior } \\
\text { Facial Height Including Maxillary } \\
\text { Complex }\end{array}$ \\
\hline Nasion to Gnathion & N-Gn & Anterior Facial Height \\
\hline Gnathion to Upper Incisor Tip & Gn-UIT & Potion of Lower Facial Height \\
\hline Gnathion to Lower Incisor Tip & Gn-LIT & $\begin{array}{l}\text { Lower Facial Height Including } \\
\text { Mandibular Dental Complex }\end{array}$ \\
\hline Gnathion to Incisal Plane & Gn-IP & $\begin{array}{l}\text { Mathematically Derived Lower } \\
\text { Facial Height Including } \\
\text { Mandibular Dental Complex }\end{array}$ \\
\hline $\begin{array}{l}\text { Sella Turcica to Posterior Nasal } \\
\text { Spine }\end{array}$ & S-PNS & $\begin{array}{l}\text { Sphenoid Sinus and Posterior } \\
\text { Nasal Space Along Nasion } \\
\text { Gnathion Line }\end{array}$ \\
\hline Sella Turcica to Sphenoid Floor & S-Sph Floor & $\begin{array}{l}\text { Sphenoid Sinus Along Nasion } \\
\text { Gnathion Line }\end{array}$ \\
\hline $\begin{array}{l}\text { Sphenoid Floor to Posterior Nasal } \\
\text { Spine }\end{array}$ & Sph Floor-PNS & $\begin{array}{l}\text { Posterior Nasal Space Along } \\
\text { Nasion Gnathion Line }\end{array}$ \\
\hline Sella Turcica to Gnathion & S-Gn & Transverse Facial Length \\
\hline Posterior Nasal Spine to Gnathion & PNS-Gn & $\begin{array}{l}\text { Mathematically Derived Portion } \\
\text { of Transverse Facial Length }\end{array}$ \\
\hline Sphenoid Floor to Gnathion & Sph Floor-Gn & $\begin{array}{l}\text { Mathematically Derived Portion } \\
\text { of Transverse Facial Length }\end{array}$ \\
\hline $\begin{array}{l}\text { Maximal Sphenoid Sinus } \\
\text { Posterior-Anterior Length }\end{array}$ & $\begin{array}{l}\text { Sph Sin PA } \\
\text { Length }\end{array}$ & Sphenoid Sinus Length \\
\hline $\begin{array}{l}\text { Maximal Right Maxillary Sinus } \\
\text { Posterior-Anterior Length }\end{array}$ & $\begin{array}{l}\text { Rt Mx Sin PA } \\
\text { Length }\end{array}$ & Right Maxillary Sinus Length \\
\hline $\begin{array}{l}\text { Maximal Left Maxillary Sinus } \\
\text { Posterior-Anterior Length }\end{array}$ & $\begin{array}{l}\text { Lt Mx Sin PA } \\
\text { Length }\end{array}$ & Left Maxillary Sinus Length \\
\hline Posterior Facial Height & Post Facial Hgt & Posterior Facial Height \\
\hline
\end{tabular}


Table 3. Coronal Linear Dimensions Measurements.

\begin{tabular}{|c|c|c|}
\hline Measurement & Abbreviation & Definition \\
\hline $\begin{array}{l}\text { Maximal Sphenoid Sinus } \\
\text { Superior-Inferior Height: }\end{array}$ & Sph Sin Hgt & Sphenoid Sinus Height \\
\hline $\begin{array}{l}\text { Maximal Right Maxillary Sinus } \\
\text { Superior-Inferior Height: }\end{array}$ & Rt Mx Sin Hgt & Right Maxillary Sinus Height \\
\hline $\begin{array}{l}\text { Maximal Left Maxillary Sinus } \\
\text { Superior-Inferior Height }\end{array}$ & Lt Mx Sin Hgt & Left Maxillary Sinus Height \\
\hline Lateral Orbital Distance at Nasion & $\begin{array}{l}\text { Lat Orb } \\
\text { Distance }\end{array}$ & Transverse Orbital Width of Face \\
\hline $\begin{array}{l}\text { Maximal Sphenoid Sinus Medial- } \\
\text { Lateral Width }\end{array}$ & Sph Sin Width & Sphenoid Sinus Width \\
\hline $\begin{array}{l}\text { Maximal Right Maxillary Sinus } \\
\text { Medial-Lateral Width }\end{array}$ & $\begin{array}{l}\text { Rt Mx Sin } \\
\text { Width }\end{array}$ & Right Maxillary Sinus Width \\
\hline $\begin{array}{l}\text { Maximal Left Maxillary Sinus } \\
\text { Medial-Lateral Width }\end{array}$ & $\begin{array}{l}\text { Lt Mx Sin } \\
\text { Width }\end{array}$ & Left Maxillary Sinus Width \\
\hline $\begin{array}{l}\text { Maximal Outer Right to Outer } \\
\text { Left Maxillary Sinus Medial- } \\
\text { Lateral Width }\end{array}$ & $\begin{array}{l}\text { Outer Mx Sin } \\
\text { Width }\end{array}$ & $\begin{array}{l}\text { Transverse Maxillary Sinus Width } \\
\text { of Face }\end{array}$ \\
\hline $\begin{array}{l}\text { Minimal Inner Right to Inner Left } \\
\text { Maxillary Sinus }\end{array}$ & $\begin{array}{l}\text { Inner Mx Sin } \\
\quad \text { Width }\end{array}$ & $\begin{array}{l}\text { Transverse inner Maxillary Sinus } \\
\text { Complex Width }\end{array}$ \\
\hline
\end{tabular}


Table 4. Sagittal Angular Dimensions Measurements.

\begin{tabular}{|c|c|c|}
\hline Measurement & Abbreviation & Definition \\
\hline $\begin{array}{l}\text { Sella Turcica to Nasion to A- } \\
\text { Point }\end{array}$ & SNA & $\begin{array}{l}\text { Position of Maxilla Relative to } \\
\text { Cranial Base }\end{array}$ \\
\hline $\begin{array}{l}\text { Sella Turcica to Nasion to B- } \\
\text { Point }\end{array}$ & SNB & $\begin{array}{l}\text { Position of Mandible Relative to } \\
\text { Cranial Base }\end{array}$ \\
\hline A-Point to Nasion to B-Point & ANB & $\begin{array}{l}\text { Position of Maxilla Relative to } \\
\text { Mandible }\end{array}$ \\
\hline $\begin{array}{l}\text { Sella Turcica to Posterior Nasal } \\
\text { Spine to Gnathion }\end{array}$ & S-PNS-Gn & $\begin{array}{l}\text { Position of Posterior Palate } \\
\text { Relative to Cranial Base and } \\
\text { Mandible }\end{array}$ \\
\hline $\begin{array}{l}\text { Sphenoid Sinus Long Axis to } \\
\text { Gnathion }\end{array}$ & $\begin{array}{l}\text { Sph Sin Long } \\
\text { Axis-Gn }\end{array}$ & $\begin{array}{l}\text { Position of Mandible Relative to } \\
\text { Sphenoid Sinus }\end{array}$ \\
\hline $\mathrm{XY}$ Axis Angle & NBa-SGn & $\begin{array}{l}\text { Facial Angle Relative to Cranial } \\
\text { Base }\end{array}$ \\
\hline $\begin{array}{l}\text { Sella Turcica to Nasion with } \\
\text { Left Gonion to Gnathion }\end{array}$ & SN-GoGn & $\begin{array}{l}\text { Mandibular Plane Relative to } \\
\text { Cranial Base }\end{array}$ \\
\hline
\end{tabular}

\section{Volumetric Measurement Procedures and Description:}

The Sinus/Airway option was selected on left toolbar and used to measure all volumes (Figure 16). 


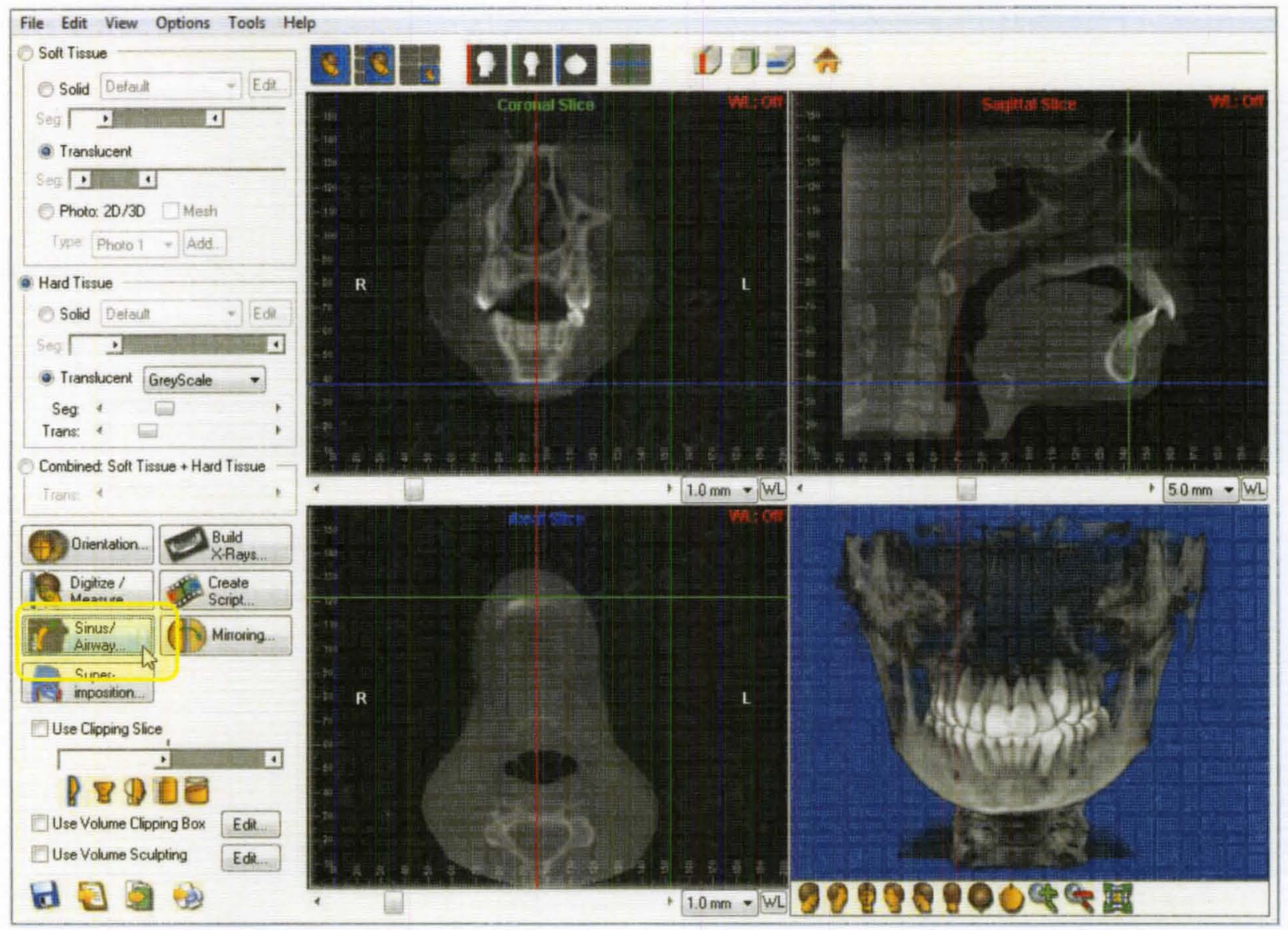

Figure 16. Screen capture of Dolphin 3D Imaging software display indicating location of Sinus/Airway option.

Orientation of the image was not performed as measurements were volumetric.

There was no option to modify the slice thickness. Brightness, contrast and magnification were modified as required (Figures 14 and 15).

In the Draft window of the Sinus/Airway display, a sagittal image is presented (Figure 17). 


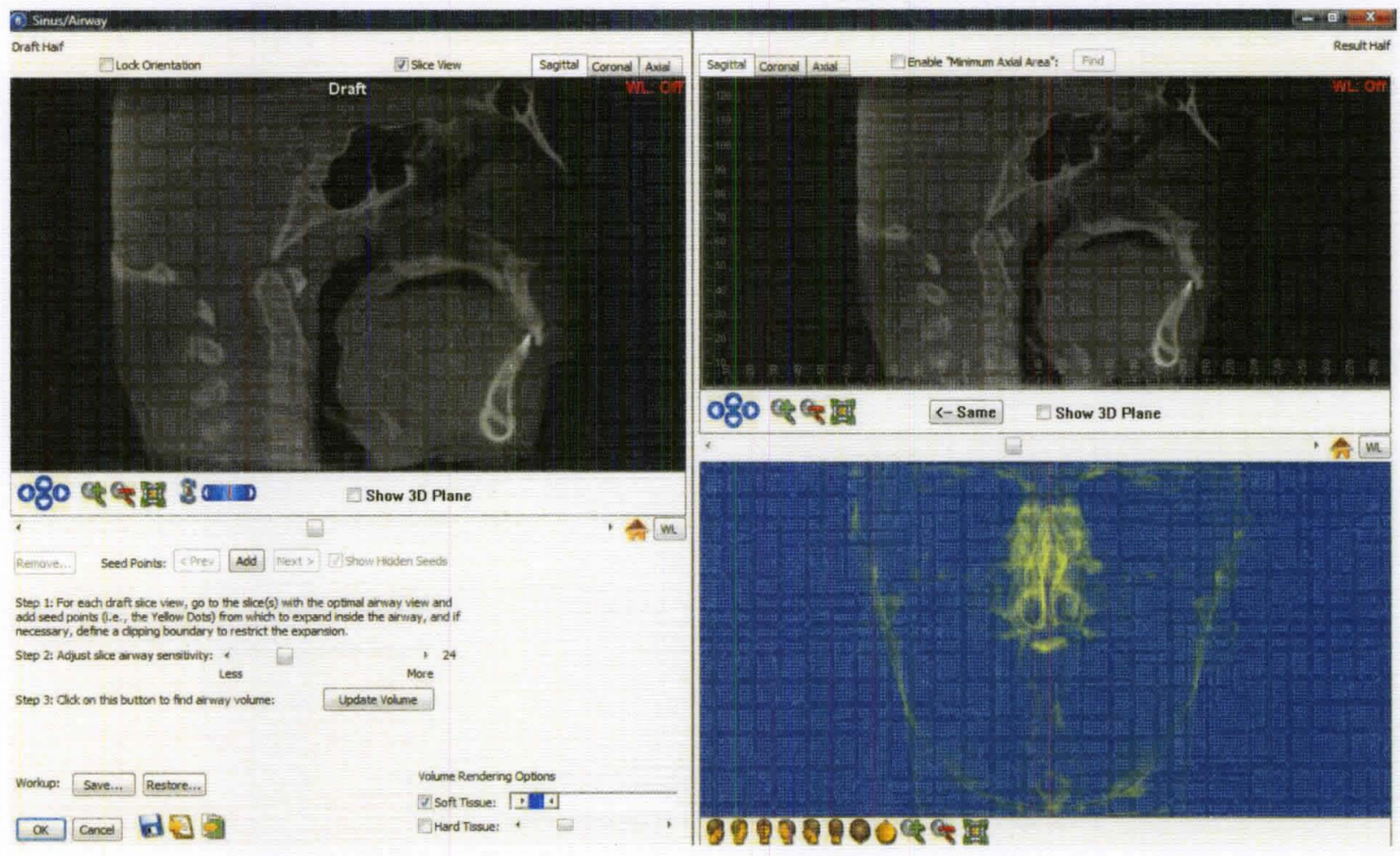

Figure 17. Screen capture of Dolphin 3D Imaging software displaying Sinus/Airway

Window.

Using the mouse cursor, the boundaries of the cortical extent of the sinus was identified by clicking points that would automatically be joined. The sagittal slices were scrolled through from one end to the other. The points encircling the sinus were moved only outwardly to ensure the entirety of the sinus was contained within this boundary (Figure 18). The axial, then coronal tabs were selected and the same method was applied for new independent tracings in each respective view. 


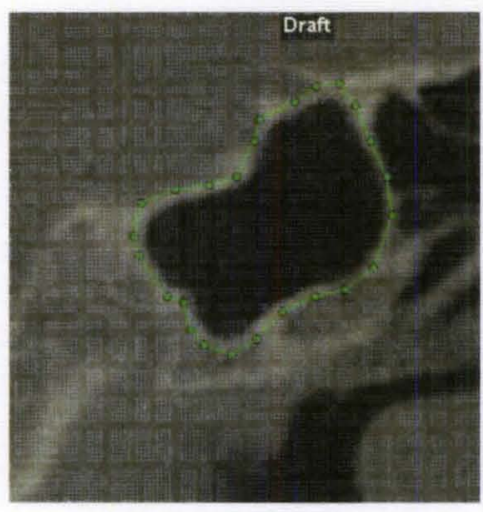

(a)

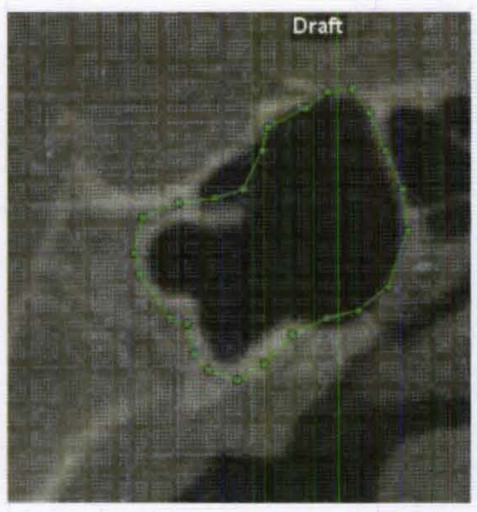

(b)

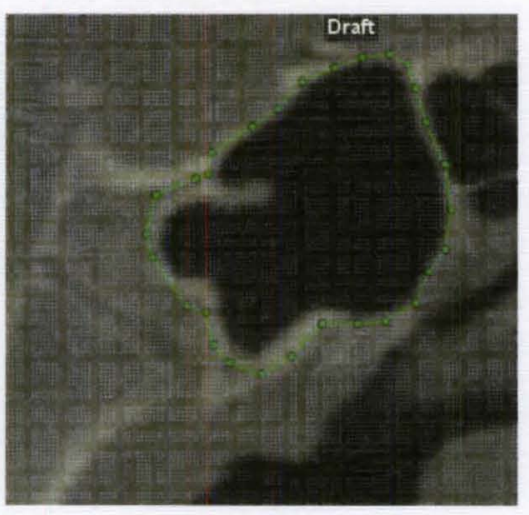

(c)

Figure 18. Cropped mid-sagittal image demonstrating outlining of the borders of the

sphenoid sinus (a). Lateral sagittal image plane with sinus dimension larger than initial tracing (b). Magnified image shown in (b) demonstrating borders after adjustment allowing for entire containment of sinus (c).

Segmentation inclusional seed points were then added to the sinuses to select the area to be included for volumetric assessment. This was done by clicking "add" tab for seeds and then clicking in the area where the seed was to be added (Figure 19).

Seed Points: <Prev Add Next > $\square$ Show Hidden Seeds

Figure 19. Cropped image of Seed Points Toolbar.

Where septa divided the sinus being measured, the seed would not extend its selection area and another seed point would need to be added (Figure 20). 


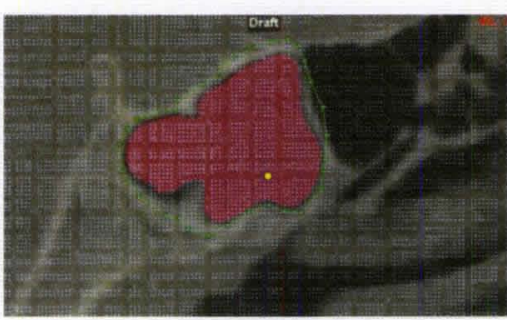

(a)

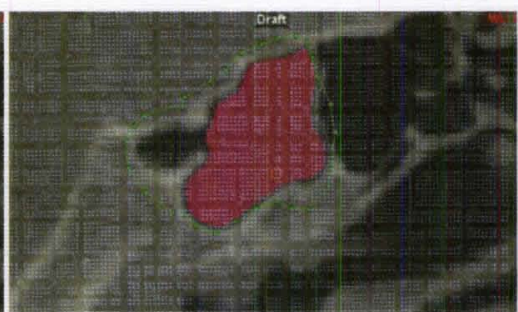

(b)

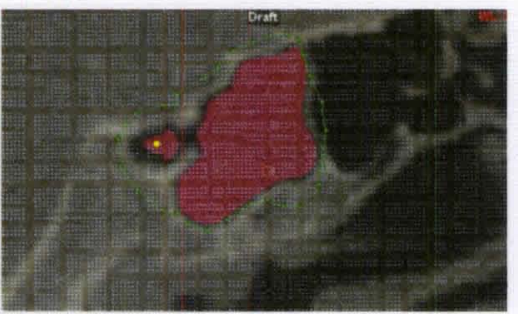

(c)

Figure 20. Magnified cropped image demonstrating initial placement of seed point within sinus colorizing values within a specific voxel range (a), lateral sagittal slice showing non-inclusion of a part of the sinus (b) and addition of secondary seed point including volume within this separated region (c).

After placement of all sinus seed points, the sensitivity of the seeds was adjusted. Seed sensitivity adjustment dictated the range of values of the voxel to be included (Figure 21). The desired sensitivity was the highest value that included all of the areas of that sinus without detecting or "bleeding" into adjacent, non-representative sinus areas (Figure 22).

Adjust slice airway sensitivity: Less
1 60

More

Figure 21. Cropped image of Air Sensitivity Toolbar. 


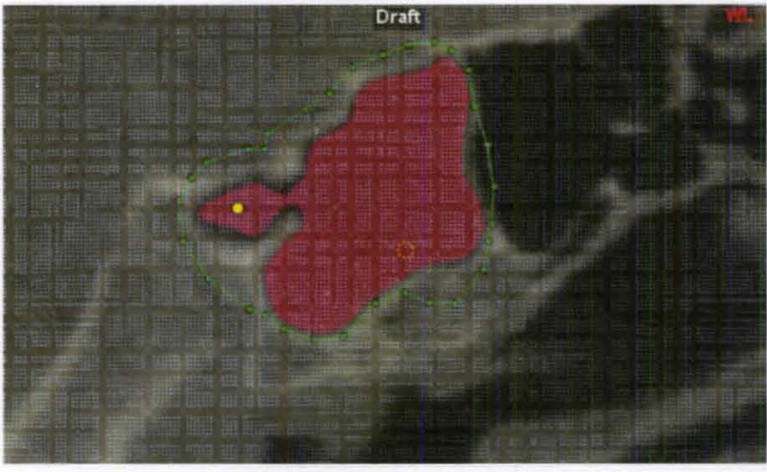

(a)

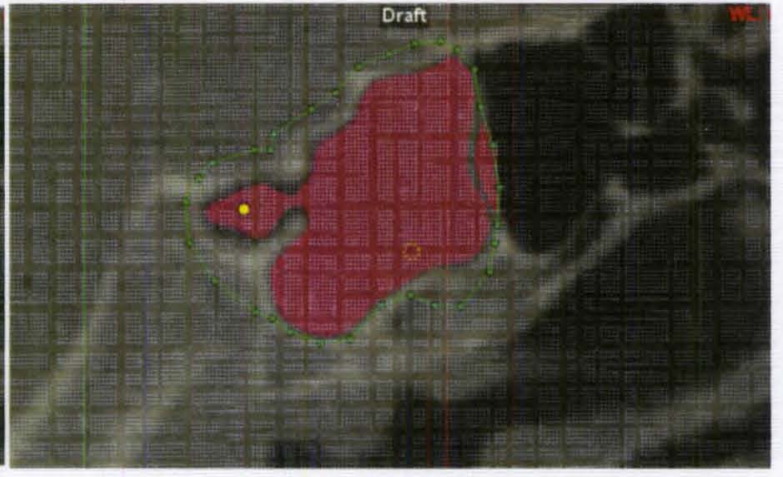

(b)

Figure 22. Maximum seed sensitivity without extending to non-representative area (a) and excessive seed sensitivity that has extended to non-representative area (b).

The sensitivity level chosen in one slice view affected the sensitivity in all other views. Following sensitivity adjustment in all three views and after scrolling through all slices, the option "Update Volume" tab was selected (Figure 23).

Click on this button to find airway volume:

\section{Update Volume}

Figure 23. Cropped image of Update Airway Volume Toolbar.

This resulted in re-segmentation of the volume and displayed the area included on a $3 \mathrm{D}$ volumetric rendering with an associated volumetric value $\left(\mathrm{mm}^{3}\right)$ (Figure 24). 


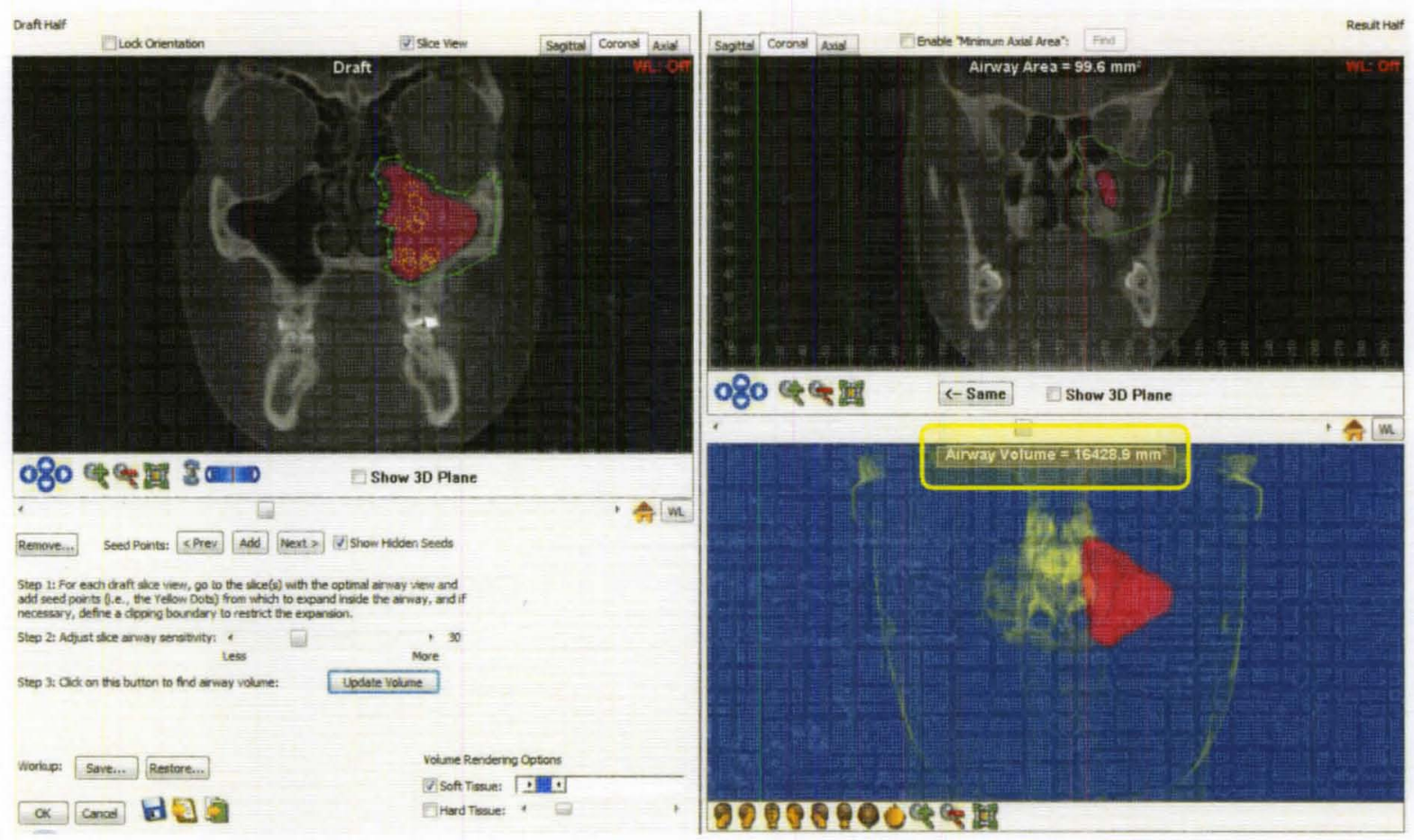

Figure 24. Screen capture of Dolphin 3D Imaging software display indicating airway volume.

The value displayed was recorded in the data analysis spreadsheet. The "Remove" tab selected and the" Remove ALL Seed Points and Boundaries" option was selected.

This procedure for sinus volume measurement was performed to determine the sphenoid, right maxillary and left maxillary sinus volumes.

\section{Statistical Analysis}

PASW statistical software was used to assess the measured values. The data in the data analysis spreadsheet was imported into the PASW statistical software program. After importation, the data analysis spreadsheet was converted into a proprietary format (PASW, *.sav) and saved. 
Four additional measurements were calculated within the PASW program by the addition of columns and appropriate formulae. These included:

1. Maximal Maxillary Sinus Posterior-Anterior Length Average (Mx Sin PA Length)

2. Maximal Maxillary Sinus Superior-Inferior Height Average (Mx Sin Hgt)

3. Maximal Maxillary Sinus Medial-Lateral Width Average (Mx Sin Width)

4. Maxillary Sinus Volume Average (Mx Sin Vol)

\section{Group Comparisons}

All measurements collected were subjected to Oneway ANOVA testing comparing the three developmental groups. Differences identified between groups based on the F-test were further subjected to Tukey Post Hoc tests. The level of significance for all analyses was set at $\alpha \leq 0.05$.

Measurements not found to have statistically significant group differences were combined and analyzed together whereas groups that demonstrated statistical significance were analyzed separately. Analysis consisted of bivariate Pearson correlations. These results were examined for correlations of clinical interest.

Multiple regression analysis was applied to these identified measurements. Outcome measures were chosen based on those thought to have clinical relevance. Associated predictor variables were chosen based on measurements found to have statistically significant correlation to the outcome measure being assessed. Predictor variables found to have $p$ values greater than 0.05 were not regarded as significant and 
removed as predictor variables. The multiple regressions were then reassessed and the change in the $\mathrm{R}$ squared value observed.

\section{Intra-Observer Reliability and Repeatability}

Using the website: www.random.org random integers were generated to select 9 of the 27 subjects to remeasure (Figure 25).

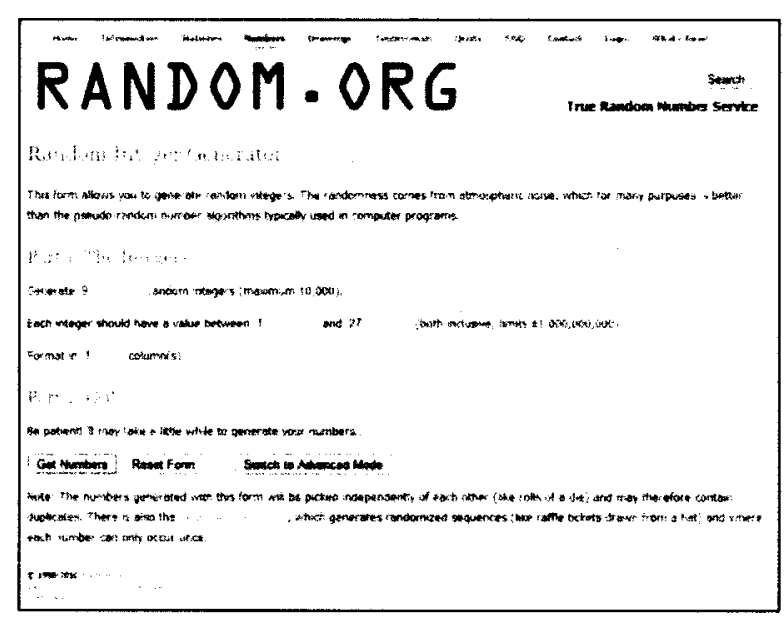

(a)

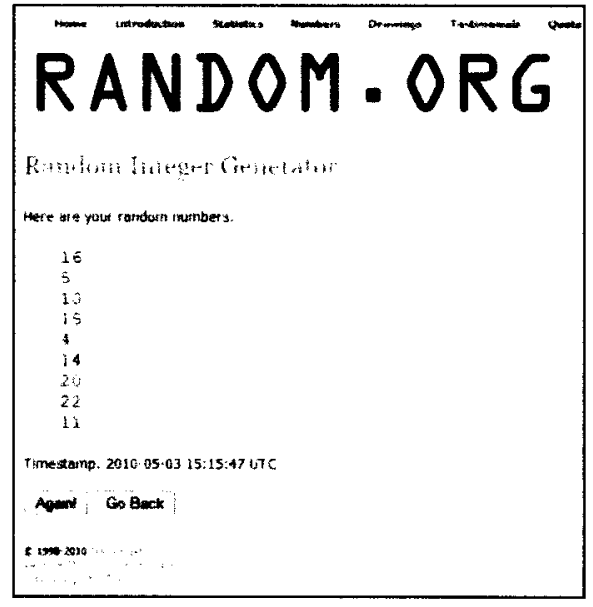

(b)

Figure 25. Random sequence generator used to determine which subjects to remeasure (a), resultant random numbers generated (b).

Only one line, one angle and one sinus volume were remeasured. The bivariate Pearson correlations of each variable with all the other variables of the 27 subjects were reviewed to select three such measurements that were not correlated with one another. Thus the three variables measured were independent. 
Three measurements were made with the same techniques as described earlier. With the use of the PASW statistical software, the random subject measurement values were compared to the initial measurements of the same individuals.

Repeatability is a measure of the amount of variation between a value remeasured under the same conditions. This was assessed by comparing the means of the first measurements with the second measurements through a paired t-test.

Intra-observer reliability is a measure of the amount of agreement between remeasurements by a single observer. This was assessed through the intraclass correlation coefficient (ICC). 


\section{CHAPTER IV}

\section{RESULTS}

Exclusion criteria were applied to the patient radiologic database as previously described in the Methods and Materials section. The sample stratified according to spheno-occipital fusion and age is shown in Table 5.

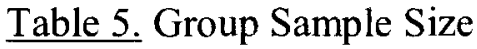

\begin{tabular}{ccc}
\hline Group & Group Definition & Sample Size \\
\hline $\mathbf{1}$ & Pre-fused Spheno-Occipital Synchondrosis & 8 \\
$\mathbf{2}$ & Fused Spheno-Occipital Synchondrosis when Under 18 Years Old & 9 \\
$\mathbf{3}$ & Subjects 18 Years Old and Older with Fused Spheno-Occipital & 10 \\
& Synchondrosis & \\
\hline
\end{tabular}

Appendix D provides the actual linear, angular and volumetric measurements for all subjects including repeated measures.

Table 6 shows the mean ( \pm standard deviation) dimensions for each group and the pooled overall group for craniofacial and sinus linear measurements. 
Table 6. Comparison of Mean Linear Measurements ( \pm standard deviation) for Craniofacial and Sinus Parameters for Each Group. ANOVA values are shown and significance at $\mathrm{p} \leq .05$ are bolded.

\begin{tabular}{|c|c|c|c|c|c|c|}
\hline \multirow[b]{2}{*}{ Parameter (mm) } & \multirow{2}{*}{$\begin{array}{c}\text { Group } 1 \\
(n=8)\end{array}$} & \multirow{2}{*}{$\begin{array}{c}\text { Group } 2 \\
(n=9)\end{array}$} & \multirow{2}{*}{$\begin{array}{c}\text { Group } 3 \\
(n=10)\end{array}$} & \multirow{2}{*}{$\begin{array}{l}\text { Pooled } \\
(n=27)\end{array}$} & \multicolumn{2}{|c|}{ Significance } \\
\hline & & & & & $\mathbf{F}$ & $p$ \\
\hline \multicolumn{7}{|l|}{ Craniofacial } \\
\hline N-ANS & $\begin{array}{c}46.79 \pm \\
3.58\end{array}$ & $\begin{array}{c}47.97 \pm \\
2.02\end{array}$ & $\begin{array}{c}49.08 \pm \\
2.53\end{array}$ & $\begin{array}{c}48.03 \pm \\
2.80\end{array}$ & 1.559 & .231 \\
\hline ANS-UIT & $\begin{array}{c}27.24 \pm \\
2.07\end{array}$ & $\begin{array}{c}28.38 \pm \\
3.10\end{array}$ & $\begin{array}{c}27.75 \pm \\
2.41\end{array}$ & $\begin{array}{c}27.81 \pm \\
2.52\end{array}$ & .419 & .663 \\
\hline ANS-LIT & $\begin{array}{c}22.65 \pm \\
2.14\end{array}$ & $\begin{array}{c}26.16 \pm \\
4.20\end{array}$ & $\begin{array}{c}26.18 \pm \\
2.46\end{array}$ & $\begin{array}{c}25.12 \pm \\
3.38\end{array}$ & 3.679 & .040 \\
\hline $\mathrm{N}-$ UIT & $\begin{array}{c}93.58 \pm \\
7.16\end{array}$ & $\begin{array}{c}95.93 \pm \\
4.04\end{array}$ & $\begin{array}{c}98.16 \pm \\
5.06\end{array}$ & $\begin{array}{c}96.06 \pm \\
5.60\end{array}$ & 1.559 & .231 \\
\hline Gn-UIT & $\begin{array}{c}28.98 \pm \\
1.61\end{array}$ & $\begin{array}{c}33.96 \pm \\
3.84\end{array}$ & $\begin{array}{c}35.68 \pm \\
2.89\end{array}$ & $\begin{array}{c}33.12 \pm \\
4.02\end{array}$ & 11.895 & .000 \\
\hline Gn-LIT & $\begin{array}{c}33.58 \pm \\
2.50\end{array}$ & $\begin{array}{c}36.31 \pm \\
2.38\end{array}$ & $\begin{array}{c}37.24 \pm \\
2.71\end{array}$ & $\begin{array}{c}35.84 \pm \\
2.89\end{array}$ & 4.848 & .017 \\
\hline ANS-IP & $\begin{array}{c}24.94 \pm \\
1.87\end{array}$ & $\begin{array}{c}27.27 \pm \\
3.53\end{array}$ & $\begin{array}{c}26.96 \pm \\
2.34\end{array}$ & $\begin{array}{c}26.47 \pm \\
2.78\end{array}$ & 1.852 & .179 \\
\hline Gn-IP & $\begin{array}{c}31.28 \pm \\
1.87\end{array}$ & $\begin{array}{c}35.13 \pm \\
3.02\end{array}$ & $\begin{array}{c}36.46 \pm \\
2.72\end{array}$ & $\begin{array}{c}34.48 \pm \\
3.34\end{array}$ & 9.133 & .001 \\
\hline N-Gn & $\begin{array}{c}103.01 \pm \\
5.50\end{array}$ & $\begin{array}{c}110.37 \pm \\
7.30\end{array}$ & $\begin{array}{c}112.50 \pm \\
6.18\end{array}$ & $\begin{array}{c}108.98 \pm \\
7.36\end{array}$ & 5.219 & .013 \\
\hline S-Sph Floor & $\begin{array}{c}21.90 \pm \\
2.89\end{array}$ & $\begin{array}{c}23.47 \pm \\
2.20\end{array}$ & $\begin{array}{c}23.76 \pm \\
2.16\end{array}$ & $\begin{array}{c}23.11 \pm \\
2.45\end{array}$ & 1.472 & .249 \\
\hline Sph Floor-PNS & $\begin{array}{c}21.42 \pm \\
2.54\end{array}$ & $\begin{array}{c}22.86 \pm \\
2.62\end{array}$ & $\begin{array}{c}21.64 \pm \\
1.75\end{array}$ & $\begin{array}{c}21.98 \pm \\
2.31\end{array}$ & .988 & .387 \\
\hline S-PNS & $\begin{array}{c}43.32 \pm \\
4.37\end{array}$ & $\begin{array}{c}46.32 \pm \\
1.91\end{array}$ & $\begin{array}{c}45.40 \pm \\
2.55\end{array}$ & $\begin{array}{c}45.09 \pm \\
3.17\end{array}$ & 2.140 & .140 \\
\hline PNS-Gn & $\begin{array}{c}65.18 \pm \\
5.30\end{array}$ & $\begin{array}{c}74.51 \pm \\
4.90\end{array}$ & $\begin{array}{c}77.13 \pm \\
5.94\end{array}$ & $\begin{array}{c}72.71 \pm \\
7.30\end{array}$ & 11.537 & .000 \\
\hline Sph Floor-Gn & $\begin{array}{c}86.60 \pm \\
6.33\end{array}$ & $\begin{array}{c}97.37 \pm \\
6.58\end{array}$ & $\begin{array}{l}98.77 \\
\pm 6.20\end{array}$ & $\begin{array}{c}94.70 \pm \\
8.15\end{array}$ & 9.304 & .001 \\
\hline
\end{tabular}


Table 6 (Continued). Comparison of Mean Linear Measurements ( \pm standard deviation) for Craniofacial and Sinus Parameters for Each Group. ANOVA values are shown and significance at $\mathrm{p} \leq .05$ are bolded.

\begin{tabular}{|c|c|c|c|c|c|c|}
\hline \multirow[b]{2}{*}{ Parameter (mm) } & \multirow{2}{*}{$\begin{array}{c}\text { Group } 1 \\
(n=8)\end{array}$} & \multirow{2}{*}{$\begin{array}{c}\text { Group } 2 \\
(n=9)\end{array}$} & \multirow{2}{*}{$\begin{array}{c}\text { Group } 3 \\
(n=10)\end{array}$} & \multirow{2}{*}{$\begin{array}{l}\text { Pooled } \\
(n=27)\end{array}$} & \multicolumn{2}{|c|}{ Significance } \\
\hline & & & & & $\mathbf{F}$ & $P$ \\
\hline \multicolumn{7}{|l|}{ Craniofacial } \\
\hline S-Gn & $\begin{array}{c}108.50 \pm \\
7.88\end{array}$ & $\begin{array}{c}120.83 \pm \\
5.79\end{array}$ & $\begin{array}{c}122.53 \pm \\
6.29\end{array}$ & $\begin{array}{c}117.81 \pm \\
8.90\end{array}$ & 11.3111 & .000 \\
\hline Post Facial Hgt & $\begin{array}{c}64.42 \pm \\
8.96\end{array}$ & $\begin{array}{c}75.12 \pm \\
6.56\end{array}$ & $\begin{array}{c}72.86 \pm \\
15.16\end{array}$ & $\begin{array}{c}71.11 \pm \\
11.61\end{array}$ & 2.151 & .138 \\
\hline Lat Orb Distance & $\begin{array}{c}86.34 \pm \\
6.13\end{array}$ & $\begin{array}{c}88.93 \pm \\
5.45\end{array}$ & $\begin{array}{c}84.92 \pm \\
8.06\end{array}$ & $\begin{array}{c}86.68 \pm \\
6.69\end{array}$ & .858 & .437 \\
\hline Outer Mx Sinus & $\begin{array}{c}75.68 \pm \\
6.07\end{array}$ & $\begin{array}{c}79.20 \pm \\
6.81\end{array}$ & $\begin{array}{c}75.02 \pm \\
6.05\end{array}$ & $\begin{array}{c}76.61 \pm \\
6.36\end{array}$ & 1.160 & .330 \\
\hline Inner Mx Sinus & $\begin{array}{c}26.42 \pm \\
3.13\end{array}$ & $\begin{array}{c}26.07 \pm \\
3.05\end{array}$ & $\begin{array}{c}26.67 \pm \\
5.21\end{array}$ & $\begin{array}{c}26.40 \pm \\
3.87\end{array}$ & .054 & .948 \\
\hline \multicolumn{7}{|l|}{ Sphenoid Sinus } \\
\hline Sph Sin PA Length & $\begin{array}{c}22.20 \pm \\
6.26\end{array}$ & $\begin{array}{c}29.31 \pm \\
5.19\end{array}$ & $\begin{array}{c}28.41 \pm \\
4.42\end{array}$ & $\begin{array}{c}26.87 \pm \\
5.94\end{array}$ & 4.541 & .021 \\
\hline Sph Sin Hgt & $\begin{array}{c}20.84 \pm \\
3.81\end{array}$ & $\begin{array}{c}23.24 \pm \\
2.34\end{array}$ & $\begin{array}{c}23.58 \pm \\
1.95\end{array}$ & $\begin{array}{c}22.66 \pm \\
2.89\end{array}$ & 2.545 & .099 \\
\hline Sph Sin Width & $\begin{array}{c}31.09 \pm \\
10.10\end{array}$ & $\begin{array}{c}33.76 \pm \\
7.78\end{array}$ & $\begin{array}{c}33.70 \pm \\
6.92\end{array}$ & $\begin{array}{c}32.94 \pm \\
8.01\end{array}$ & .289 & .752 \\
\hline \multicolumn{7}{|l|}{ Maxillary Sinus } \\
\hline Mx Sin PA Length* & $\begin{array}{c}34.92 \pm \\
2.81\end{array}$ & $\begin{array}{c}38.54 \pm \\
2.57\end{array}$ & $\begin{array}{c}35.94 \pm \\
5.53\end{array}$ & $\begin{array}{c}36.50 \pm \\
4.13\end{array}$ & 1.905 & .171 \\
\hline Mx Sin $\mathrm{Hgt}^{*}$ & $\begin{array}{c}28.91 \pm \\
4.92\end{array}$ & $\begin{array}{c}33.25 \pm \\
5.62\end{array}$ & $\begin{array}{c}30.68 \pm \\
4.78\end{array}$ & $\begin{array}{c}31.01 \pm \\
5.22\end{array}$ & 1.560 & .231 \\
\hline Mx Sin Width* & $\begin{array}{c}24.54 \pm \\
3.88\end{array}$ & $\begin{array}{c}26.12 \pm \\
5.05\end{array}$ & $\begin{array}{c}23.86 \pm \\
5.22\end{array}$ & $\begin{array}{c}24.81 \pm \\
4.72\end{array}$ & .543 & .588 \\
\hline
\end{tabular}

* Average of measurements from left and right

Table 7 shows the mean ( \pm standard deviation) dimensions for each group and the pooled overall group for craniofacial and sinus angular measurements. 
Table 7. Comparison of Mean Angular Measurements ( \pm standard deviation) for Craniofacial and Sinus Parameters for Each Group. ANOVA values are shown and significance at $\mathrm{p} \leq .05$ are bolded.

\begin{tabular}{|c|c|c|c|c|c|c|}
\hline \multirow{2}{*}{ Parameter $\left({ }^{\circ}\right)$} & \multirow{2}{*}{$\begin{array}{c}\text { Group } 1 \\
(n=8)\end{array}$} & \multirow{2}{*}{$\begin{array}{c}\text { Group } 2 \\
(n=9)\end{array}$} & \multirow{2}{*}{$\begin{array}{c}\text { Group } 3 \\
(n=10)\end{array}$} & \multirow{2}{*}{$\begin{array}{l}\text { Pooled } \\
(n=27)\end{array}$} & \multicolumn{2}{|c|}{ Significance } \\
\hline & & & & & $\mathbf{F}$ & $p$ \\
\hline \multicolumn{7}{|l|}{ Craniofacial } \\
\hline SNA & $\begin{array}{c}81.21 \pm \\
4.63\end{array}$ & $85.08 \pm 2.29$ & $83.72 \pm 4.50$ & $83.43 \pm 4.11$ & 2.073 & .148 \\
\hline SNB & $\begin{array}{c}77.50 \pm \\
5.13\end{array}$ & $81.17 \pm 2.10$ & $81.20 \pm 3.53$ & $80.09 \pm 3.96$ & 2.768 & .083 \\
\hline ANB & $3.77 \pm 1.57$ & $4.03 \pm 1.96$ & $3.68 \pm 2.12$ & $3.83 \pm 1.85$ & .084 & .919 \\
\hline S-PNS-Gn & $\begin{array}{c}172.79 \pm \\
4.40\end{array}$ & $\begin{array}{c}170.91 \pm \\
4.48\end{array}$ & $\begin{array}{c}171.06 \pm \\
3.98\end{array}$ & $\begin{array}{c}171.52 \pm \\
4.19\end{array}$ & .501 & .612 \\
\hline $\begin{array}{l}\text { XY Axis } \\
\text { Angle }\end{array}$ & $\begin{array}{c}86.65 \pm \\
3.59\end{array}$ & $85.27 \pm 3.39$ & $84.21 \pm 3.27$ & $85.28 \pm 3.42$ & 1.141 & .336 \\
\hline SN-GoGn & $\begin{array}{c}35.01 \pm \\
6.07\end{array}$ & $30.02 \pm 4.30$ & $29.04 \pm 3.89$ & $31.14 \pm 5.25$ & 3.878 & .035 \\
\hline $\begin{array}{l}\text { Sph Sin Long } \\
\text { Axis-Gn }\end{array}$ & $\begin{array}{c}88.52 \pm \\
5.13\end{array}$ & $81.88 \pm 7.51$ & $81.33 \pm 7.62$ & $83.64 \pm 7.42$ & 2.821 & .079 \\
\hline
\end{tabular}


Table 8 shows the mean ( \pm standard deviation) dimensions for each group and the pooled overall group for craniofacial and sinus volumetric measurements.

Table 8. Comparison of Mean Volumetric Measurements ( \pm standard deviation) for Sinus Parameters for Each Group. ANOVA values are shown and significance at $\mathrm{p} \leq .05$ are bolded.

\begin{tabular}{|c|c|c|c|c|c|c|}
\hline Parameter $\left(\mathrm{mm}^{3}\right)$ & $\begin{array}{c}\text { Group l } \\
(n=8)\end{array}$ & $\begin{array}{c}\text { Group } 2 \\
(n=9)\end{array}$ & $\begin{array}{c}\text { Group } 3 \\
(n=10)\end{array}$ & $\begin{array}{l}\text { Pooled } \\
(n=27)\end{array}$ & \multicolumn{2}{|c|}{ Significance } \\
\hline & & & & & $\mathbf{F}$ & $p$ \\
\hline \multicolumn{7}{|l|}{ Sphenoid Sinus } \\
\hline Sphenoid Sinus Vol & $\begin{array}{c}8,569.79 \pm \\
4,496.90\end{array}$ & $\begin{array}{c}11,169.33 \\
\pm \\
3,071.53\end{array}$ & $\begin{array}{c}10,422.09 \\
\pm \\
3,023.09\end{array}$ & $\begin{array}{c}10,122.34 \\
\pm \\
3,559.00\end{array}$ & 1.205 & .317 \\
\hline \multicolumn{7}{|l|}{ Maxillary Sinus } \\
\hline Maxillary Sinus Vol* & $\begin{array}{r}11,865.36 \\
\pm 3,068.13\end{array}$ & $\begin{array}{c}16,965.12 \\
\pm \\
5,766.15\end{array}$ & $\begin{array}{c}13,290.94 \\
\pm \\
4,772.55\end{array}$ & $\begin{array}{c}14,093.27 \\
\pm \\
5,027.81\end{array}$ & 2.691 & .088 \\
\hline
\end{tabular}

* Average of measurements from left and right 


\section{Variation in Measurements Between Groups}

ANOVA revealed only some differences between groups. Table 9 summarizes parameters that demonstrated significance at $P \leq .050$.

Table 9. Summary of ANOVA Comparisons Between all Groups.

\begin{tabular}{ccc}
\hline Parameter & F & $\boldsymbol{P}$ \\
\hline ANS-LIT & 3.679 & .040 \\
Gn-UIT & 11.895 & .000 \\
Gn-LIT & 4.848 & .017 \\
Gn-IP & 9.133 & .001 \\
N-Gn & 5.219 & .013 \\
PNS-Gn & 11.537 & .000 \\
Sph Floor-Gn & 9.304 & .001 \\
S-Gn & 11.311 & .000 \\
Sph Sin PA Length & 4.541 & .021 \\
SN-GoGn & 3.878 & .035 \\
\hline
\end{tabular}

Table 10 shows the Post Hoc Tukey tests for parameters found to demonstrate significance $(\mathrm{p} \leq .05)$ in Tables 8 and 9. 
Table 10. Post Hoc Tukey Test Comparisons.

\begin{tabular}{ccc}
\hline Parameter & Group & $\boldsymbol{P}$ \\
\hline ANS-LIT & None & None \\
Gn-UIT & $1<2$ & .006 \\
& $1<3$ & .000 \\
Gn-LIT & $1<3$ & .015 \\
Gn-IP & $1<2$ & .015 \\
& $1<3$ & .001 \\
N-Gn & $1<3$ & .012 \\
PNS-Gn & $1<2$ & .005 \\
& $1<3$ & .000 \\
Sph Floor-Gn & $1<2$ & .005 \\
& $1<3$ & .001 \\
S-Gn & $1<2$ & .005 \\
& $1<3$ & .000 \\
Sph Sin PA Length & $1<2$ & .027 \\
SN-GoGn & $1>3$ & .036 \\
\hline
\end{tabular}

For the 27 measurements which did not demonstrate differences between groups, data were pooled and bivariate Pearson correlations and multiple regressions were calculated. 
Relationship Between Linear, Angular and Volumetric Relationship of the Sinuses and Other Selected Craniomaxillofacial Dimensions

Tables 11 to 16 shows the bivariate Pearson correlation and $p$-value for the pooled group for craniofacial and sinus linear, angular and volumetric measurements. 
Table 11. Bivariate Pearson Correlations Between Sinus and Craniomaxillofacial

Dimensions ( $\mathrm{R}$ ( $\mathrm{p}$ value)). Values shown with significance at $\mathrm{p} \leq .05$ are bolded.

\begin{tabular}{|c|c|c|c|c|c|}
\hline \multirow[t]{2}{*}{ Secondary } & & \multicolumn{4}{|c|}{ Maxillary Sinus Dimensions } \\
\hline & & Height* & PA* & Width* & Volume \\
\hline \multirow[t]{4}{*}{$\begin{array}{c}\text { Maxillary } \\
\text { Sinus }\end{array}$} & Height* & & & & \\
\hline & $\mathbf{P A}^{*}$ & $.57(.00)$ & & & \\
\hline & Width* & $.60(.00)$ & $.62(.00)$ & & \\
\hline & Volume & $.84(.00)$ & $.80(.00)$ & $.75(.00)$ & \\
\hline \multirow[t]{3}{*}{ Sphenoid Sinus } & Height & $.38(.05)$ & $.27(.17)$ & $.14(.48)$ & $.31(.11)$ \\
\hline & Width & $.17(.40)$ & $.10(.63)$ & $.36(.07)$ & $.11(.59)$ \\
\hline & Volume & $.40(.04)$ & $.22(.28)$ & $.39(.05)$ & $.38(.05)$ \\
\hline \multirow[t]{17}{*}{ Cranio-facial } & N-ANS & $.43(.02)$ & $.67(.00)$ & $.29(.14)$ & $.50(.01)$ \\
\hline & ANS-UIT & $.17(.40)$ & $.30(.14)$ & $.09(.66)$ & $.27(.18)$ \\
\hline & N-UIT & $.44(.02)$ & $.67(.00)$ & $.29(.14)$ & $.50(.01)$ \\
\hline & ANS-IP & $.25(.21)$ & $.38(.05)$ & $.15(.47)$ & $.40(.04)$ \\
\hline & S-Sph Floor & $-.06(.77)$ & $.12(.56)$ & $.01(.97)$ & $.04(.82)$ \\
\hline & Sph Floor-PNS & $.39(.04)$ & $.29(.14)$ & $.28(.16)$ & $.49(.01)$ \\
\hline & S-PNS & $.24(.23)$ & $.30(.13)$ & $.21(.30)$ & $.39(.04)$ \\
\hline & Post Facial Hgt & $.34(.08)$ & $.31(.12)$ & $-0.3(.88)$ & $.29(.14)$ \\
\hline & Lat Orb Distance & $.25(.21)$ & $.26(.19)$ & $.32(.10)$ & $.35(.07)$ \\
\hline & Outer Mx Sinus & $.54(.00)$ & $.59(.00)$ & $.93(.00)$ & $.75(.00)$ \\
\hline & Inner Mx Sinus & $-.52(.00)$ & $-.54(.00)$ & $-.76(.00)$ & $-.59(.00)$ \\
\hline & SNA & $-.26(.19)$ & $-.06(.75)$ & $-.27(.18)$ & $-.16(.43)$ \\
\hline & SNB & $-.15(.46)$ & $.17(.93)$ & $-.24(.23)$ & $-.07(.71)$ \\
\hline & ANB & $-.14(.47)$ & $-.01(.95)$ & $.08(.67)$ & $-.01(.98)$ \\
\hline & S-PNS-Gn & $-.26(.19)$ & $-.25(.21)$ & $-.22(.27)$ & $-.24(.24)$ \\
\hline & XY Axis Angle & $.37(.06)$ & $.14(.48)$ & $.35(.07)$ & $.32(.11)$ \\
\hline & $\begin{array}{l}\text { Sph Sin Long Axis- } \\
\text { Gn }\end{array}$ & $.19(.34)$ & $.23(.24)$ & $.17(.39)$ & $.24(.24)$ \\
\hline
\end{tabular}

\footnotetext{
* Average of measurements from left and right
} 
Table 12. Bivariate Pearson Correlation Between Sphenoid Sinus and Craniomaxillofacial Dimensions ( $R$ ( $p$ value)). Values shown with significance at $p \leq .05$ are bolded.

\begin{tabular}{|c|c|c|c|c|}
\hline \multirow[t]{2}{*}{ Secondary } & & \multicolumn{3}{|c|}{ Sphenoid Sinus Dimensions } \\
\hline & & Height & Width & Volume \\
\hline \multirow[t]{3}{*}{ Sphenoid Sinus } & Height & & & \\
\hline & Width & $.57(.00)$ & & \\
\hline & Volume & $.78(00)$ & $.82(.00)$ & \\
\hline \multirow[t]{17}{*}{ Cranio-facial } & N-ANS & $.35(.08)$ & $.18(.36)$ & $.15(.45)$ \\
\hline & ANS-UIT & $.16(.43)$ & $.13(.52)$ & $.00(1.00)$ \\
\hline & N-UIT & $.35(.08)$ & $.18(.36)$ & $.15(.45)$ \\
\hline & ANS-IP & $.19(.33)$ & $.09(.66)$ & $.03(.88)$ \\
\hline & S-Sph Floor & $.64(.00)$ & $.48(.01)$ & $.59(.00)$ \\
\hline & Sph Floor-PNS & $-.13(.52)$ & $.05(.80)$ & $.11(.60)$ \\
\hline & S-PNS & $.40(.04)$ & $.41(.03)$ & $.54(.00)$ \\
\hline & Post Facial Hgt & $.22(.28)$ & $.06(.79)$ & $.16(.42)$ \\
\hline & Lat Orb Distance & $.32(.11)$ & $.52(.00)$ & $.41(.03)$ \\
\hline & Outer Mx Sinus & $.19(.35)$ & $.42(.03)$ & $.44(.02)$ \\
\hline & Inner Mx Sinus & $.06(.75)$ & $.04(.85)$ & $-.04(.86)$ \\
\hline & SNA & $.28(.16)$ & $.33(.09)$ & $.33(.10)$ \\
\hline & SNB & $.17(.41)$ & $.18(.37)$ & $.26(.19)$ \\
\hline & ANB & $.26(.18)$ & $.18(.37)$ & $.23(.26)$ \\
\hline & S-PNS-Gn & $-.02(.92)$ & $-.13(.51)$ & $-.24(.24)$ \\
\hline & XY Axis Angle & $-.23(.25)$ & $-.02(.92)$ & $-.13(.53)$ \\
\hline & Sph Sin Long Axis-Gn & $.06(.76)$ & $-.18(.37)$ & $-.05(.79)$ \\
\hline
\end{tabular}


Table 13. Bivariate Pearson Correlations Between Craniomaxillofacial Dimensions

$(\mathrm{R}$ ( $\mathrm{p}$ value)). Values shown with significance at $\mathrm{p} \leq .05$ are bolded.

\begin{tabular}{|c|c|c|c|c|c|}
\hline \multirow[t]{2}{*}{ Secondary } & & \multicolumn{4}{|c|}{ Cranio-facial Dimensions } \\
\hline & & N-ANS & $\begin{array}{l}\text { ANS- } \\
\text { UIT }\end{array}$ & N-UIT & ANS-IP \\
\hline \multirow[t]{17}{*}{$\begin{array}{c}\text { Cranio- } \\
\text { facial }\end{array}$} & N-ANS & & & & \\
\hline & ANS-UIT & $-.30(.13)$ & & & \\
\hline & N-UIT & $1.00(.00)$ & $.30(.13)$ & & \\
\hline & ANS-IP & $.31(.11)$ & $.92(.00)$ & $.31(.11)$ & \\
\hline & S-Sph Floor & $.24(.22)$ & $.07(.72)$ & $.24(.22)$ & $0.78(.70)$ \\
\hline & Sph Floor-PNS & $.29(.14)$ & $.17(.41)$ & $.29(.14)$ & $.20(.32)$ \\
\hline & S-PNS & $.40(.04)$ & $.18(.38)$ & $.40(.04)$ & $.20(.31)$ \\
\hline & Post Facial Hgt & $.24(.23)$ & $.35(.07)$ & $.24(.23)$ & $.38(.05)$ \\
\hline & Lat Orb Distance & $.35(.07)$ & $.48(.01)$ & $.35(.07)$ & $.42(.03)$ \\
\hline & Outer Mx Sinus & $.30(.13)$ & $.25(.21)$ & $.30(.13)$ & $.29(.14)$ \\
\hline & Inner Mx Sinus & $-.26(.18)$ & $.13(.53)$ & $-.26(.18)$ & $.07(.73)$ \\
\hline & SNA & $-.04(.86)$ & $-.01(.98)$ & $-.04(.86)$ & $.03(.89)$ \\
\hline & SNB & $.03(.88)$ & $-.06(.78)$ & $.03(.88)$ & $.06(.75)$ \\
\hline & ANB & $-.07(.74)$ & $.03(.90)$ & $-.07(.74)$ & $-.05(.79)$ \\
\hline & S-PNS-Gn & $-.20(.30)$ & $.01(.97)$ & $-.20(.30)$ & $.03(.88)$ \\
\hline & XY Axis Angle & $.05(.79)$ & $.32(.10)$ & $.05(.79)$ & $.25(.21)$ \\
\hline & $\begin{array}{l}\text { Sph Sin Long } \\
\text { Axis-Gn }\end{array}$ & $.07(.73)$ & $.25(.22)$ & $.07(.73)$ & $.14(.50)$ \\
\hline
\end{tabular}


Table 14. Bivariate Pearson Correlations Between Craniomaxillofacial Dimensions

( $R$ ( $p$ value)). Values shown with significance at $p \leq .05$ are bolded.

\begin{tabular}{|c|c|c|c|c|c|}
\hline \multirow[t]{2}{*}{ Secondary } & & \multicolumn{4}{|c|}{ Cranio-facial Dimensions } \\
\hline & & $\begin{array}{l}\text { S-Sph } \\
\text { Floor }\end{array}$ & $\begin{array}{c}\text { Sph } \\
\text { Floor- } \\
\text { PNS }\end{array}$ & S-PNS & $\begin{array}{c}\text { Post Facial } \\
\text { Hgt }\end{array}$ \\
\hline \multirow[t]{13}{*}{$\begin{array}{l}\text { Cranio- } \\
\text { facial }\end{array}$} & S-Sph Floor & & & & \\
\hline & Sph Floor-PNS & $-.11(.57)$ & & & \\
\hline & S-PNS & $.69(.00)$ & $.64(.00)$ & & \\
\hline & Post Facial Hgt & $.06(.78)$ & $.45(.02)$ & $.37(.06)$ & \\
\hline & Lat Orb Distance & $.38(.05)$ & $.20(.33)$ & $.43(.02)$ & $.29(.15)$ \\
\hline & Outer Mx Sinus & $.12(.54)$ & $.42(.03)$ & $.40(.04)$ & $.01(.98)$ \\
\hline & Inner Mx Sinus & $.22(.26)$ & $-.11(58)$ & $09(.65)$ & $.08(.69)$ \\
\hline & SNA & $.56(.00)$ & $.12(.56)$ & $.52(.01)$ & $.13(.53)$ \\
\hline & SNB & $.47(.01)$ & $.29(.14)$ & $.57(.00)$ & $.40(.04)$ \\
\hline & ANB & $.24(.22)$ & $-.29(.15)$ & $-.02(.92)$ & $-.46(.02)$ \\
\hline & S-PNS-Gn & $-.17(.39)$ & $-.36(.06)$ & $-.40(.04)$ & $-.30(.13)$ \\
\hline & XY Axis Angle & $.42(.03)$ & $.08(.71)$ & $-.27(.17)$ & $-.19(.34)$ \\
\hline & $\begin{array}{l}\text { Sph Sin Long } \\
\text { Axis-Gn }\end{array}$ & $.00(1.00)$ & $-.13(.52)$ & $-.10(.64)$ & $-.03(.87)$ \\
\hline
\end{tabular}


Table 15. Bivariate Pearson Correlations Between Craniomaxillofacial Dimensions

( $R$ ( $p$ value)). Values shown with significance at $p \leq .05$ are bolded.

\begin{tabular}{|c|c|c|c|c|c|}
\hline Secondary & & \multicolumn{4}{|c|}{ Craniofacial Dimensions } \\
\hline & & $\begin{array}{c}\text { Lat Orb } \\
\text { Distance }\end{array}$ & $\begin{array}{c}\text { Outer Mx } \\
\text { Sinus }\end{array}$ & $\begin{array}{c}\text { Inner Mx } \\
\text { Sinus }\end{array}$ & SNA \\
\hline $\begin{array}{c}\text { Cranio- } \\
\text { facial }\end{array}$ & Lat Orb Distance & & & \\
\hline & Outer Mx Sinus & $\mathbf{. 4 3 ( . 0 3 )}$ & & \\
\hline & Inner Mx Sinus & $.06(.76)$ & $-.54(.00)$ & & \\
\hline & SNA & $.14(.50)$ & $-.06(.77)$ &. $\mathbf{4 5 ( . 0 2 )}$ & \\
\hline & SNB & $.02(.91)$ & $-.10(.62)$ & $.35(.07)$ &. $\mathbf{. 8 1 ( . 0 0 )}$ \\
\hline & ANB & $-.01(.94)$ & $.16(.41)$ & $-.04(.83)$ & $.28(.16)$ \\
\hline & S-PNS-Gn & $.08(.68)$ & $-.26(.19)$ & $.04(.83)$ & $.04(.84)$ \\
\hline & XY Axis Angle & $.26(.19)$ & $.32(.11)$ & $-.27(.18)$ &.$- .44(.02)$ \\
\hline & Sph Sin Long & $.16(.41)$ & $.13(.52)$ & $-.16(.44)$ & $-.21(.28)$ \\
\hline
\end{tabular}


Table 16. Bivariate Pearson Correlations Between Craniomaxillofacial Dimensions ( $R$ ( $p$ value)). Values shown with significance at $p \leq .05$ are bolded.

\begin{tabular}{|c|c|c|c|c|c|}
\hline Secondary & & \multicolumn{4}{|c|}{ Craniofacial Dimensions } \\
\hline & & SNB & ANB & $\begin{array}{c}\text { S-PNS- } \\
\text { Gn }\end{array}$ & $\begin{array}{c}\text { XY Axis } \\
\text { Angle }\end{array}$ \\
\hline $\begin{array}{c}\text { Cranio- } \\
\text { facial }\end{array}$ & SNB & & & \\
\hline & ANB & $-.22(.28)$ & & \\
\hline & S-PNS-Gn & $-.24(.22)$ & $.24(.24)$ & & \\
\hline & XY Axis Angle & $-.64(.00)$ & $-.18(.37)$ & $.20(.31)$ & \\
\hline & $\begin{array}{c}\text { Sph Sin Long } \\
\text { Axis-Gn }\end{array}$ & $-.28(.15)$ & $.04(.86)$ & $.10(.61)$ & $.36(.06)$ \\
\hline
\end{tabular}

Multiple Regressions were applied and the results are listed in Tables 17 to 27.

Table 17 Sphenoid Sinus Width Multiple Regression with Predictor Variables Lat Orb Distance, Outer Mx Sinus and Inner Mx Sinus. Values shown with significance at $\mathrm{p} \leq .05$ are bolded.

\begin{tabular}{lccc}
\hline \multicolumn{4}{c}{$\begin{array}{c}\text { Dependant Variable }=\text { Sph Sin Width } \\
\text { R Square }=\mathbf{. 3 5 2}, \mathbf{F}=\mathbf{4 . 1 5 6 , \boldsymbol { P } = . 0 1 7}\end{array}$} \\
\hline Predictor Variable & $\begin{array}{c}\text { Standardized } \\
\text { Coefficient Beta }\end{array}$ & $\mathbf{T}$ & $\boldsymbol{P}$ \\
Lat Orb Distance & .336 & 1.673 & .108 \\
Outer Mx Sinus & .400 & 1.678 & .107 \\
Inner Mx Sinus & .232 & 1.076 & .293 \\
\hline
\end{tabular}


Table 18. Sphenoid Sinus Hgt Multiple Regression with Predictor Variables S-PNS and Post Facial Hgt. Values shown with significance at $p \leq .05$ are bolded.

\begin{tabular}{cccc}
\hline \multicolumn{4}{c}{ Dependant Variable $=$ Sph Sin Hgt } \\
R Square $=. \mathbf{1 6 4}, \mathbf{F}=\mathbf{2 . 3 5 8 ,} \boldsymbol{P = \mathbf { . 1 1 6 }}$ \\
\hline Predictor Variable & $\begin{array}{c}\text { Standardized } \\
\text { Coefficient Beta }\end{array}$ & $\mathrm{T}$ & $\boldsymbol{p}$ \\
S-PNS & .370 & 1.839 & .078 \\
Post Facial Hgt & .078 & .387 & .702 \\
\hline
\end{tabular}

Table 19. Sphenoid Sinus Vol Multiple Regression with Predictor Variables Sph Sin Hgt, Sph Sin Width and S-PNS. Values shown with significance at $p \leq .05$ are bolded.

\begin{tabular}{cccc}
\hline \multicolumn{4}{c}{ Dependant Variable $=$ Sph Sinus Vol } \\
R Square $=\mathbf{. 8 2 0}, \mathbf{F}=\mathbf{4 0 . 4 7 8 , p = . 0 0 0}$ \\
\hline Predictor Variable & $\begin{array}{c}\text { Standardized } \\
\text { Coefficient Beta }\end{array}$ & T & $\boldsymbol{P}$ \\
Sph Sin Hgt & .435 & 4.202 & $\mathbf{. 0 0 0}$ \\
Sph Sin Width & .511 & 4.910 & $\mathbf{. 0 0 0}$ \\
S-PNS & .152 & 1.623 & .118 \\
\hline
\end{tabular}

Table 20. Sphenoid Sinus Vol Multiple Regression with Predictor Variables Sph Sin Hgt and Sph Sin Width. Values shown with significance at $\mathrm{p} \leq .05$ are bolded.

\begin{tabular}{cccc}
\hline \multicolumn{4}{c}{ Dependant Variable $=$ Sph Sinus Vol } \\
R Square $=\mathbf{8 2 3}, \mathbf{F}=\mathbf{5 5 . 6 0 9 ,} \boldsymbol{p}=\mathbf{. 0 0 0}$ \\
\hline Predictor Variable & $\begin{array}{c}\text { Standardized } \\
\text { Coefficient Beta }\end{array}$ & $\mathbf{T}$ & $\boldsymbol{P}$ \\
Sph Sin Hgt & .472 & 4.527 & $\mathbf{. 0 0 0}$ \\
Sph Sin Width & .552 & 5.294 & $\mathbf{. 0 0 0}$ \\
\hline
\end{tabular}


Table 21. Sphenoid Sinus Vol Multiple Regression with Predictor Variables Lat Orb Distance, Outer Mx Sinus and Inner Mx Sinus. Values shown with significance at $p \leq .05$ are bolded.

\begin{tabular}{lccc}
\hline \multicolumn{4}{c}{ Dependant Variable $=$ Sph Sinus Vol } \\
R Square $=. \mathbf{2 8 3}, \mathbf{F}=\mathbf{3 . 0 2 8 ,} \boldsymbol{p}=\mathbf{. 0 5 0}$ \\
\hline Predictor Variable & $\begin{array}{c}\text { Standardized } \\
\text { Coefficient Beta }\end{array}$ & $\mathbf{T}$ & $\boldsymbol{p}$ \\
Lat Orb Distance & .199 & .941 & .357 \\
Outer Mx Sinus & .470 & 1.874 & .074 \\
Inner Mx Sinus & .206 & .908 & .374 \\
\hline
\end{tabular}

Table 22. Mx Sin Width* Multiple Regression with Predictor Variables Lat Orb Distance, Outer Mx Sinus and Inner Mx Sinus. Values shown with significance at $\mathrm{p} \leq .05$ are bolded.

\begin{tabular}{cccc}
\hline \multicolumn{4}{c}{ Dependant Variable $=$ Mx Sin Width* } \\
R Square $=\mathbf{. 9 5 6 , F}=\mathbf{1 6 6 . 4 3 8 ,} \boldsymbol{p}=\mathbf{. 0 0 0}$ \\
\hline Predictor Variable & $\begin{array}{c}\text { Standardized } \\
\text { Coefficient Beta }\end{array}$ & $\mathbf{t}$ & $\boldsymbol{p}$ \\
Lat Orb Distance & .045 & .850 & .404 \\
Outer Mx Sinus & .699 & 11.254 & $\mathbf{. 0 0 0}$ \\
Inner Mx Sinus & -.387 & -6.872 & $\mathbf{. 0 0 0}$ \\
\hline
\end{tabular}

* Average of measurements from left and right 
Table 23. Mx Sin Vol* Multiple Regression with Predictor Variables Lat Orb Distance, Outer Mx Sinus and Inner Mx Sinus. Values shown with significance at $p \leq .05$ are bolded.

\begin{tabular}{cccc}
\hline \multicolumn{4}{c}{$\begin{array}{c}\text { Dependant Variable }=\mathbf{M x} \text { Sin Vol* } \\
\text { R Square }=\mathbf{. 6 3 4}, \mathbf{F}=\mathbf{1 3 . 2 5 7}, \boldsymbol{p}=\mathbf{. 0 0 0}\end{array}$} \\
\hline Predictor Variable & $\begin{array}{c}\text { Standardized } \\
\text { Coefficient Beta }\end{array}$ & $\mathbf{t}$ & $\boldsymbol{P}$ \\
Lat Orb Distance & .150 & .995 & .330 \\
Outer Mx Sinus & .513 & 2.864 & $\mathbf{. 0 0 9}$ \\
Inner Mx Sinus & -.327 & -2.014 & .056 \\
\hline
\end{tabular}

* Average of measurements from left and right

Table 24. Mx Sin Vol* Multiple Regression with Predictor Variables Mx Sin PA Length*, Mx Sin $\mathrm{Hgt}^{*}$, Mx Sin Width* and Inner Mx Sinus. Values shown with significance at $\mathrm{p} \leq .05$ are bolded.

\begin{tabular}{|c|c|c|c|}
\hline \multicolumn{4}{|c|}{$\begin{array}{l}\text { Dependant Variable }=\text { Mx Sin Vol* } \\
\text { R Square }=.885, F=42.316, p=.000\end{array}$} \\
\hline Predictor Variable & $\begin{array}{l}\text { Standardized } \\
\text { Coefficient Beta }\end{array}$ & $\mathbf{t}$ & $\boldsymbol{P}$ \\
\hline Mx Sin PA Length* & .386 & 3.942 & .001 \\
\hline Mx Sin Hgt* & .501 & 5.221 & .000 \\
\hline Mx Sin Width* & .278 & 2.228 & .036 \\
\hline Inner Mx Sin & .090 & .797 & .434 \\
\hline
\end{tabular}

* Average of measurements from left and right 
Table 25. Mx Sin Vol* Multiple Regression with Predictor Variables Mx Sin PA Length*, Mx Sin Hgt* and Mx Sin Width*. Values shown with significance at $\mathrm{p} \leq .05$ are bolded.

\begin{tabular}{cccc}
\hline \multicolumn{4}{c}{ Dependant Variable $=$ Mx Sin Vol* } \\
R Square $=\mathbf{. 8 8 2}, \mathbf{F}=\mathbf{5 7 . 1 1 5}, \boldsymbol{p}=\mathbf{. 0 0 0}$ \\
\hline Predictor Variable & $\begin{array}{c}\text { Standardized } \\
\text { Coefficient Beta }\end{array}$ & $\mathbf{T}$ & $\boldsymbol{P}$ \\
Mx Sin PA Length* & .378 & 3.911 & $\mathbf{. 0 0 1}$ \\
Mx Sin Hgt* & .494 & 5.213 & $\mathbf{. 0 0 0}$ \\
Mx Sin Width* & .219 & 2.201 & $\mathbf{. 0 3 8}$ \\
\hline
\end{tabular}

* Average of measurements from left and right

Table 26. N-ANS Multiple Regression with Predictor Variables Mx Sin Vol*, Mx Sin Width*, Mx Sin Hgt* and Mx Sin PA Length*. Values shown with significance at $\mathrm{p} \leq .05$ are bolded.

\begin{tabular}{cccc}
\hline \multicolumn{4}{c}{ Dependant Variable $=\mathbf{N}-$ ANS } \\
R Square $=\mathbf{. 4 9 7}, \mathbf{F}=\mathbf{5 . 4 2 7 , \boldsymbol { p } = \mathbf { . 0 0 3 }}$ \\
\hline Predictor Variable & $\begin{array}{c}\text { Standardized } \\
\text { Coefficient Beta }\end{array}$ & $\mathbf{T}$ & $\boldsymbol{P}$ \\
Mx Sin Vol* & -.240 & -.546 & .591 \\
Mx Sin Width* & -.228 & -.987 & .334 \\
Mx Sin Hgt* & .307 & 1.041 & .309 \\
Mx Sin PA Length* & .824 & 3.133 & $\mathbf{. 0 0 5}$ \\
\hline
\end{tabular}

* Average of measurements from left and right 
Table 27. N-ANS Multiple Regression with Predictor Variable Mx Sin PA Length*. Values shown with significance at $\mathrm{p} \leq .05$ are bolded.

\begin{tabular}{cccc}
\hline \multicolumn{4}{c}{ Dependant Variable $=$ N-ANS } \\
R Square $=. \mathbf{4 2 2}, \mathbf{F}=\mathbf{1 9 . 9 6 1 , p = . 0 0 0}$ & \\
\hline $\begin{array}{c}\text { Standardized } \\
\text { Coefficient Beta }\end{array}$ & $\mathbf{T}$ & $\boldsymbol{P}$ \\
Predictor Variable & .666 & 4.468 & $\mathbf{. 0 0 0}$ \\
\hline Mx Sin PA Length* & Average of measurements from left and right &
\end{tabular}

\section{Intra-Observer Reliability}

The intra-observer variability of repeated measurements was assessed with a paired 2-taled $t$-test. A $p$ value $\leq 0.05$ indicates that there was a statistically significant difference between initial and remeasured values. Results are shown in Table 28 .

Table 28. T-Test Results of Remeasured Values. Values shown with significance at $\mathbf{p} \leq$ .05 are bolded.

\begin{tabular}{cccc}
\hline \multirow{2}{*}{ Parameter } & $\begin{array}{c}\text { Mean(SD) } \\
\text { Original Measure }\end{array}$ & $\begin{array}{c}\text { Mean(SD) } \\
\text { Repeat Measure }\end{array}$ & $\boldsymbol{p}$ \\
\hline ANS-IP & $28.06( \pm 3.01)$ & $28.09( \pm 2.89)$ & .751 \\
SNB & $80.13( \pm 3.90)$ & $79.52( \pm 3.96)$ & .139 \\
\multirow{2}{*}{ Sph Sin Vol } & 10140.71 & 10367.30 & .444 \\
& $( \pm 4210.56)$ & $( \pm 4522.51)$ & \\
\hline
\end{tabular}

Intra-observer reliability was also assessed with the Intraclass Correlation Coefficient. A $p$ value $\leq 0.05$ indicates that there was no statistically significant difference between initial and remeasured values. Results are shown in Table 29. 
Table 29. Intraclass Correlation Coefficient. Values shown with significance at $p \leq .05$ are bolded.

\begin{tabular}{cccc}
\hline Parameter & ICC & F & $\boldsymbol{p}$ \\
\hline ANS-IP & .997 & 376.327 & $\mathbf{. 0 0 0}$ \\
SNB & .979 & 48.565 & $\mathbf{. 0 0 0}$ \\
Sph Sin Vol & .991 & 106.017 & $\mathbf{. 0 0 0}$ \\
\hline
\end{tabular}




\section{CHAPTER V}

\section{DISCUSSION}

\section{HYPOTHESIS I}

ANOVA revealed that there were statistically significant differences between each of the three development/age groups for the summarized measurements (Table 9). These findings support that there is a significant increase in lower anterior facial height in an anterior and inferior direction with increase in development/age (Enlow and Hans, 1996). Part of this is contributed by the continued growth of the spheno-occipital synchondrosis leading to an anteriorly and inferiorly positioned mandible (Coben, 1998).

N-Gn, and Gn-IP were significantly different between groupings while there was no difference in N-IP or N-ANS. These findings concur with those of Nasjleti and Kowalski (1975) who showed a change in the proportion of upper facial height to the total facial height between age groups in the developing child.

Contrary to Enlow and Hans (1996), measurements of upper facial height and the Sph Sin Hgt were not significantly different between groups. This may be the result of vertical growth of the nasomaxillary complex occurring prior to that of the mandible before the age of the current study's youngest subjects. Another possibility is that vertical growth of the mandible occurs in growth spurts and is easier to detect differences in measurements than the steadier growth of the developing maxilla. 
The lack of difference in maxillary and sphenoid sinus dimensions, except Sph Sin PA Length, between the three groups was expected as this study's youngest subject group was 8-15 years old. This appears to be the age after which the largest growth spurts of sphenoid and maxillary sinus have occurred (Park, et al., 2010).

The current study found slightly smaller maxillary sinus dimensions compared to other studies; maxillary sinus PA length $36.5 \mathrm{~mm}$ compared to $39.6 \mathrm{~mm}$ (Spaeth, et al., 1997) and $40 \mathrm{~mm}$ (Barghouth, et al., 2002); maxillary sinus width $24.8 \mathrm{~mm}$ compared to $30.8 \mathrm{~mm}$ (Spaeth, et al., 1997) and $30 \mathrm{~mm}$ (Barghouth, et al., 2002); maxillary sinus height $31.0 \mathrm{~mm}$ compared to $38 \mathrm{~mm}$ (Barghouth, et al., 2002) and maxillary sinus volume $14.09 \mathrm{~cm}^{3}$ compared to $14.83 \mathrm{~cm}^{3}$ (Park, et al., 2010). These smaller values may be attributed to the current study not measuring through septa and different representative values obtained with the technology used (El and Palomo, 2010).

The present study found larger sphenoid sinus dimensions compared to previous report; sphenoid sinus width $32.9 \mathrm{~mm}$ compared to $30.1 \mathrm{~mm}$ (Spaeth, et al., 1997); and sphenoid sinus volume $10.12 \mathrm{~cm}^{3}$ compared to $6.94 \mathrm{~cm}^{3}$ (Park, et al., 2010). These larger values may be attributed to different measurement technique and technology (El and Palomo, 2010).

It is unclear why there was a statistically significant difference in Sph Sin PA Length between the three sample groups. The Sph Sin PA Length found in group 2, made up of subjects $14-17$ years old, and was $29.3 \mathrm{~mm}$. This was only slightly larger than findings from Spaeth et al., (1997) whose subjects were 12-18 years old and had a sphenoid sinus PA length ranging from $23.7-28.0 \mathrm{~mm}$. 
Rothstein and Yoon-Tarlie (2000) postulated that, "“excessively developed” sinuses may contribute to a more protrusively positioned maxilla." Our results do not support this hypothesis as no correlation was found between SNA and any maxillary or sphenoid sinus dimensions.

\section{HYPOTHESIS II}

Bivariate Pearson correlations showed that there were significant relationships between external topographic measurements and internal measurements. Correlations were found between the Lat Orb Distance and the: Outer Mx Sin Width, S-PNS, ANSUIT, Sph Sin Width and the Sph Sin Vol. Correlations were also found between the NANS and the: S-PNS, Mx Sin Hgt, Mx Sin PA Length and the Mx Sin Vol.

\section{HYPOTHESIS III}

Bivariate correlations and multiple regression analysis showed that there were significant relationships between linear and volumetric dimensions of the sphenoid sinus, maxillary sinuses and other selected craniomaxillofacial dimensions.

Multiple regression analysis showed the predictor variables Sph Sin Hgt and Sph Sin Width to be significant in determining the value of the Sph Sin Vol. Similarly, multiple regression analysis showed the predictor variables Mx Sin Hgt, Mx Sin Width and Mx Sin PA Length to be significant in determining the value of the Mx Sin Vol. The

Standardized Coefficient Betas with corresponding $\mathrm{T}$ values from these analyses are listed 
in Tables 20 and 25 for three dimensional calculations when airway volume segmentation software is not available.

It has been suggested that the maxillary sinuses grow in a lateral and inferior direction (Leclerc and Leclerc, 2009). The current study found:

- a negative correlation between the Outer Mx Sin Width and the Inner Mx Sin Width

- positive correlations between the Mx Sin Vol to Mx Sin PA Length, Mx Sin Width, Mx Sin Hgt and the Inner Mx Sin Width

- positive correlations between the Sph Sin Vol to Sph Sin Width and Sph Sin Hgt

Therefore, the results presented in this study find that the maxillary sinuses do not expand solely in a lateral and inferior direction. The findings in Tables 11 and 12 support that the sinuses grow in a more "balloon" style of expansion

When comparing the same dimension of the sphenoid sinus with that of the maxillary sinus, a positive correlation was found between the Mx Sin Hgt and the Sph Sin Hgt, as well as between the Mx Sin Vol and the Sph Sin Vol, but not between the Mx Sin Width and the Sph Sin Width. Correlations were also found in different dimensions of the maxillary sinus with relation to the sphenoid sinus; the Mx Sin Width was correlated to the Sph Sin Vol and the Mx Sin Hgt was correlated to the Sph Sin Vol. The findings in this study support those of Emirzeoglu et al., (2007), that the dimensions of paranasal sinuses are closely related to each other. 
A review of correlations found in this study has highlighted the importance of the correlation between S-PNS to several other structures. These include the:

- Sph Sin Vol

- Sph Sin Width

- Sph Sin Hgt

- $\mathrm{Mx}$ Sin Vol

- Outer Mx Sin Width

- Lat Orb Distance

- N-ANS

- N-UIT

- SNA

- SNB

- S-PNS-Gn (negative correlation)

Assumptions must not be prematurely made between oxygen flow through the posterior nasopharyngeal airway and form as the cause for these structural correlations (Harari, et al., 2010), as the same correlations between the Sph Floor-PNS do not replicate similar findings as would be expected. The cause for these multiple structural associations with S-PNS is presently unknown.

A review of correlations also found correlations between the N-ANS to Mx Sin Hgt, Mx Sin PA Length and Mx Sin Vol. No correlations were found between the N-ANS and any of the sphenoid dimensions. In conclusion, where S-PNS has several structural 
correlations with sphenoid sinus dimensions, N-ANS has several structural correlations with maxillary sinus dimensions.

\section{HYPOTHESIS IV}

There were statistically significant correlations found between vertical, anteroposterior and transverse craniomaxillofacial dimensions. A positive bivariate correlation was found between Sph Sin Width and: S-PNS, and the Lat Orb Distance. Another positive correlation was found between the Mx Sin PA Length and the N-ANS. The Outer Mx Sin Width was positively correlated to S-PNS. The SNA was also found to have a positive bivariate correlation with: S-PNS, and the Inner Mx Sin Width. These findings support that dimensions of particular craniomaxillofacial structures do not enlarge independently in a linear fashion along one plane. Hence, craniomaxillofacial growth assessments must not ignore the changes occurring simultaneously in all three dimensions.

\section{HYPOTHESES V AND VI}

There was no statistically significant difference between repeated and initial measurements for the sample of representative volumetric and linear dimensions for subjects in three developmental groups based on age and fusion of the spheno-occipital synchondrosis. Further, there was high intra-observer reliability of repeat measurements. While the volumetric results presented in this study are highly repeatable this does not imply that their values are highly representative of their respective structures' true 
volumes. Different software can result in drastically different values for the same airway volume measured (El and Palomo, 2010).

\section{LIMITATIONS AND FUTURE STUDIES}

One limitation of this study is that after the exclusion criteria were applied, only a small sample size $(\mathrm{n}=27)$ remained. As a result, measurements were obtained, and where no significant differences were found between groups, results from the three groups were combined into one large sample group and further statistical assessments were conducted. This was done in place of assessing each of the three desired development/age groups independently. Despite this small sample size, there were enough results with statistical significance to draw conclusions. Future studies should obtain larger sample sizes and assess mean volumes and correlations specific to developmental stages of growth.

This study excluded a lot of datasets based on not having teeth in occlusion and having the complete mandible included in the image. This was done to include specific craniomaxillofacial skeletal measurements of the mandible. Many of these measurements were eliminated from the combined group ( $\mathrm{n}=27$ ) because of differences found with ANOVA between the three smaller sample groups based on development/age. Using this same database, a future study could obtain a larger sample size by not examining specific craniomaxillofacial measurements of the mandible and including patients regardless of having teeth in occlusion, posterior contacts or the mandible in the image.

Another shortcoming of this retrospective study is that a complete medical history of subjects was not able to be obtained. Resultantly, this study relied on the accuracy of the radiologic reports and findings in images as the standard with which subjects were excluded. For example, without being able to ask subjects if they had a history of wearing 
braces, it became necessary to rely on seeing brackets in the acquired dataset or a mention in the radiologic report of a history of having worn braces as the basis for exclusion. Future studies should be designed in a prospective fashion requesting specific medical histories.

Further, without subject histories it was not possible to know the ethnicity and sex of subjects which has been suggested to have a statistically significant difference on measurements (Shea, 1977; Spaeth, et al., 1997). Hence, this study attempted to compensate for sex by using development as opposed to chronologic age to separate the growing subjects in groups 1 and 2 . The sample size in this study was too small to assess statistically significant differences in males and females in the present study sample. Other studies have shown no difference in sinus volumes between males and females (Barghouth, et al., 2002). Future studies should obtain larger sample sizes and obtain a history of sex and ethnicity.

Due mostly, to the retrospective nature of the current study and available scans, it was not possible to determine changes in dimensions that resulted in individuals over time. Three subjects had remained after exclusion criteria were applied who had datasets available from two different time points. However, the results from comparing these three subjects would not have much statistical value. In place, the current study compared development/age by relying upon a cross section of subjects at three development/age points for a "snapshot" of what could be expected. Future studies would ideally be prospective and obtain datasets at two time points for the same subject. This would provide more information for changes in dimensional relationships between the sphenoid 
sinus, maxillary sinuses and other selected craniomaxillofacial structures with growth over time.

This study is limited by the resolution of subject images, motion artefacts and accuracy of the computer software to be able to discern and measure structures accordingly. Occasionally, the image requirements of the computer used for utilising the $3 \mathrm{D}$ software were more than the computer could manage and the computer would "crash." This resulted in the need for the dataset to be reloaded and reoriented. Despite several attempts while reloading and reorienting, the image could not always be reoriented to parallel initial measurements exactly. Remeasurements taken to test intraobserver reliability required reloading, reorientation and remeasurements and no significant difference was able to be detected between initial and repeat measurements (Tables 28 and 29). Hence, the inconsistency of being unable to reorient the images exactly was not considered a statistically significant source of error. In the future, perhaps software companies will be able to create programs which will allow for the exact reorientation of images to initial orientations.

Volumetric measurements required the placing of seeds and the observer to define the threshold of opacity of the voxels in the airway to count towards the volume measured. These two techniques, (seed placing and voxel opacity threshold selection), are observer dependant. Results from repeat measurements showed a high ability of the observer to use the same technique (Tables 28 and 29). Future studies should use multiple observers for recording such volumes and compare inter-observer reliability of measuring these volumes based on these observer specific techniques. 


\section{CHAPTER VI}

\section{CONCLUSION}

In this study we analyzed the dimensions of the sphenoid sinus, maxillary sinuses and other selected craniomaxillofacial structures between groups of subjects divided into three developmental groups based on age and fusion of the spheno-occipital synchondrosis. Retrospective datasets of 27 patients existed after exclusion criteria were applied.

ANOVA revealed differences between groups for the following measurements:

- ANS-LIT

- Gn-UIT

- Gn-LIT

- Gn-IP

- N-Gn

- PNS-Gn

- Sph Floor-Gn

- S-Gn

- Sph Sin PA Length

- SN-GoGn

Measurements without differences between groups were grouped together. 
The results of this study suggest that correlations exist between topographic and internal measurements. These include correlations between:

- Lat Orb Distance and: Outer Mx Sin Width, S-PNS, ANS-UIT, Sph Sin Width and Sph Sin Vol

- N-ANS and: S-PNS, Mx Sin Hgt, Mx Sin PA Length, Mx Sin Vol

The results of this study suggest that correlations exist between volumetric and linear dimensions of the sphenoid and maxillary sinuses and other selected craniomaxillofacial dimensions. Multiple regressions showed associations when the following Predictor Variables were used to predict the Dependant Variable (Predictor Variable: Dependant Variable):

- Sph Sin Hgt and Sph Sin Width : Sph Sin Vol

- Mx Sin Hgt, Mx Sin Width and Mx Sin PA Length : Mx Sin Vol

Significant bivariate correlations were found that include, but are not limited to, existing between:

- Outer Mx Sin Width and Inner Mx Sin Width (negative correlation)

- Mx Sin Vol to Mx Sin PA Length, Mx Sin Width, Mx Sin Hgt and Inner Mx Sin Width

- Sph Sin Vol to Sph Sin Width and Sph Sin Hgt

- Mx Sin Hgt and Sph Sin Hgt

- Mx Sin Vol and Sph Sin Vol

- Mx Sin Width and Sph Sin Vol

- Mx Sin Hgt and Sph Sin Vol 
- $\quad$ S-PNS to Sph Sin Vol, Sph Sin Width, Sph Sin Hgt, Mx Sin Vol and, Outer Mx Sin Width, Lat Orb Distance, N-ANS, N-UIT, SNA, SNB and S-PNS-Gn (negative correlation)

- N-ANS to Mx Sin Hgt, Mx Sin PA Length and Mx Sin Vol

Significant bivariate correlations were expected, but not found, between the following selected dimensions:

- Mx Sin Width and Sph Sin Width

- N-ANS and any of the sphenoid dimensions

The results of this study suggest that correlations exist between vertical, anteroposterior and transverse dimensions. These include:

- Sph Sin Width and S-PNS and Lat Orb Distance

- Mx Sin PA Length and N-ANS.

- $\quad$ Outer Mx Sin Width and S-PNS

- SNA and S-PNS and Inner Mx Sin Width

The results of this study are presented to provide the basis for an objective normal relationship of sphenoid and maxillary sinuses and other selected craniomaxillofacial structures and for studies involving craniofacial form, anomalies and diseases of the sinuses. 


\section{REFERENCES}

Akhlaghi M, Valizadeh B, Gharedaghi J. Closure time of spheno-occipital suture in the male cadavers referred to legal medicine organization. Acta Medica Iranica. 2008;46(2):105-108.

American Association of Orthodontists. House of delegates acts on resolutions.

"www.aaomembers.org/Resources/Publications/ebulletin-05-06-10.cfm". Accessed Nov 16, 2010.

Barghouth G, Prior JO, Lepori D, Duvoisin B, Schnyder P, Gudinchet F. Paranasal sinuses in children: size evaluation of maxillary, sphenoid, and frontal sinuses by magnetic resonance imaging and proposal of volume index percentile curves. Eur Radiol. 2002 Jun;12(6):1451-1458.

Basdra EK, Stellzig A, Komposch G. The importance of the maxillary sinuses in facial development: a case report. Eur J Orthod. 1998 Feb;20(1):1-4.

Brichard M, Ketelbant R, Thilloy G, Riggs E, Laude M. [Correlation between pneumatic cavities and facial growth. II. Development of the frontal, sphenoid and maxillary sinuses during orthodontic care] Bull Group Int Rech Sci Stomatol.Odontol. 1979 Apr;22(2):35-42. 
Chenin DL, Chenin DA, Chenin ST, Choi J. Dynamic cone-beam computed tomography in orthodontic treatment. J Clin Orthod. 2009 Aug;43(8):507-512.

Coben SE. The spheno-occipital synchondrosis: the missing link between the profession's concept of craniofacial growth and orthodontic treatment. Am J Orthod Dentofacial Orthop. 1998 Dec;114(6):709-12.

El H, Palomo JM. Measuring the airway in 3 dimensions: a reliability and accuracy study. Am J Orthod Dentofacial Orthop. 2010 Apr;137(4 Suppl):S50.e1-9.

Elwany S, Yacout YM, Talaat M, El-Nahass M, Gunied A, Talaat M. Surgical anatomy of the sphenoid sinus. J Laryngol Otol. 1983 Mar;97(3):227-241.

Emirzeoglu M, Sahin B, Bilgic S, Celebi M, Uzun A. Volumetric evaluation of the paranasal sinuses in normal subjects using computer tomography images: a stereological study. Auris Nasus Larynx. 2007 Jun;34(2):191-195.

Enlow DH, Hans MG. Essentials of Facial Growth, $\left(1^{\text {st }}\right.$ ed. $)$ Philadelphia, PA 1996 W.B. Saunders Co.

Farman AG. Personal communication from the President of the American Academy of Oral and Maxillofacial Radiology. 2010 Nov.

Farman AG, Scarfe WC. Development of imaging selection criteria and procedures should precede cephalometric assessment with cone-beam computed tomography. Am J Orthod Dentofacial Orthop. 2006 Aug;130(2):257-265. 
Fudalej P, Kokich VG, Leroux B. Determining the cessation of vertical growth of the craniofacial structures to facilitate placement of single-tooth implants. Am J Orthod Dentofacial Orthop. 2007 Apr;131(4 Suppl):S59-S67.

Harari D, Redlich M, Miri S, Hamud T, Gross M. The effect of mouth breathing versus nasal breathing on dentofacial and craniofacial development in orthodontic patients. Laryngoscope. 2010 Oct;120(10):2089-2093.

Haskell JA, McCrillis J, Haskell BS, Scheetz JP, Scarfe WC, Farman AG. Effects of Mandibular Advancement Device (MAD) on Airway Dimensions Assessed With Cone-Beam Computed Tomography. Semin Orthod. 2009 Jun;15(2):132-158.

Hechler SL. Cone-beam CT: applications in orthodontics. Dent Clin North Am. 2008 Oct;52(4):809-823.

Hahn GW. Retention: the step-child of Orthodontia. Angle Orthod. 1944 Jan;14(1):3-12.

Hounsfield GN. Nobel lecture, 8 December 1979. Computed medical imaging. J Radiol. 1980 Jun-Jul;6l(6-7):459-468.

Kim HJ, Friedman EM, Sulek M, Duncan NO, McCluggage C. Paranasal sinus development in chronic sinusitis, cystic fibrosis, and normal comparison population: a computerized tomography correlation study. Am J Rhinol. 1997 Jul-Aug;11(4):275-281.

Kosko JR, Hall BE, Tunkel DE. Acquired maxillary sinus hypoplasia: a consequence of endoscopic sinus surgery? Laryngoscope. 1996 Oct;106(10):1210-1213. 
Leclerc JE, Leclerc JT. Sphenoid sinus development in choanal atresia. Int J Pediatr Otorhinolaryngol. 2009 Dec;73(12):1746-1750.

Mah JK, Huang JC, Choo H. Practical applications of cone-beam computed tomography in orthodontics. J Am Dent Assoc. 2010 Oct;141 Suppl 3:7S-13S.

Mair EA, Bolger WE, Breisch EA. Sinus and facial growth after pediatric endoscopic sinus surgery. Arch Otolaryngol Head Neck Surg. 1995 May;121(5):547552.

McNamara JA. Influence of respiratory pattern on craniofacial growth. Angle Orthod. 1981 Oct;51(4):269-300.

Nasjleti CE, Kowalski CJ. Stability of upper face height-total face height ratio with increasing age. J Dent Res. 1975 Nov-Dec;54(6):1241.

Oktay $\mathrm{H}$. The study of the maxillary sinus areas in different orthodontic malocclusions. Am J Orthod Dentofacial Orthop. 1992 Aug;102(2):143-145.

Park IH, Song JS, Choi H, Kim TH, Hoon S, Lee SH, Lee HM. Volumetric study in the development of paranasal sinuses by CT imaging in Asian: A Pilot study. Int J Pediatr Otorhinolaryngol. 2010 Sep 20. [Epub ahead of print].

Pirelli P, Saponara M, De Rosa C, Fanucci E. Orthodontics and obstructive sleep apnea in children. Med Clin North Am. 2010 May;94(3):517-529.

Rae TC, Hill RA, Hamada Y, Koppe T. Clinal variation of maxillary sinus volume in Japanese macaques (Macaca fuscata). Am J Primatol. 2003 Apr;59(4):153158. 
Rothstein T, Yoon-Tarlie C. Dental and facial skeletal characteristics and growth of males and females with class II, division 1 malocclusion between the ages of 10 and 14 (revisited)-part I: characteristics of size, form, and position. Am J Orthod Dentofacial Orthop. 2000 Mar;117(3):320-332.

Scarfe WC, Farman AG, Sukovic P. Clinical applications of cone-beam computed tomography in dental practice. J Can Dent Assoc. 2006 Feb;72(1):75-80.

Seward FS. Frankfort horizontal plane, facial angle and facial type. Aust Orthod J. 1968 Jun;1(4):106-108.

Shea BT. Eskimo craniofacial morphology, cold stress and the maxillary sinus. Am J Phys Anthropol. 1977 Sep;47(2):289-300.

Spaeth J, Krügelstein U, Schlöndorff G. The paranasal sinuses in CT-imaging: development from birth to age 25. Int J Pediatr Otorhinolaryngol. 1997 Feb 14;39(1):25-40.

Uchida Y, Goto M, Katsuki T, Soejima Y. Measurement of maxillary sinus volume using computerized tomographic images. Int J Oral Maxillofac Implants. 1998 Nov-Dec;13(6):811-818.

Wolf G, Anderhuber W, Kuhn F. Development of the paranasal sinuses in children: implications for paranasal sinus surgery. Ann Otol Rhinol Laryngol. 1993 Sep;102(9):705-711. 
Yonetsu K, Watanabe M, Nakamura T. Age-related expansion and reduction in aeration of the sphenoid sinus: volume assessment by helical CT scanning. AJNR Am J Neuroradiol. 2000 Jan;21(1):179-182. 
APPENDICES

\section{APPENDIX A - Approval of Protocol by Human Studies Committee}

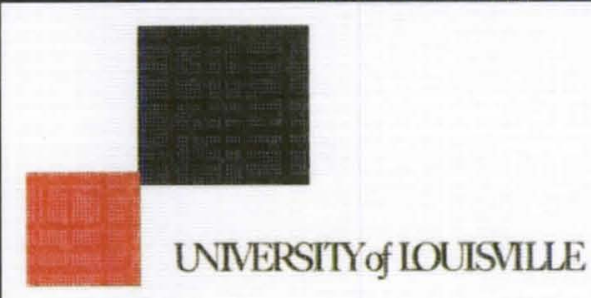

UNIERSITY of IOUISVLLE
INSTITUTIONAL REVIEW BOARDS

University of Louisville

MedCenter One, Suite 200

501 E. Broadway

Louisville, Kentucky 40202-1798

Office: $\quad 502-852-5188$

Fax: $\quad 502-852-2164$

To: Scarfe, William

From: The University of Louisville Institutional Review Board (IRB)

Date: Wednesday, March 17, 2010

Subject: Approval Letter

Tracking \#: 10.0093

Title: $\quad$ THREE DIMENSIONAL ANALYSIS OF THE SPHENOID SINUS AND RELATIONSHIPS TO OTHER CRANIOMAXILLOFACIAL STRUCTURES USING CONE-BEAM COMPUTED TOMOGRAPHY

Approval $\quad 3 / 16 / 201012: 00: 00 \mathrm{AM}$

Date:

Expiration 3/15/2011 12:00:00 AM

Date:

This study was reviewed on $03 / 16 / 2010$ by the chair/vice chair of the Institutional Review Board and approved through the Expedited Review Procedure, according to 45 CFR 46.110(b), since this study falls under Expedited Category (5) Research involving materials (data, documents, records, or specimens) that have been collected, or will be collected solely for non-research purposes (such as medical treatment or diagnosis).

This study was also approved through 45 CFR 46.116 (D), which means that it has been granted a waiver of informed consent because it meets the following criteria:

- The research involves no more than minimal risk to the subjects.

- The waiver or alteration will not adversely affect the rights and welfare of the subjects.

- The research could not practicably be carried out without the waiver or alteration.

- Whenever appropriate, the subjects will be provided with the additional pertinent information after participation.

The following items have been approved:

- Research Protocol, not dated

- Data Collection Form, not dated 
- HIPAA Complete Waiver, not dated

This study now has final IRB approval from 03/16/2010 through 03/15/2011. You should complete and return the Progress Report/Continuation Request Form EIGHT weeks prior to this date in order to ensure that no lapse in approval occurs. The committee will be advised of this action at their next full board meeting.

\section{Site Approval}

If this study will take place at an affiliated research institution, such as Jewish Hospital/St Mary's Hospital, Norton Healthcare, or University of Louisville Hospital, site approval by the affiliated institution must be given before the research may begin.

Privacy \& Encryption Statement

The University of Louisville's Privacy and Encryption Policy requires such information as identifiable medical and health records: credit card, bank account and other personal financial information; social security numbers; proprietary research data; dates of birth (when combined with name, address and/or phone numbers) to be encrypted. For additional information: http://security.louisville.edu/PolStds/ISO/PS018.htm.

1099 Information (If Applicable)

As a reminder, in compliance with University policies and Internal Revenue Service code, all payments (including checks, gift cards, and gift certificates) to research subjects must be reported to the University Controller's Office. Petty Cash payments must also be monitored by the issuing department and reported to the Controller's Office. Before issuing compensation, each research subject must complete a $W-9$ form.

For additional information, please contact the Controller's Office at $852-8237$ or controll@louisville.edu.

The following is a link to an Instruction Sheet for BRAAN2 "How to Locate Stamped/Approved Documents in BRAAN2"

https://louisville.edu/research/braan2/help/Docs.pdf

Please begin using your newly approved (stamped) consent(s) at this time. The previous versions are no longer valid. If you need assistance in accessing any of the study documents, please feel free to contact our office at (502) 852-5188. You may also email our service account at hsppofc@louisville.edu for assistance.

Best wishes for a successful study. If you have any questions please contact the HSPPO at (502) 852-5188 or hsppofc@louisville.edu. 
Thank you.

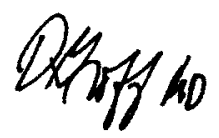

Board Designee: Groff, Diller

Once you begin your human subject research the following regulations apply:

1. Unanticipated problems or serious adverse events encountered in this research study must be reported to the IRB within five (5) work days.

2. Any modifications to the study protocol or informed consent form must be reviewed and approved by the IRB prior to implementation.

3. You may not use a modified informed consent form until it has been approved and validated by the IRB.

4. Please note that the IRB operates in accordance with laws and regulations of the United States and guidance provided by the Office of Human Research Protection (OHRP), the Food and Drug Administration (FDA), the Office of Civil Rights (OCR) and other Federal and State Agencies when applicable.

5. You should complete and SUBMIT the Continuation Request Form eight weeks prior to this date in order to ensure that no lapse in approval occurs.

Letter Sent By: Tabb, Stephanie, 3/17/2010 4:13 PM 


\section{APPENDIX B - Reasons for Exclusions From Initial Database}

Field of View

\begin{tabular}{|c|c|}
\hline Hand and wrist image & 19 \\
Mandible only & 802 \\
Mandible and maxilla only & 7 \\
Landmarks not captured in field of view & 21 \\
Maxilla only & 677 \\
Skull only & 1 \\
\hline
\end{tabular}

Age

\begin{tabular}{|l|l|}
\hline Scan of patients older than 39 years old & 483 \\
\hline
\end{tabular} 


\section{Structural Abnormalities}

\begin{tabular}{|c|c|}
\hline Sleep apnea & 6 \\
Cleft lip and palate & 12 \\
Craniofacial anomalies & 3 \\
Known or suspected hemifacial microsomia & 4 \\
Marked facial asymmetry & 6 \\
Maxillofacial skeletal anomalies - dentocraniofacial anomalies & 2 \\
Plagiocephaly & 1 \\
Skeletal anterior, posterior and vertical craniofacial discrepancies & 12 \\
\hline
\end{tabular}

\section{Associated Syndromes}

\begin{tabular}{|c|c|}
\hline C1-C2 arthrosis syndrome & 1 \\
Cleidocranial dysplasia & 3 \\
Crouzon syndrome & 2 \\
Goldenhar syndrome & 2 \\
Multiple eruption cysts & 1 \\
Oculodentodigital dysplasia signs & 1 \\
Suspected keratocystic odontogenic tumour & 9 \\
Saethre-Chotzen syndrome & 2 \\
Suspected or known ectodermal dysplasia & 3 \\
Treacher-Collins syndrome & 1 \\
Unknown suspected syndrome & 5 \\
\hline
\end{tabular}




\section{Systemic Abnormalities}

\begin{tabular}{|c|c|}
\hline Dentinogenesis imperfecta & 1 \\
Neurofibromatosis & 1 \\
Rheumatoid arthritis & 3 \\
\hline
\end{tabular}

\section{Temporomandibular Joint Abnormalities}

\begin{tabular}{c|c|}
\hline Adaptive remodelling of temporomandibular joint condyle & 2 \\
Mandibular condyle hyperplasia & 6 \\
Left mandibular coronoid process hyperplasia & 1 \\
Marked disc displacement in closed position & 1 \\
Misplaced mandible & 1 \\
Temporomandibular joint ankylosis & 1 \\
Temporomandibular joint changes & 6 \\
Temporomandibular joint disease & 1 \\
Temporomandibular joint osteoarthritis & 15 \\
\hline
\end{tabular}




\section{Fracture/Surgical}

\begin{tabular}{|c|c|}
\hline Anterior implant of maxillary central incisor & $\overline{1}$ \\
\hline Artificial temporomandibular joint & 1 \\
\hline Condylar surgery & 1 \\
\hline Displaced maxillary fracture & 1 \\
\hline Displaced fracture of right infraorbital rim & 1 \\
\hline Facial fracture involving the zygoma & 1 \\
\hline Plate and healing fracture involving the maxilla & 2 \\
\hline Fractured mandibular condylar head & 2 \\
\hline Left resected mandible & 1 \\
\hline Image following fracture & 11 \\
\hline Image following orthognathic surgery & 2 \\
\hline Surgical defect & 2 \\
\hline Surgical follow-up & 22 \\
\hline Trauma and plating & 1 \\
\hline
\end{tabular}




\section{Local/Regional Changes}

\begin{tabular}{|c|c|}
\hline Ameloblastoma & 1 \\
\hline Expanded anterior ascending ramus & 1 \\
\hline Healing defects with recurrent cystic lesions & 1 \\
\hline Monostotic fibrous dysplasia & 1 \\
\hline Benign non-odontogenic lesion where biopsy was suggested & 1 \\
\hline Benign odontogenic tumour & 1 \\
\hline Compound odontoma affecting eruption of anterior mandibular dentition formation & 1 \\
\hline Maxillary pathologic lesion & 1 \\
\hline Odontogenic myxoma & 1 \\
\hline Odontoma & 1 \\
\hline Palatal tumour & 1 \\
\hline Suspected intraosseous hemangioma & 1 \\
\hline Recurrent cystic lesion & 1 \\
\hline Suspected or known neoplasm & 5 \\
\hline Suspected or known recurrent tumour & 2 \\
\hline
\end{tabular}




\section{Sinus}

\begin{tabular}{|c|c|}
\hline Generalised osteomeatal thickening & 1 \\
Hypertrophic maxillary sinus & 1 \\
Mucosal retention phenomenon & 3 \\
Mucosal thickening & 6 \\
Mucous extravasation phenomenon & 1 \\
Opacification of maxillary sinus & 1 \\
Sinusitis & 4 \\
\hline
\end{tabular}

\section{Braces}

\begin{tabular}{|l|r|}
\hline Known history of braces & 1 \\
Currently in braces & 10 \\
\hline
\end{tabular}

\section{Scan Issues}

\begin{tabular}{|c|c|}
\hline Corrupt, errors or missing images & 9 \\
Insufficient information to track patient's image & 3 \\
Motion artefact & 1 \\
\hline
\end{tabular}

\section{Open Occlusion}

\begin{tabular}{|l|l|}
\hline Dentition not in occlusion during scan & 23 \\
\hline
\end{tabular}


Posterior Contact Bilaterally

\begin{tabular}{|c|l|}
\hline Edentulous & 3 \\
Lacking at least one posterior contact on each side & 2 \\
\hline
\end{tabular}




\section{APPENDIX C - Methodology for the Identification of Landmarks for Measurements}

Nasion to Anterior Nasal Spine (Sagittal): In the midsagittal plane, the anteriorposterior crosshair was placed over the Anterior Nasal Spine. The first point was placed on the Nasion and the second point was placed directly inferior along the anteriorposterior crosshair. Under magnification, the superior-inferior crosshair was placed over the first point and the first point was adjusted as necessary. The image was then scrolled to the second point which was moved accordingly if required, to ensure that it was at the intersection of the two crosshairs (Figure 26).

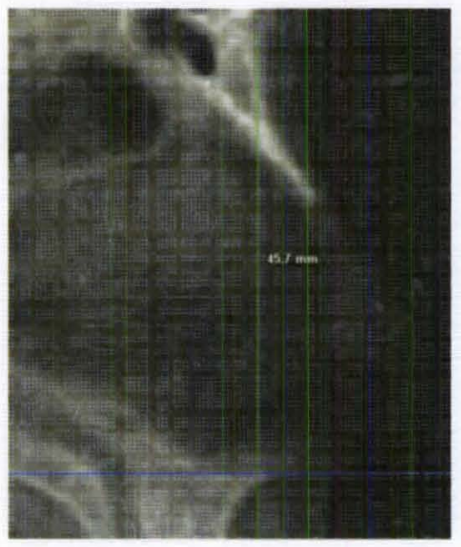

Figure 26. Nasion to Anterior Nasal Spine.

Anterior Nasal Spine to Upper Incisor Tip (Sagittal): In the midsagittal plane, the anterior-posterior crosshair was placed over the Anterior Nasal Spine. The first point was placed on the Upper Incisor Tip and the second point was placed directly superior along the anterior-posterior crosshair. Under magnification, the superior-inferior crosshair 
was placed over the first point and the first point was adjusted as necessary. The image was then scrolled to the second point which was moved accordingly, if required, to ensure that it was at the intersection of the two crosshairs (Figure 27). In case of overlapping central incisors both appearing in this plane, and everywhere else in the midsagittal plane the Upper Incisor Tip was being measured, the most inferior Upper Incisor Tip was used.

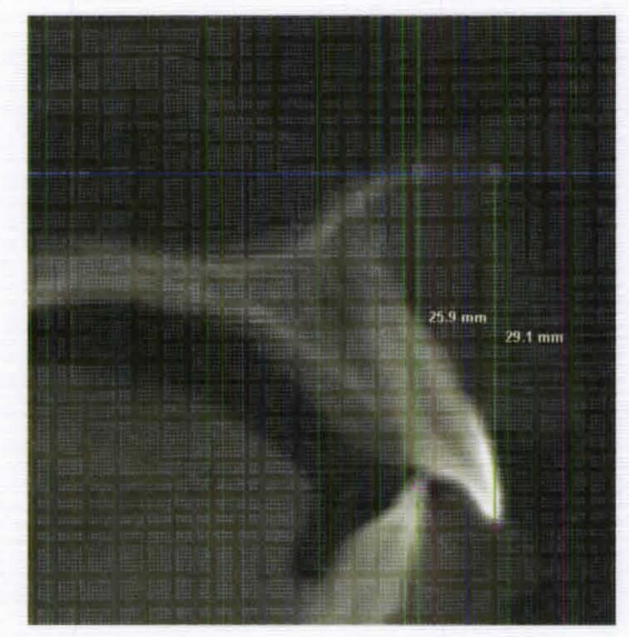

Figure 27. Anterior Nasal Spine to Upper and Lower Incisor Tip.

Anterior Nasal Spine to Lower Incisor Tip (Sagittal): In the midsagittal plane, the anterior-posterior crosshair was placed over the Anterior Nasal Spine. The first point was placed on the Lower Incisor Tip and the second point was placed directly superior along the anterior-posterior crosshair. Under magnification, the superior-inferior crosshair was placed over the first point and the first point was adjusted as necessary. The image was then scrolled to the second point which was moved accordingly, if required, to ensure that it was at the intersection of the two crosshairs (Figure 27). In case of overlapping central incisors both appearing in this plane, and everywhere else in the midsagittal plane 
the Lower Incisor Tip was being measured, the most superior Lower Incisor Tip was used.

Anterior Nasal Spine to Incisal Plane (Sagittal): The excel data spreadsheet was used to average the linear values of the Anterior Nasal Spine to Upper Incisor Tip and the Anterior Nasal Spine to Lower Incisor Tip.

Nasion to Gnathion (Sagittal): In the midsagittal plane, the anterior-posterior crosshair was placed over the Gnathion. The first point was placed over Nasion and the second point was placed directly inferior along the anterior-posterior crosshair. Under magnification, the superior-inferior crosshair was placed over the first point and the first point was adjusted as necessary. The image was then scrolled to the second point which was moved accordingly, if required, to ensure it was at the in intersection of the two crosshairs (Figure 28).

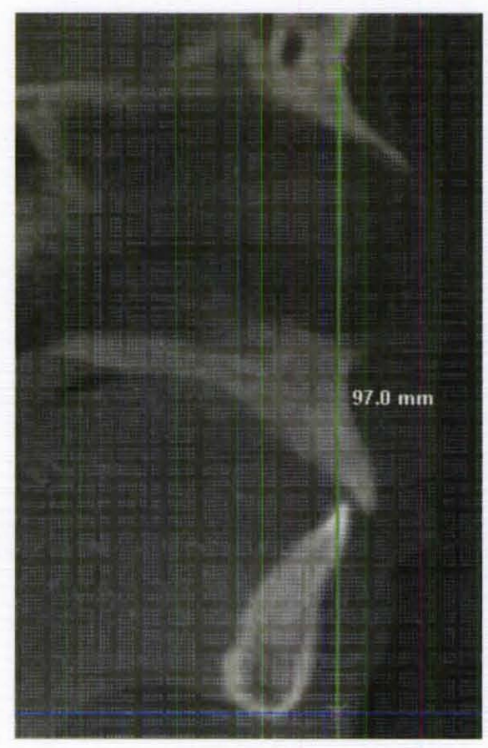

Figure 28. Nasion to Gnathion. 
Gnathion to Upper Incisor Tip (Sagittal): In the midsagittal plane, the anteriorposterior crosshair was placed over the Gnathion. The first point was placed on the Upper Incisor Tip and the second point was placed directly inferior along the anterior-posterior crosshair. Under magnification, the superior-inferior crosshair was placed over the first point and the first point was adjusted as necessary. The image was then scrolled to the second point which was moved accordingly, if required, to ensure that it was at the intersection of the two crosshairs (Figure 29).

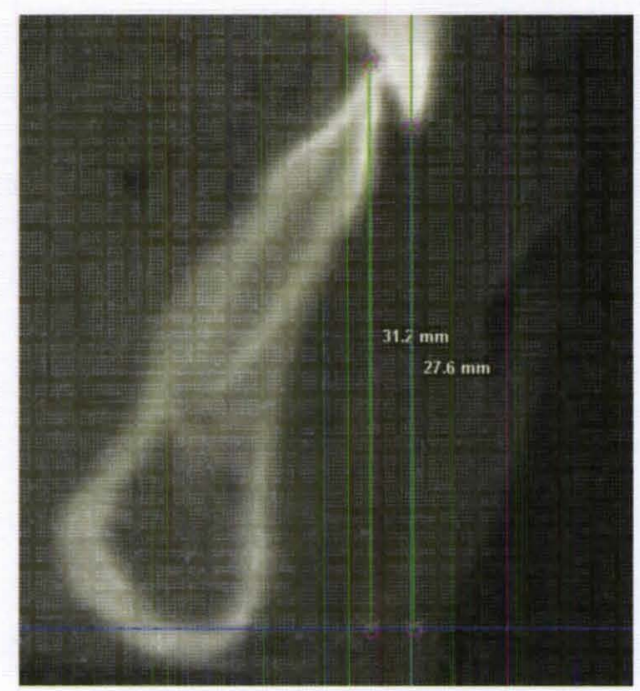

Figure 29. Gnathion to Upper and Lower Incisor Tip.

Gnathion to Lower Incisor Tip (Sagittal): In the midsagittal plane, the anteriorposterior crosshair was placed over the Gnathion. The first point was placed on the Lower Incisor Tip and the second point was placed directly inferior along the anterior-posterior crosshair. Under magnification, the superior-inferior crosshair was placed over the first point and the first point was adjusted as necessary. The image was then scrolled to the 
second point which was moved accordingly, if required, to ensure that it was at the intersection of the two crosshairs (Figure 29).

Gnathion to Incisal Plane (Sagittal): The excel data spreadsheet was used to average the linear values of the Gnathion to Lower Incisor Tip and the Gnathion to Upper Incisor Tip.

Sella Turcica to Nasion to A-Point (Sagittal): In the midsagittal plane points were marked under magnification in the center of the Sella Turcica, then on Nasion and finally at A-point (Figure 30).

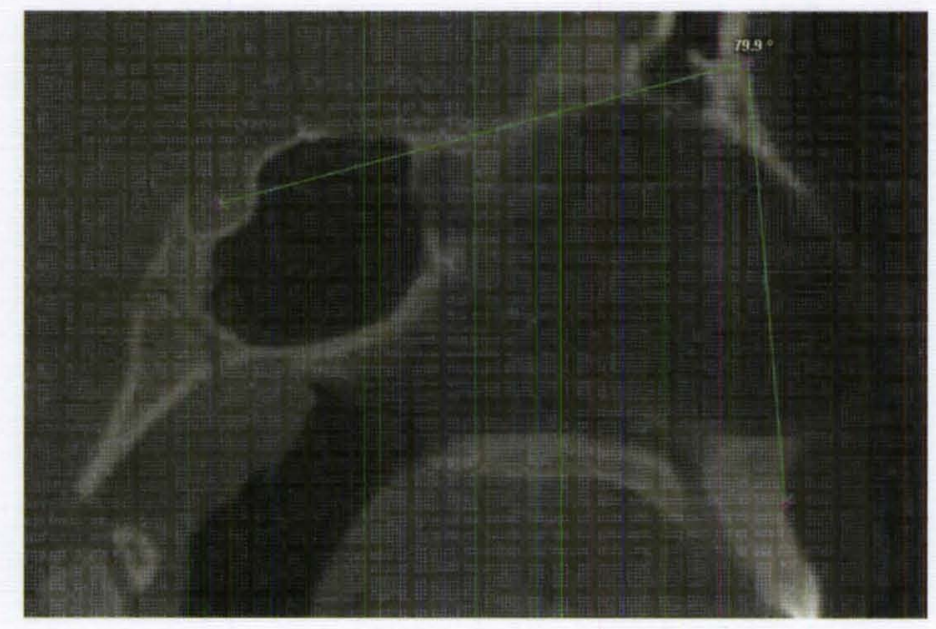

Figure 30. Sella Turcica to Nasion to A-Point.

Sella Turcica to Nasion to B-Point (Sagittal): In the midsagittal plane points were marked under magnification in the center of the Sella Turcica, then Nasion and finally B-point (Figure 31). 


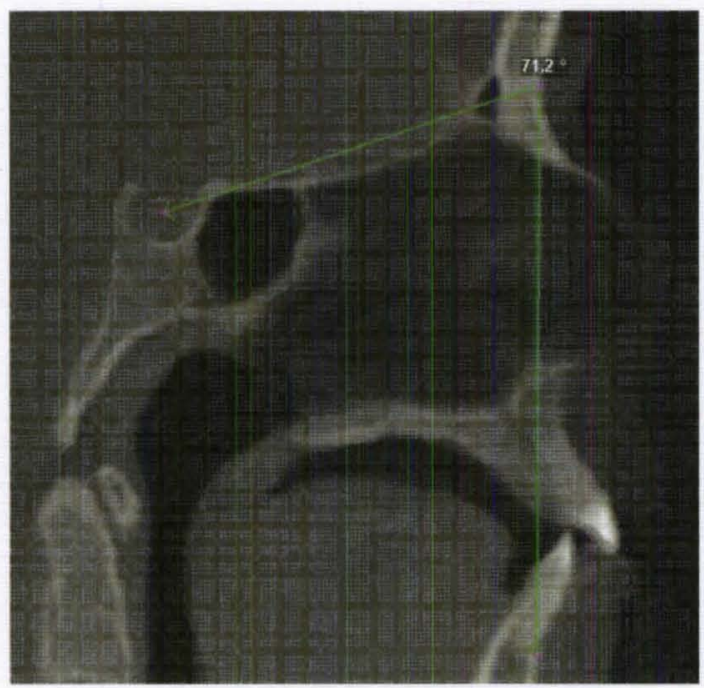

Figure 31. Sella Turcica to Nasion to B-Point.

A-Point to Nasion to B-Point (Sagittal): In the midsagittal plane points were marked under magnification at A-Point, then $\mathrm{N}$ and finally at B-point (Figure 32).

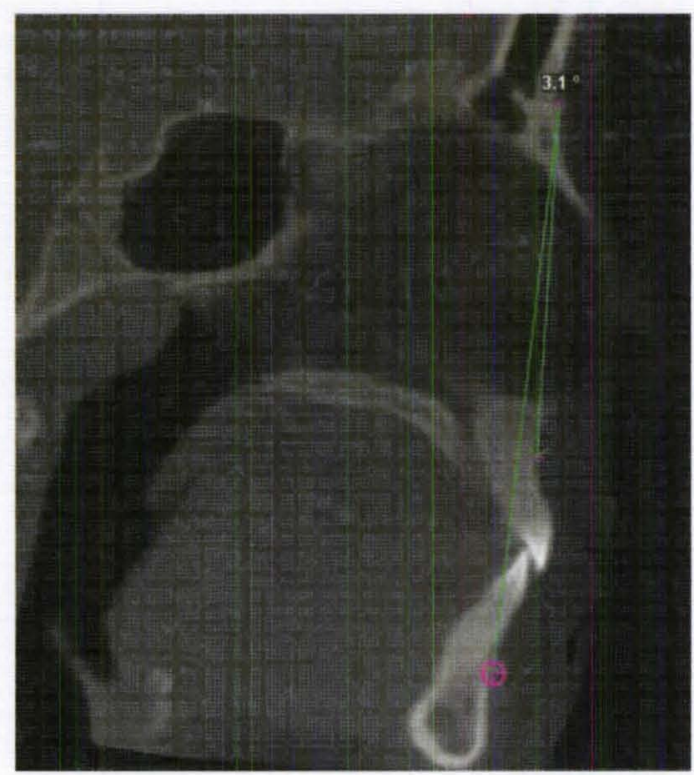

Figure 32. A-Point to Nasion to B-Point. 
Sella Turcica to Posterior Nasal Spine (Sagittal): In the midsagittal plane points were placed under magnification in the center of the Sella Turcica and at the most posterior aspect of the Posterior Nasal Spine (Figure 33).

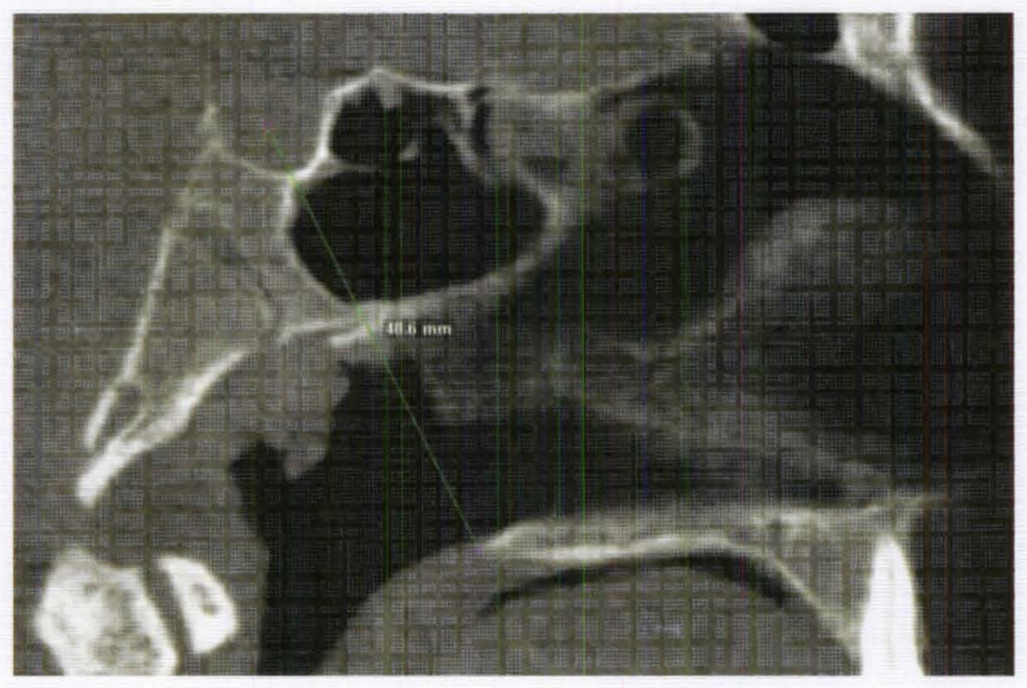

Figure 33. Sella Turcica to Posterior Nasal Spine.

Sella Turcica to Sphenoid Floor (Sagittal): In the midsagittal plane, under magnification a point was placed overlapping the Sella Turcica point marked in the Sella Turcica to Posterior Nasal Spine measurement. A second point was placed along this line at the junction of the outer cortex of the body of the sphenoid inferiorly at its junction with the superior margin of the vomer (Figure 34). 


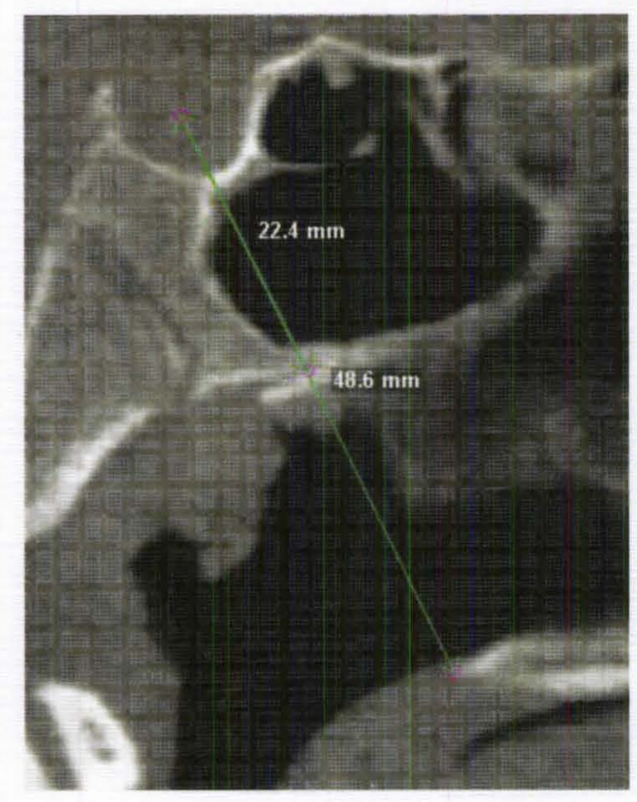

Figure 34. Sella Turcica to Sphenoid Floor.

Sphenoid Floor to Posterior Nasal Spine (Sagittal): The excel data spreadsheet was used to determine this linear value by subtracting the values of the Sella Turcica to sphenoid floor measurement from the Sella Turcica to Posterior Nasal Spine measurement (Figure 34).

Sella Turcica to Gnathion (Sagittal): In the midsagittal plane, under magnification, a point was placed overlapping the Sella Turcica point marked in the Sella Turcica to Posterior Nasal Spine measurement. The second point was placed on the Gnathion (Figure 35). 


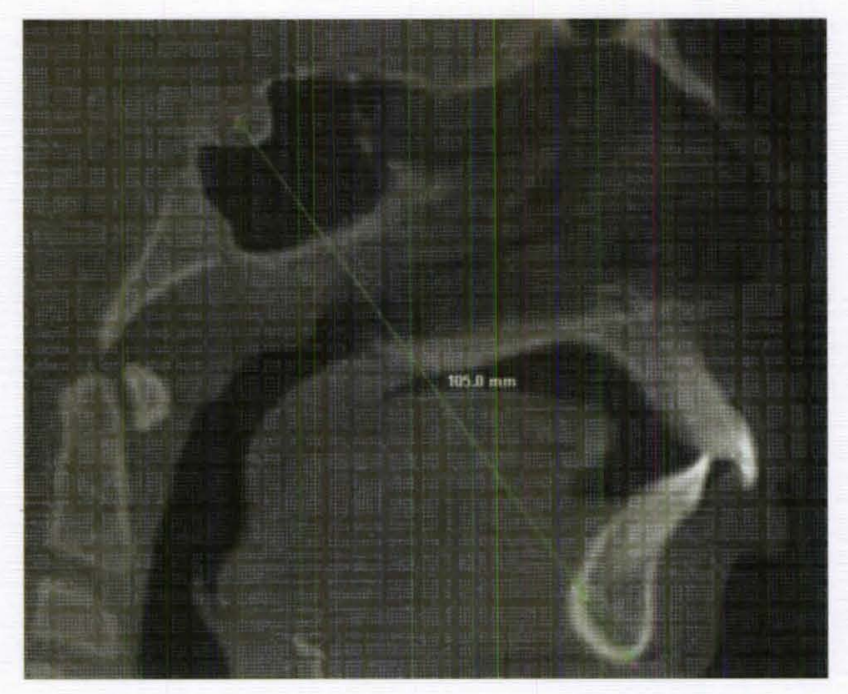

Figure 35. Sella Turcica to Gnathion.

Posterior Nasal Spine to Gnathion (Sagittal): The excel data spreadsheet was used to determine this linear value by subtracting the values of the Sella Turcica to Posterior Nasal Spine measurement from the Sella Turcica to Gnathion measurement (Figures 33 and 35).

Sella Turcica to Posterior Nasal Spine to Gnathion (Sagittal): This angular measurement was measured in the midsagittal plane through marking points under magnification in the center of the Sella Turcica, then on the posterior aspect of the Posterior Nasal Spine and finally on Gnathion (Figure 36). 


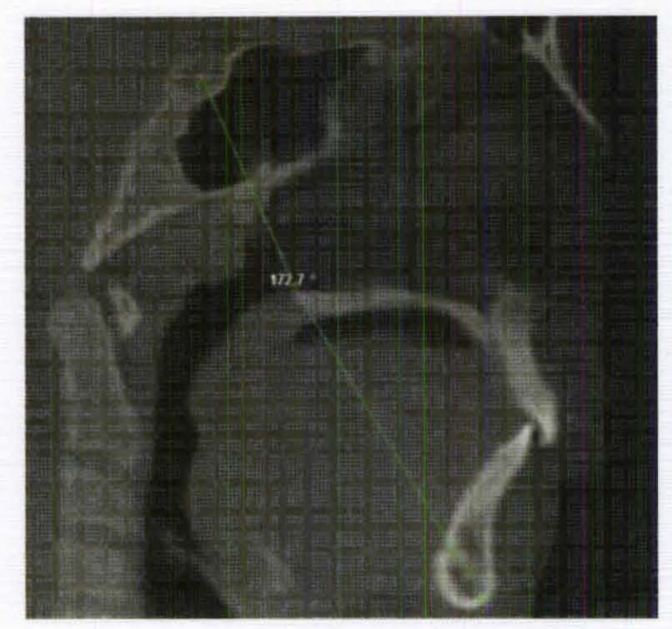

Figure 36. Sella Turcica to Posterior Nasal Spine to Gnathion.

Sphenoid Floor to Gnathion (Sagittal): The excel data spreadsheet was used to determine this linear value by subtracting the values of the Sella Turcica to sphenoid floor measurement from the Sella Turcica to Gnathion measurement (Figures 34 and 35).

Sphenoid Sinus Long Axis to Gnathion (Sagittal): In the midsagittal plane the sagittal slice was inspected and rotated such that the anterior-posterior crosshair would bisect the long axis of the sphenoid sinus. Three to six guide-lines were placed on the screen in what was at that time a superior-inferior direction. The guide-lines were superimposed with, what was at that time, the superior-inferior crosshair. Magnification was used to ensure the guidelines were parallel to this crosshair while touching the borders of the sphenoid sinus inner cortex. Immediately after placement of each guideline, prior to movement of the crosshair, the guideline was reduced to half its height while one if its ends were left unperturbed touching one of the inner cortical borders. A line was then placed that, upon inspection, best intersected the remaining ends of the guidelines towards the middle of the long axis of the sphenoid sinus. The angle tool was selected. A point was placed in an anterior location of the long axis line, then a point was 
placed at the junction of the Sella Turcica with the Gnathion line, and finally a point was placed at inferior location along the Sella Turcica Gnathion line. The sagittal slice was then reoriented to the original orientation as previously described (Figure 37).

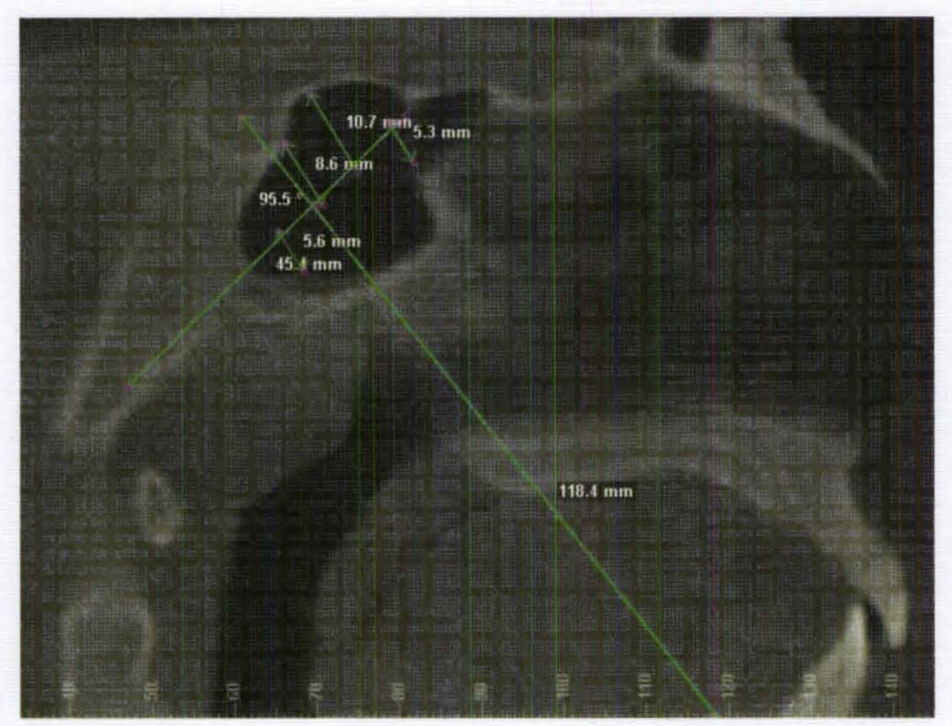

Figure 37. Sphenoid Sinus Long Axis to Gnathion.

Maximal Sphenoid Sinus Posterior-Anterior Length (Sagittal): In the midsagittal plane, at $0.5 \mathrm{~mm}$ slab thickness, the anterior-posterior crosshair was placed through the sphenoid sinus at the location suspected to have the longest length. Three to five lines were drawn from the posterior to the anterior inner cortical margins of the sphenoid sinus in locations suspected to have the greatest length by moving the anteriorposterior crosshair superior or inferior as required and by scrolling through the sagittal planes medially-laterally. Under magnification the anterior-posterior crosshair was used as a guide to ensure measurements were parallel to Frankfort Horizontal. Measurements being recorded would not cross any radiopaque areas such as septa as demonstrated in the 
figure below on the left. The measurement with the largest value was recorded in the excel data spreadsheet (Figure 38).

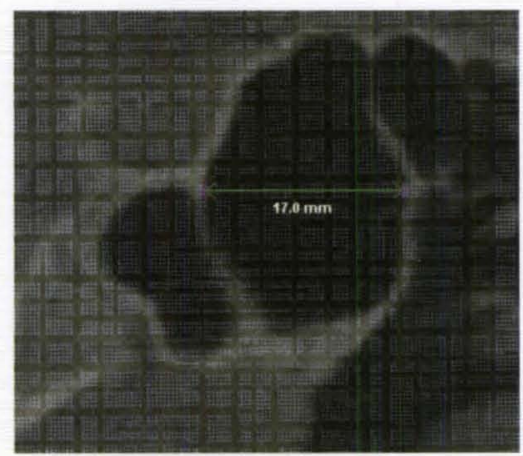

(a)

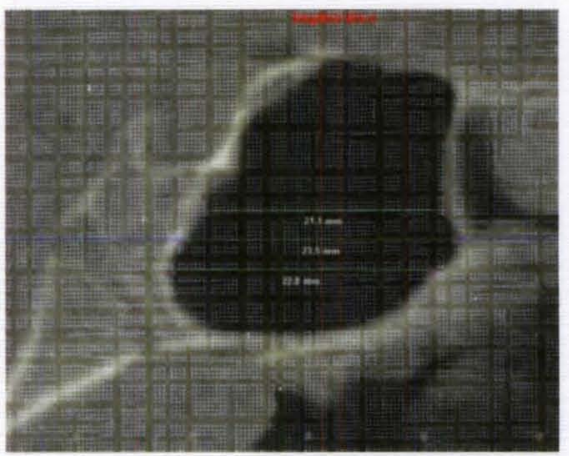

(B)

Figure 38. Maximal Sphenoid Sinus Posterior-Anterior Length in lateral sagittal slice (a), and in a different lateral sagittal slice measured at 3 locations (b).

\section{Maximal Right Maxillary Sinus Posterior-Anterior Length (Sagittal): The}

same technique was applied as that used to measure the Maximal Sphenoid Sinus Posterior-Anterior Length (Figure 39).

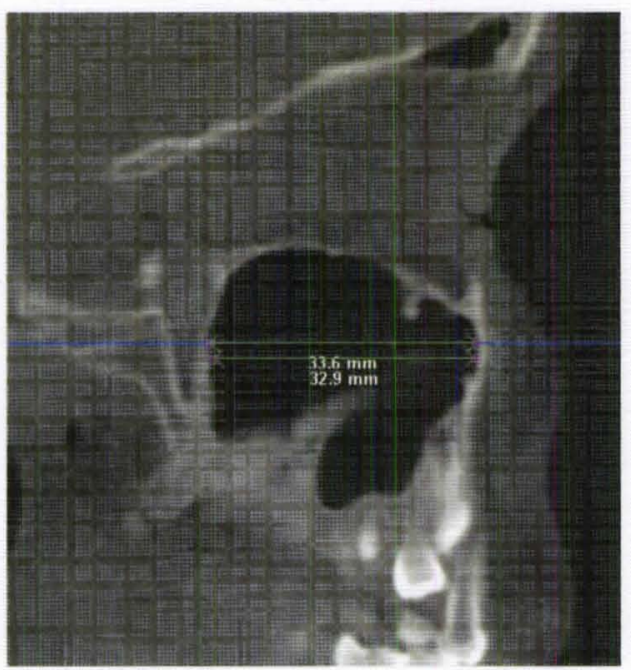

Figure 39. Maximal Right Maxillary Sinus Posterior-Anterior Length. 
Maximal Left Maxillary Sinus Posterior-Anterior Length (Sagittal): The same technique was applied as that used to measure the Maximal Sphenoid Sinus PosteriorAnterior Length independently of the plane used to measure the maximal right maxillary sinus posterior-anterior length (Figure 39).

\section{XY Axis Angle (Nasion to Basion with Gnathion to Sella Turcica) (Sagittal):}

In the mid sagittal plane, a line was drawn from Nasion to Basion. A second line was drawn from Sella Turcica to Gnathion. The first point of this angular measurement was placed toward the forward end of the Nasion-Basion line. The second point was placed at the intersection of the two lines. The third point was placed toward the bottom end of the Sella Turcica-Gnathion line (Figure 40).

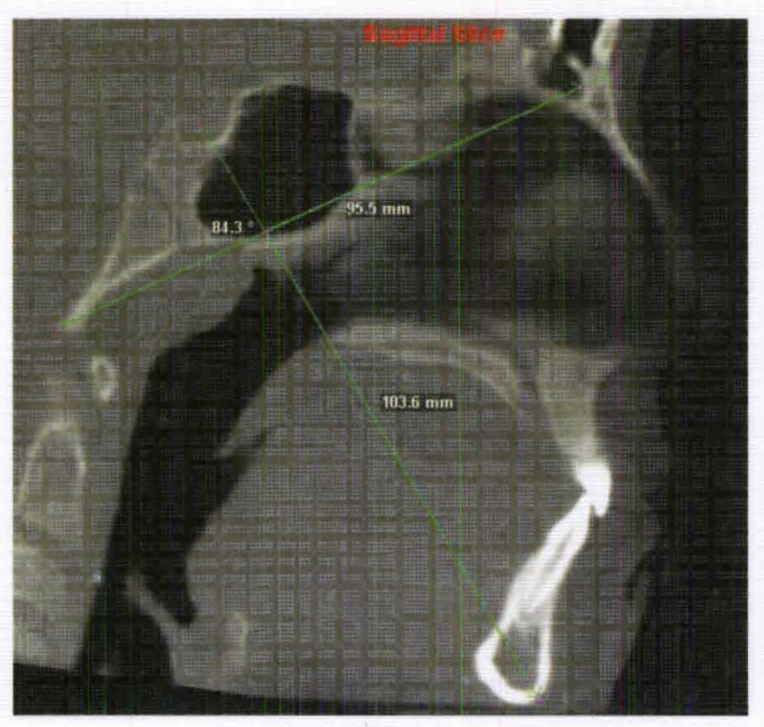

Figure 40. XY Axis Angle (Nasion to Basion with Sella Turcica to Gnathion). 
Posterior Facial Height (Sagittal): Using the $5.0 \mathrm{~mm}$ slab, in the midsagittal plane, the crosshairs were placed to intersect over the center of the Sella Turcica. The sagittal slice view was moved laterally until the Gonion appeared most clear. A line was placed measuring the distance from the intersection of the crosshairs to the Gonion (Figure 41).

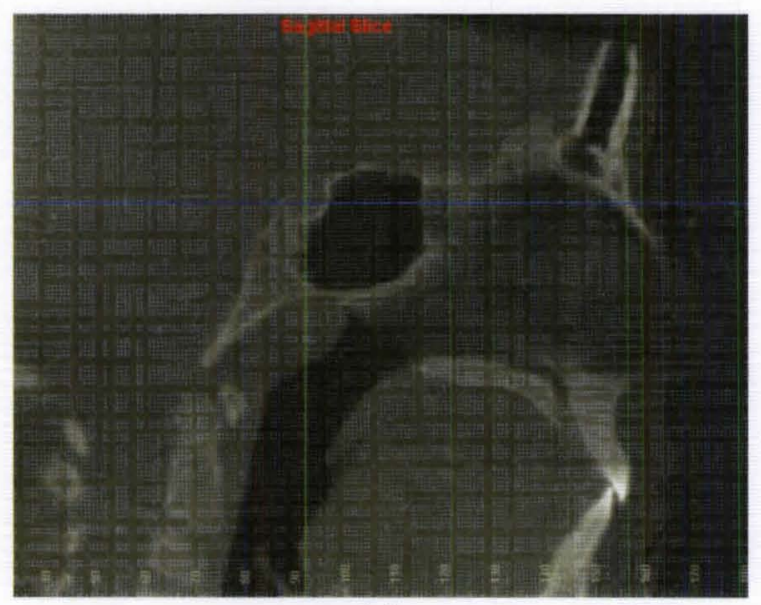

(a)

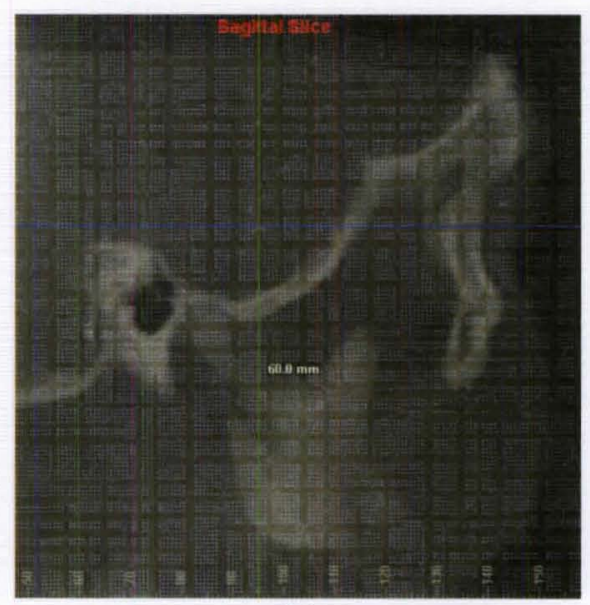

(b)

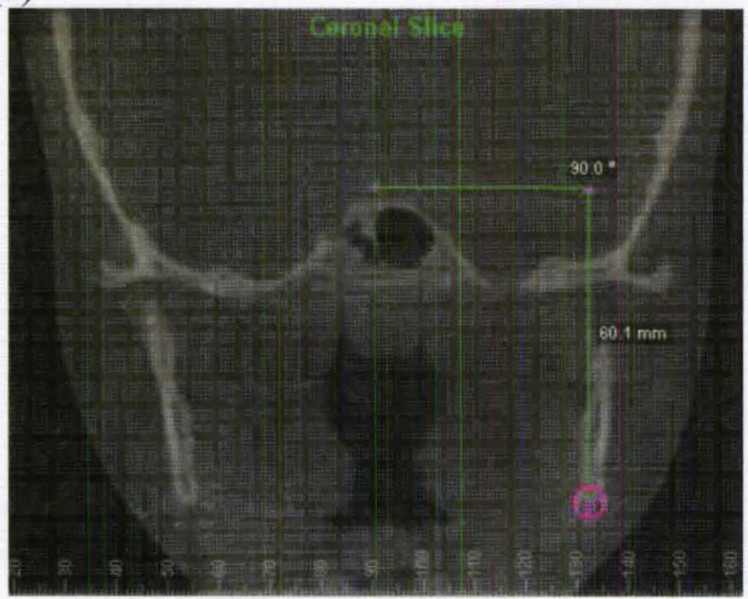

(c)

Figure 41. Intersection of crosshairs over Sella Turcica in midsagittal view (a), measurement from crosshairs to Gonion in sagittal view (b), coronal view of S-Go measurement (c). 
Sella Turcica to Nasion with Left Gonion to Gnathion (Sagittal): Using the

Steiner/SM analysis, in the midsagittal plane with $5.0 \mathrm{~mm}$ thickness, points were marked at Nasion, Sella Turcica and Gnathion. The sagittal moved laterally to mark the Gonion (Figure 42).

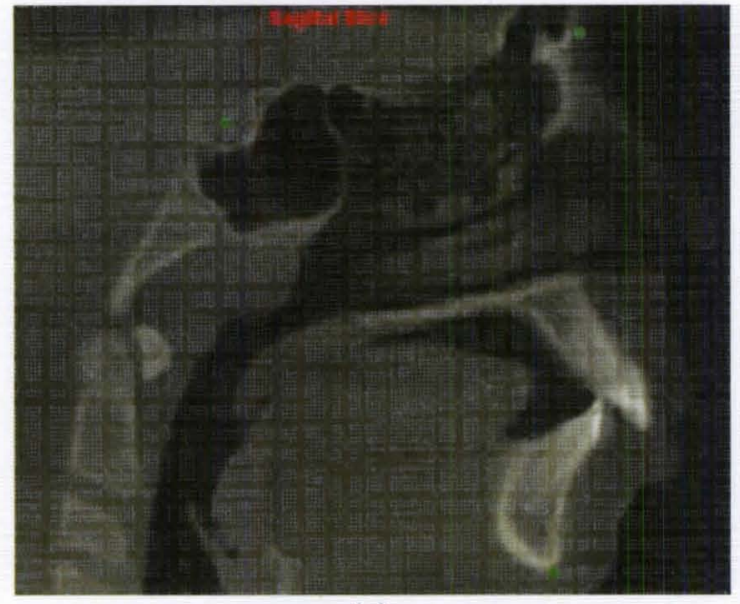

(a)

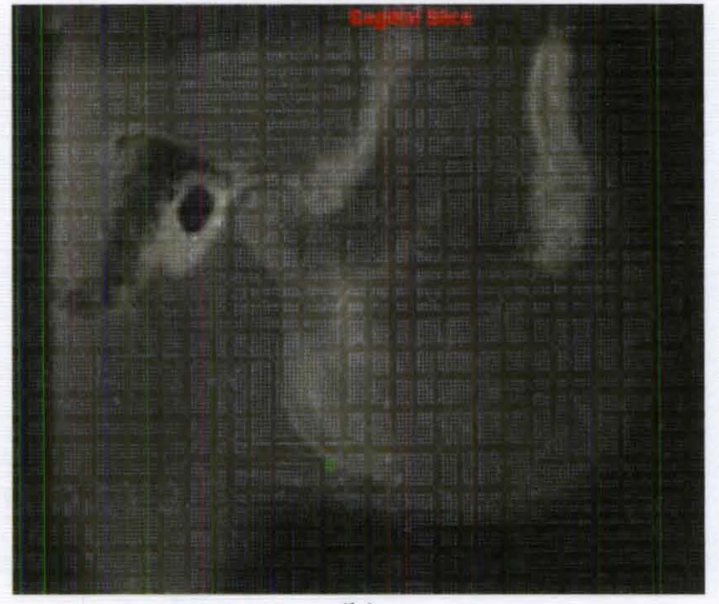

(b)

Figure 42. Midsagittal plane with markings placed at Sella Turcica, Nasion and Gnathion (a), and in a lateral sagittal plane with marking placed at Gonion (b). 
Maximal Sphenoid Sinus Superior-Inferior Height (Coronal): In a coronal plane, at $0.5 \mathrm{~mm}$ slab thickness, the superior-inferior crosshair was placed through the sphenoid sinus at the location suspected to have the tallest height. Three to five lines were drawn from the inferior to the superior inner cortical margins of the sphenoid sinus in locations suspected to have the greatest height by moving the anterior-posterior crosshair medially-laterally as required and by scrolling through the coronal planes anteriorlyposteriorly. Under magnification the inferior-superior crosshair was used as a guide to ensure measurements were parallel to Frankfort Horizontal. Measurements being recorded would not cross any radiopaque areas, such as septa, as demonstrated in Figure 38. The measurement with the largest value was recorded in the excel data spreadsheet (Figure 43).

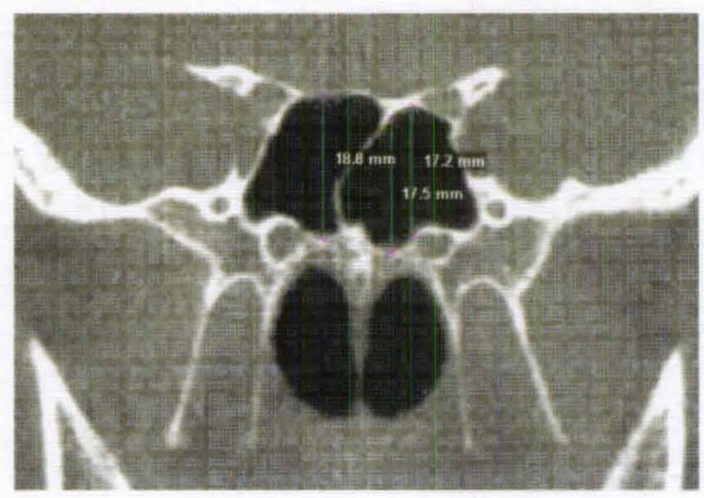

Figure 43. Maximal Sphenoid Sinus Superior-Inferior Height.

Maximal Right Maxillary Sinus Superior-Inferior Height (Coronal): The same technique was applied as that used to measure the maximal sphenoid sinus superiorinferior height (Figure 44). 


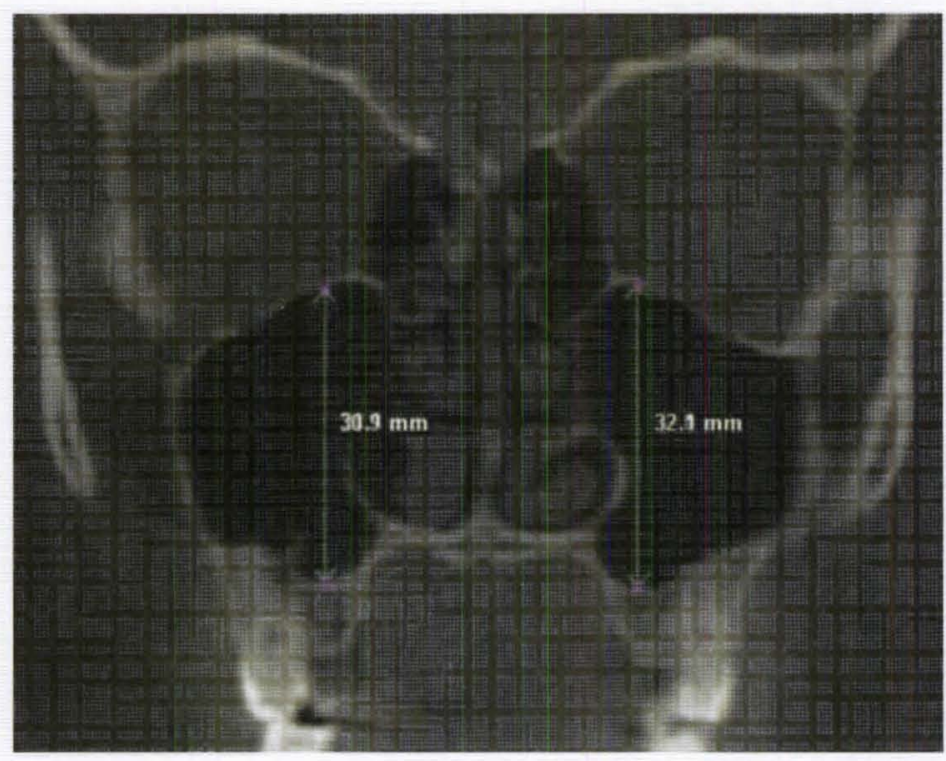

Figure 44. Maximal Maxillary Sinus Superior-Inferior Height.

Maximal Left Maxillary Sinus Superior-Inferior Height (Coronal): The same technique was applied as that used to measure the maximal sphenoid sinus superiorinferior height independently of the plane used to measure the maximal right maxillary sinus superior-inferior height (Figure 44).

Maximal Lateral Orbital Distance (Coronal): The coronal slice, with $0.5 \mathrm{~mm}$ thickness, was moved as anterior as possible while still clearly displaying Nasion. The medial-lateral crosshair was placed over this landmark. Three to five lines were drawn from the lateral orbital margins along the medial-lateral crosshair on slices suspected of having the greatest lateral orbital distance. This was done by scrolling through the coronal planes anteriorly-posteriorly. Under magnification the medial-lateral crosshair was used as a guide to ensure measurements were parallel to Frankfort Horizontal. The measurement with the largest value was recorded in the excel data spreadsheet (Figure 45). 


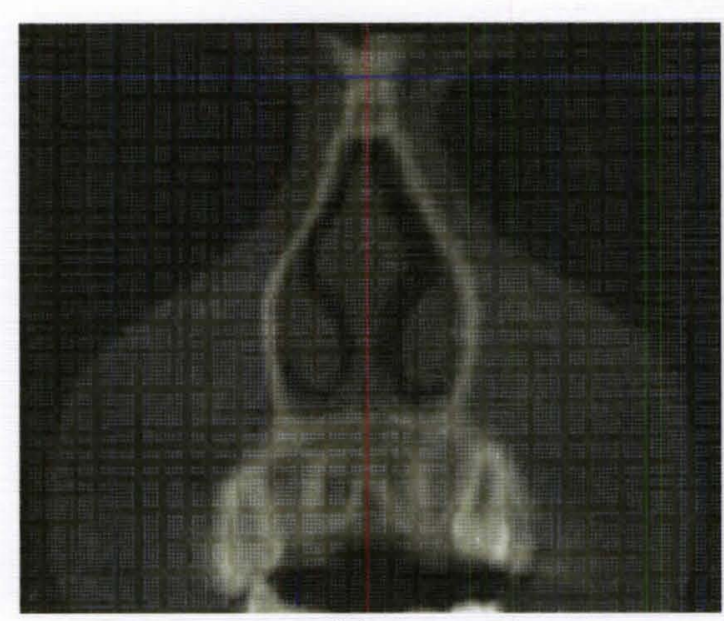

(a)

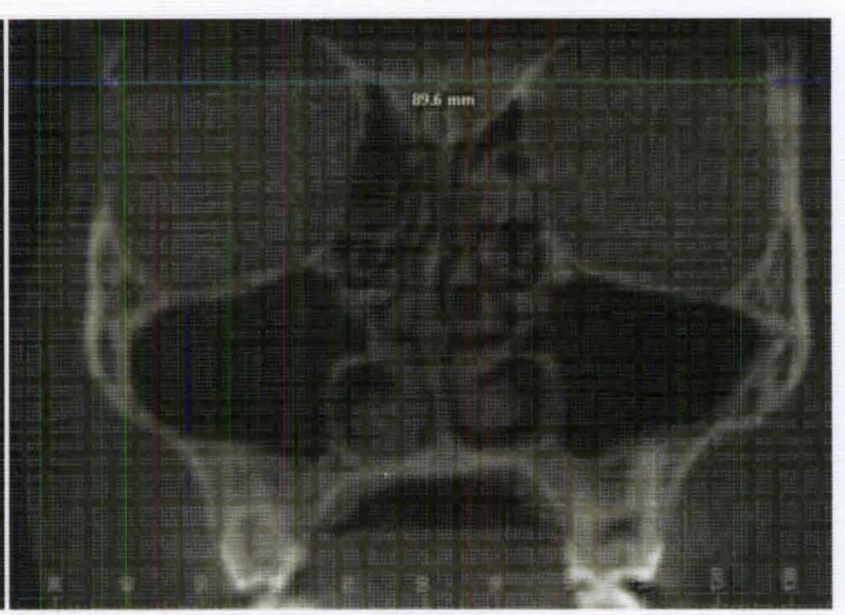

(b)

Figure 45. Maximal Lateral Orbital Distance. Crosshair alignment over Nasion (a), Maximal Lateral-Lateral Width (b).

Maximal Sphenoid Sinus Medial-Lateral Width (Coronal): In a coronal plane, at $0.5 \mathrm{~mm}$ slab thickness, the medial-lateral crosshair was placed through the sphenoid sinus at the location suspected to have the widest medial-lateral width. Three to five lines were drawn from the over the crosshair from one inner cortical margin to the other of the sphenoid sinus in locations suspected to have the greatest width by moving the medial-lateral crosshair superiorly-inferiorly as required and by scrolling through the coronal planes anteriorly-posteriorly. Under magnification the medial-lateral crosshair was used as a guide to ensure measurements were parallel to Frankfort Horizontal. Measurements being recorded were able to cross only a thin radiopaque midline septum, (Figure 46). The measurement with the largest value was recorded in the excel data spreadsheet. 


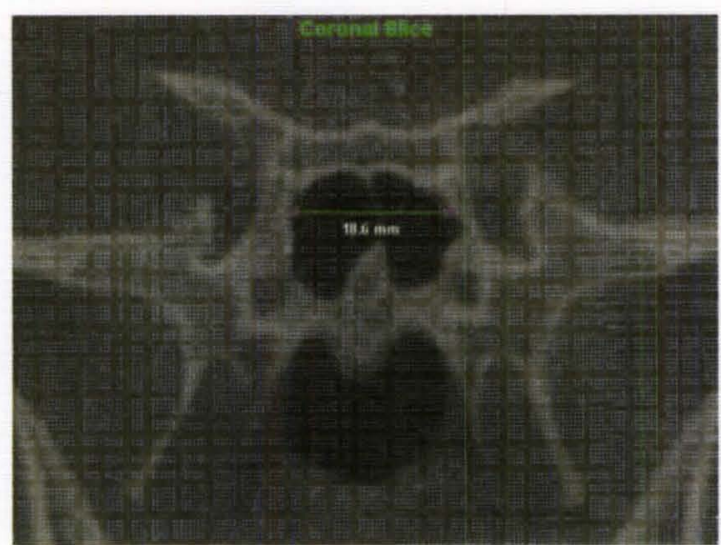

(a)

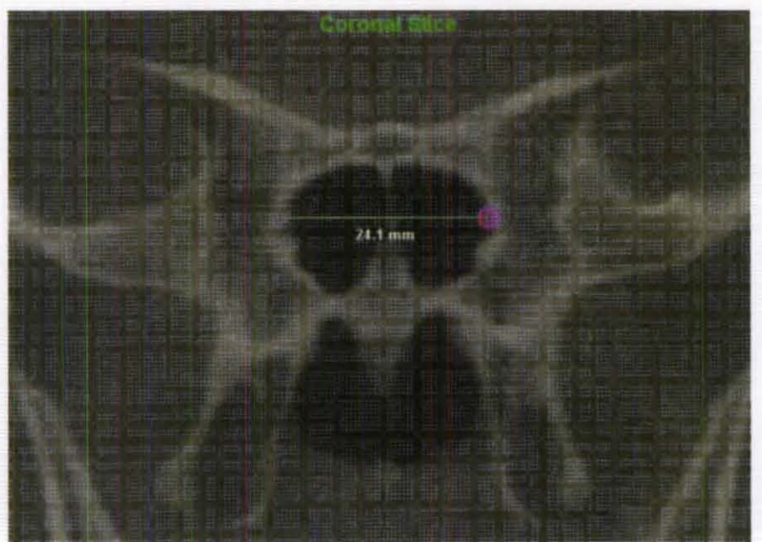

(b)

Figure 46. Maximal Sphenoid Sinus Medial-Lateral Width in coronal slice (a), Maximal

Sphenoid Sinus Medial-Lateral Width measured in another coronal slice (b).

Maximal Right Maxillary Sinus Medial-Lateral Width (Coronal): The same technique was applied, as that used to measure the maximal sphenoid sinus medial-lateral width except it was not permissible for this measurement being recorded to cross any radiopaque areas, such as septa. (Figure 47).

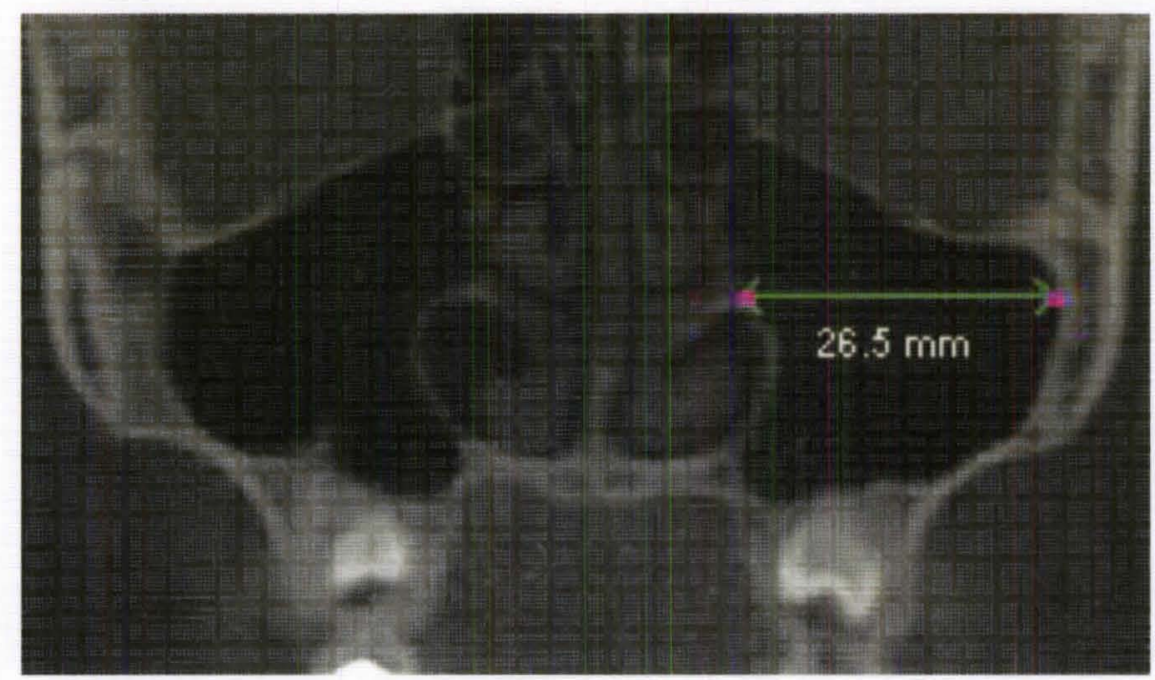

Figure 47. Maximal Left Maxillary Sinus Medial-Lateral Width. 
Maximal Left Maxillary Sinus Medial-Lateral Width (Coronal): The same technique was applied as that used to measure the maximal sphenoid sinus medial-lateral width independently of the plane used to measure the maximal right maxillary sinus medial-lateral height (Figure 47).

\section{Maximal Outer Right to Outer Left Maxillary Sinus Medial-Lateral Width}

(Coronal): In a coronal plane, at $0.5 \mathrm{~mm}$ slab thickness, the medial-lateral crosshair was placed through the maxillary sinuses at the location suspected to have the widest mediallateral width. Three to five lines were drawn from the crosshair of one inner cortical margin to the other in locations suspected to have the greatest width by moving the medial-lateral crosshair superiorly-inferiorly as required and by scrolling through the coronal planes anteriorly-posteriorly. Under magnification the medial-lateral crosshair was used as a guide to ensure measurements were parallel to Frankfort Horizontal. The only radiopacity these measurements were able to cross were those of the midline nasal structure. The measurement with the largest value was recorded in the excel data spreadsheet (Figure 48).

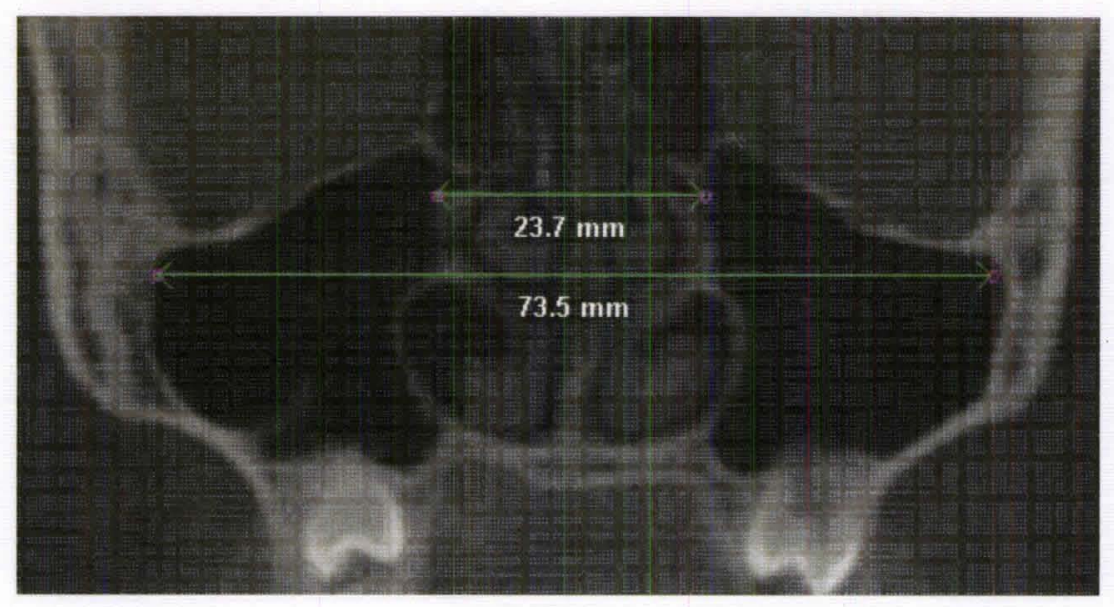

Figure 48. Maximal Outer and Minimal Inner Right to Left Maxillary Sinus MedialLateral Width. 
Minimal Inner Right to Inner Left Maxillary Sinus (Coronal): The same coronal slice and thickness as the maximal outer right to left maxillary sinus mediallateral width measurement was used for this measurement. The medial-lateral crosshair was used and three to five measurements were taken to discover the smallest possible value by placing two points along the medial inner cortices of the right and left maxillary sinus. The measurement was not required to be along the same line as the Maximal Outer Right to Left Maxillary Sinus Medial-Lateral Width (Figure 48). 


\section{APPENDIX D - Linear, Angular and Volumetric Measurements}

\begin{tabular}{|c|c|c|c|c|c|c|c|c|c|c|}
\hline Anonymized & Group & Age & N-ANS & ANS-UIT & ANS-LIT & Gn. UIT & Gn-LIT & $N \cdot G_{n}$ & ANS-IP & Gn-If \\
\hline 1 & 1 & 11 & 45.9 & 28.8 & 22.7 & 28.2 & 34.0 & 102.8 & 25.8 & 31.1 \\
\hline 2 & 1 & 10 & 47.0 & 27.1 & 21.1 & 29.6 & 35.7 & 103.8 & 24.1 & 32.7 \\
\hline 3 & 1 & 13 & 52.1 & 27.5 & 22.4 & 29.1 & 34.1 & 108.7 & 25.0 & 31.6 \\
\hline 4 & 1 & 12 & 41.7 & 28.9 & 25.2 & 26.6 & 30.4 & 97.3 & 27.1 & 28.5 \\
\hline 5 & 1 & 12 & 47.6 & 29.2 & 26.3 & 32.0 & 35.0 & 108.9 & 27.8 & 33.5 \\
\hline 6 & 1 & 15 & 51.2 & 28.2 & 20.6 & 29.6 & 37.3 & 109.1 & 24.4 & 33.5 \\
\hline 7 & 1 & 8 & 43.1 & 24.4 & 22.6 & 29.1 & 30.9 & 96.6 & 23.5 & 30.0 \\
\hline 8 & 1 & 8 & 45.7 & 23.8 & 20.3 & 27.6 & 31.2 & 97.2 & 22.1 & 29.4 \\
\hline 9 & 2 & 16 & 47.3 & 29.8 & 24.9 & 30.9 & 35.8 & 108.0 & 27.4 & 33.4 \\
\hline 10 & 2 & 16 & 47.6 & 25.5 & 24.3 & 35.3 & 36.5 & 108.4 & 24.9 & 35.9 \\
\hline 11 & 2 & 16 & 47.6 & 32.2 & 32.0 & 38.8 & 39.2 & 118.7 & 32.1 & 39.0 \\
\hline 12 & 2 & 14 & 46.8 & 24.3 & 18.3 & 26.0 & 32.0 & 97.1 & 21.3 & 29.0 \\
\hline 13 & 2 & 17 & 49.7 & 29.4 & 26.1 & 33.0 & 36.3 & 112.1 & 27.8 & 34.7 \\
\hline 14 & 2 & 14 & 45.1 & 24.8 & 25.2 & 34.3 & 34.4 & 104.5 & 25.0 & 34.4 \\
\hline 15 & 2 & 17 & 48.5 & 31.0 & 29.4 & 33.4 & 35.0 & 112.9 & 30.2 & 34.2 \\
\hline 16 & 2 & 17 & 46.9 & 26.6 & 24.1 & 36.4 & 39.1 & 110.0 & 25.4 & 37.8 \\
\hline 17 & 2 & 17 & 52.2 & 31.8 & 31.1 & 37.5 & 38.5 & 121.7 & 31.5 & 38.0 \\
\hline 18 & 3 & 25 & 50.4 & 28.6 & 28.6 & 39.7 & 39.7 & 118.7 & 28.6 & 39.7 \\
\hline 19 & 3 & 21 & 49.5 & 25.9 & 23.8 & 33.9 & 35.8 & 109.2 & 24.9 & 34.9 \\
\hline 20 & 3 & 19 & 49.1 & 34.1 & 31.6 & 40.4 & 42.9 & 123.6 & 32.9 & 41.7 \\
\hline 21 & 3 & 39 & 49.3 & 27.7 & 25.1 & 35.2 & 37.9 & 112.3 & 26.4 & 36.6 \\
\hline 22 & 3 & 23 & 50.7 & 27.4 & 26.7 & 33.5 & 34.2 & 111.6 & 27.1 & 33.9 \\
\hline 23 & 3 & 26 & 49.4 & 25.6 & 25.0 & 34.6 & 35.2 & 109.6 & 25.3 & 34.9 \\
\hline 24 & 3 & 27 & 42.7 & 27.0 & 23.7 & 30.7 & 34.0 & 100.4 & 25.4 & 32.4 \\
\hline 25 & 3 & 18 & 47.5 & 26.2 & 26.2 & 37.1 & 37.1 & 110.8 & 26.2 & 37.1 \\
\hline 26 & 3 & 23 & 52.0 & 27.6 & 26.9 & 36.4 & 37.1 & 116.0 & 27.3 & 36.8 \\
\hline 27 & 3 & 32 & 50.2 & 27.4 & 24.2 & 35.3 & 38.5 & 112.9 & 25.8 & 36.9 \\
\hline 16 & Remeasure & 17 & & 26.7 & 24.5 & & & & 25.6 & \\
\hline 5 & Remeasure & 12 & & 28.4 & 26.1 & & & & 27.3 & \\
\hline 10 & Remeasure & 16 & & 25.5 & 24.8 & & & & 25.2 & \\
\hline 15 & Remeasure & 17 & & 30.9 & 29.8 & & & & 30.4 & \\
\hline 4 & Remeasure & 12 & & 29.1 & 25.9 & & & & 27.5 & \\
\hline 14 & Remeasure & 14 & & 24.9 & 25.2 & & & & 25.1 & \\
\hline 20 & Remeasure & 19 & & 34.2 & 31.6 & & & & 32.9 & \\
\hline 22 & Remeasure & 23 & & 27.2 & 27.0 & & & & 27.1 & \\
\hline 11 & Remeasure & 16 & & 30.9 & 32.4 & & & & 31.7 & \\
\hline
\end{tabular}




\begin{tabular}{|c|c|c|c|c|c|c|c|c|c|c|c|}
\hline Anonymized & SNA & SNB & ANB & S-PNS & S-Sph Floor & Sph Floor-PNS & S-Gn & PNS-Gn & S-PNS-Gn & Sph Floor-Gn & Sph Floor-PNS \\
\hline 1 & 81.7 & 74.9 & 7.1 & 43.4 & 23.5 & 19.9 & 104.7 & 61.3 & 170.4 & 81.2 & 19.9 \\
\hline 2 & 91.1 & 88.1 & 3.3 & 49.3 & 26.2 & 23.1 & 118.6 & 69.3 & 169.7 & 92.4 & 23.1 \\
\hline 3 & 78.0 & 75.1 & 2.7 & 45.4 & 22.3 & 23.1 & 113.7 & 68.3 & 172.7 & 91.4 & 23.1 \\
\hline 4 & 75.7 & 71.5 & 4.1 & 38.2 & 17.8 & 20.4 & 95.0 & 56.8 & 173.2 & 77.2 & 20.4 \\
\hline 5 & 80.9 & 79.0 & 2.2 & 41.1 & 19.9 & 21.2 & 115.1 & 74.0 & 167.6 & 95.2 & 21.2 \\
\hline 6 & 79.0 & 74.3 & 4.8 & 49.3 & 24.6 & 24.7 & 113.2 & 63.9 & 170.1 & 88.6 & 24.7 \\
\hline 7 & 83.4 & 80.6 & 2.9 & 41.4 & 18.9 & 22.5 & 104.3 & 62.9 & 178.6 & 85.4 & 22.5 \\
\hline 8 & 79.9 & 76.5 & 3.1 & 38.5 & 22.0 & 16.5 & 103.4 & 64.9 & 180.0 & 81.4 & 16.5 \\
\hline 9 & 84.5 & 81.9 & 2.6 & 47.0 & 23.2 & 23.8 & 119.7 & 72.7 & 163.6 & 96.5 & 23.8 \\
\hline 10 & 82.5 & 79.8 & 2.8 & 46.6 & 25.6 & 21.0 & 118.2 & 71.6 & 168.8 & 92.6 & 21.0 \\
\hline 11 & 86.4 & 80.2 & 6.8 & 46.9 & 24.8 & 22.1 & 127.4 & 80.5 & 174.0 & 102.6 & 22.1 \\
\hline 12 & 87.8 & 82.1 & 5.9 & 44.3 & 24.3 & 20.0 & 111.9 & 67.6 & 165.4 & 87.6 & 20.0 \\
\hline 13 & 84.0 & 77.8 & 6.4 & 43.9 & 20.7 & 23.2 & 118.5 & 74.6 & 174.7 & 97.8 & 23.2 \\
\hline 14 & 82.9 & 79.6 & 3.7 & 48.3 & 24.1 & 24.2 & 117.2 & 68.9 & 170.7 & 93.1 & 24.2 \\
\hline 15 & 85.6 & 83.8 & 1.8 & 46.4 & 26.7 & 19.7 & 122.4 & 76.0 & 173.3 & 95.7 & 19.7 \\
\hline 16 & 89.0 & 84.4 & 4.5 & 44.1 & 20.7 & 23.4 & 120.6 & 76.5 & 177.4 & 99.9 & 23.4 \\
\hline 17 & 83.0 & 80.9 & 1.8 & 49.4 & 21.1 & 28.3 & 131.6 & 82.2 & 170.3 & 110.5 & 28.3 \\
\hline 18 & 89.5 & 86.7 & 2.8 & 49.5 & 25.8 & 23.7 & 133.8 & 84.3 & 170.1 & 108.0 & 23.7 \\
\hline 19 & 78.0 & 77.9 & 0.2 & 43.2 & 21.0 & 22.2 & 119.0 & 75.8 & 170.8 & 98.0 & 22.2 \\
\hline 20 & 81.8 & 79.2 & 2.6 & 43.3 & 23.4 & 19.9 & 132.1 & 88.8 & 175.1 & 108.7 & 19.9 \\
\hline 21 & 81.7 & 75.8 & 5.9 & 41.9 & 23.3 & 18.6 & 116.0 & 74.1 & 174.5 & 92.7 & 18.6 \\
\hline 22 & 80.7 & 83.7 & 3.0 & 47.5 & 24.7 & 22.8 & 125.6 & 78.1 & 164.8 & 100.9 & 22.8 \\
\hline 23 & 87.5 & 84.2 & 3.3 & 46.5 & 23.5 & 23.0 & 122.1 & 75.6 & 167.2 & 98.6 & 23.0 \\
\hline 24 & 89.9 & 85.1 & 4.8 & 48.5 & 26.6 & 21.9 & 115.3 & 66.8 & 174.2 & 88.7 & 21.9 \\
\hline 25 & 77.7 & 80.4 & 2.8 & 43.6 & 21.0 & 22.6 & 118.2 & 74.6 & 166.1 & 97.2 & 22.6 \\
\hline 26 & 86.9 & 78.9 & 8.0 & 45.9 & 26.7 & 19.2 & 121.6 & 75.7 & 176.0 & 94.9 & 19.2 \\
\hline 27 & 83.5 & 80.1 & 3.4 & 44.1 & 21.6 & 22.5 & 121.6 & 77.5 & 171.8 & 100.0 & 22.5 \\
\hline 16 & & 82.5 & & & & & & & & & \\
\hline 5 & & 79.0 & & & & & & & & & \\
\hline 10 & & 78.4 & & & & & & & & & \\
\hline 15 & & 83.9 & & & & & & & & & \\
\hline 4 & & 71.2 & & & & & & & & & \\
\hline 14 & & 80.6 & & & & & & & & & \\
\hline 20 & & 78.1 & & & & & & & & & \\
\hline .22 & & 84.1 & & & & & & & & & \\
\hline 11 & & 77.9 & & & & & & & & & \\
\hline
\end{tabular}




\begin{tabular}{|c|ccccc|}
\hline Anonymized & PNS-Gn & Sph Sin Long Axis- Gn & Sph Sin PA Length & XY Axis Angle (NBa-GnS) & Post Fac Hgt (S-Go) \\
\hline 1 & 61.3 & 83.3 & 30.7 & 84.0 & 56.2 \\
2 & 69.3 & 95.5 & 22.4 & 81.6 & 76.2 \\
3 & 68.3 & 83.7 & 21.7 & 89.1 & 68.6 \\
4 & 56.8 & 92.5 & 14.0 & 92.4 & 49.0 \\
5 & 74.0 & 86.4 & 27.3 & 89.0 & 71.3 \\
6 & 63.9 & 91.7 & 26.7 & 88.3 & 70.2 \\
7 & 62.9 & 82.4 & 12.8 & 84.8 & 63.8 \\
8 & 64.9 & 92.7 & 22.0 & 84.0 & 60.1 \\
\hline 9 & 72.7 & 81.6 & 35.9 & 89.0 & 75.7 \\
10 & 71.6 & 81.4 & 31.6 & 80.9 & 64.7 \\
11 & 80.5 & 96.3 & 35.9 & 87.1 & 84.7 \\
12 & 67.6 & 81.3 & 31.6 & 80.6 & 71.9 \\
13 & 74.6 & 78.4 & 20.7 & 86.6 & 73.9 \\
14 & 68.9 & 73.1 & 25.3 & 88.6 & 75.6 \\
15 & 76.0 & 79.2 & 27.8 & 81.4 & 75.6 \\
16 & 76.5 & 74.3 & 30.6 & 85.5 & 69.1 \\
17 & 82.2 & 91.3 & 24.4 & 87.7 & 84.9 \\
\hline 18 & 84.3 & 82.1 & 32.5 & 82.4 & 80.0 \\
19 & 75.8 & 89.9 & 27.4 & 84.1 & 79.1 \\
20 & 88.8 & 84.0 & 27.0 & 85.7 & 89.2 \\
21 & 74.1 & 91.6 & 31.0 & 91.5 & 74.3 \\
22 & 78.1 & 86.6 & 32.2 & 83.1 & 78.5 \\
23 & 75.6 & 78.4 & 27.9 & 82.0 & 74.6 \\
24 & 66.8 & 75.4 & 29.2 & 81.2 & 70.6 \\
25 & 74.6 & 73.7 & 31.6 & 81.2 & 32.4 \\
26 & 75.7 & 84.3 & 28.0 & 87.7 & 76.7 \\
27 & 77.5 & 67.3 & 17.3 & 83.2 & \\
\hline
\end{tabular}




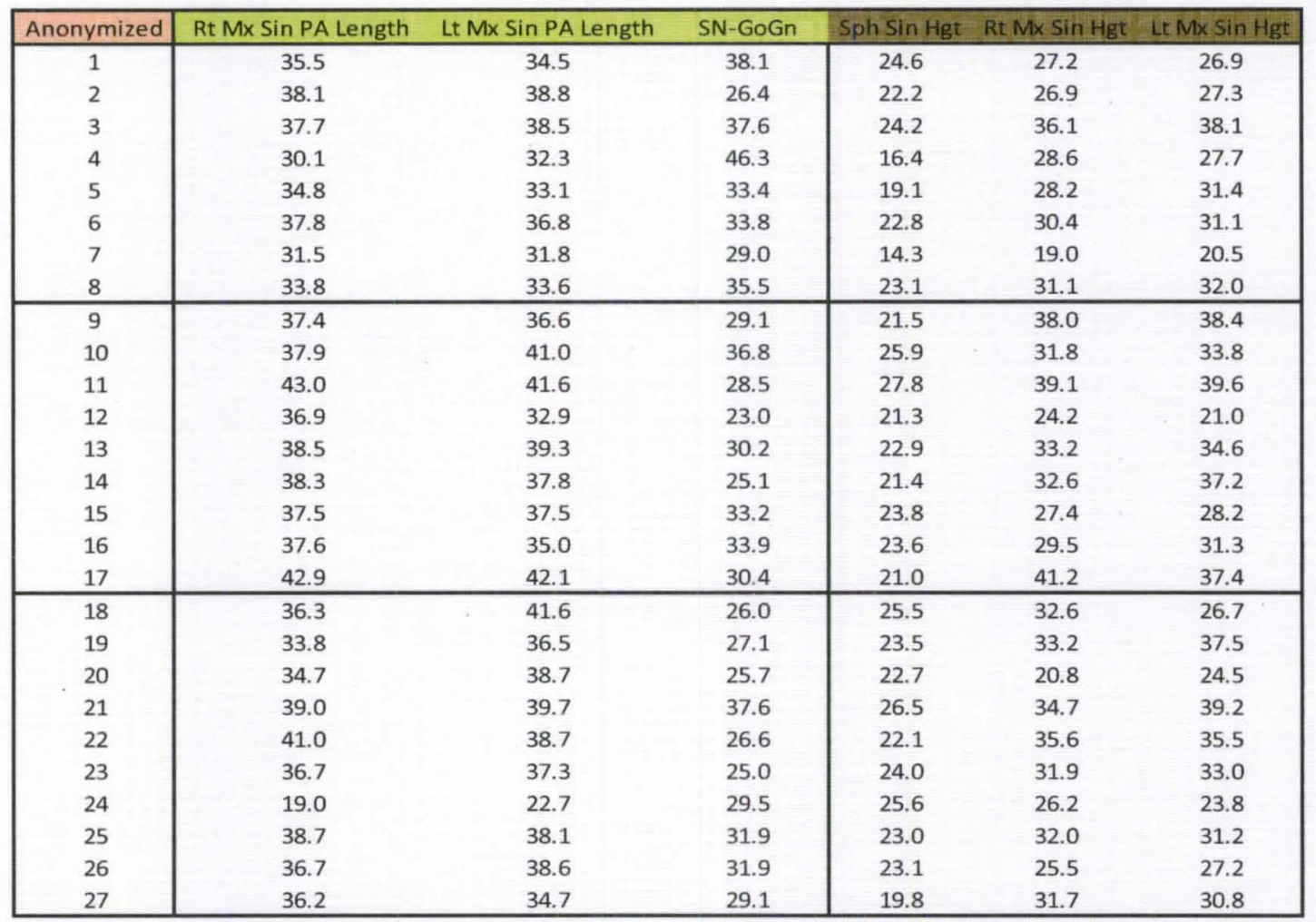




\begin{tabular}{|c|c|c|c|c|c|c|}
\hline Anonymized & Lat Orb Distance & Sph Sin Width & Rt Mx Sin Width & Lt Mx Sin Width & Outer Mx Sin & Inner Mx Sin \\
\hline 1 & 89.6 & 48.6 & 31.5 & 30.1 & 85.9 & 23.8 \\
\hline 2 & 84.5 & 32.6 & 20.7 & 20.9 & 73.4 & 28.6 \\
\hline 3 & 94.8 & 36.5 & 21.9 & 25.5 & 71.9 & 26.9 \\
\hline 4 & 76.1 & 13.8 & 22.9 & 25.6 & 75.8 & 27.7 \\
\hline 5 & 88.0 & 33.0 & 20.9 & 18.8 & 72.1 & 32.5 \\
\hline 6 & 92.6 & 33.4 & 30.2 & 28.4 & 84.0 & 24.4 \\
\hline 7 & 81.5 & 24.1 & 20.7 & 23.6 & 68.8 & 23.8 \\
\hline 8 & 83.6 & 26.7 & 24.4 & 26.5 & 73.5 & 23.7 \\
\hline 9 & 92.1 & 48.2 & 33.3 & 32.2 & 86.2 & 22.8 \\
\hline 10 & 85.2 & 40.3 & 26.6 & 29.1 & 79.2 & 24.1 \\
\hline 11 & 91.6 & 32.2 & 29.5 & 26.8 & 81.7 & 25.1 \\
\hline 12 & 77.9 & 23.2 & 17.4 & 15.5 & 65.4 & 31.9 \\
\hline 13 & 92.4 & 33.1 & 24.3 & 27.5 & 79.9 & 25.2 \\
\hline 14 & 94.9 & 37.2 & 29.3 & 33.0 & 86.2 & 24.6 \\
\hline 15 & 93.2 & 29.4 & 20.6 & 20.8 & 72.1 & 30.1 \\
\hline 16 & 84.6 & 35.6 & 24.7 & 24.3 & 78.0 & 27.0 \\
\hline 17 & 88.5 & 24.6 & 28.1 & 27.1 & 84.1 & 23.8 \\
\hline 18 & 92.4 & 48.8 & 28.3 & 29.6 & 83.8 & 31.2 \\
\hline 19 & 86.0 & 30.5 & 23.1 & 24.4 & 72.1 & 24.9 \\
\hline 20 & 96.0 & 33.3 & 18.3 & 20.9 & 71.0 & 30.9 \\
\hline 21 & 84.2 & 38.4 & 23.8 & 28.8 & 74.1 & 21.9 \\
\hline 22 & 89.7 & 26.8 & 31.4 & 31.4 & 82.9 & 19.5 \\
\hline 23 & 84.5 & 30.2 & 25.6 & 22.2 & 77.7 & 28.5 \\
\hline 24 & 85.6 & 38.4 & 11.0 & 13.7 & 63.8 & 37.0 \\
\hline 25 & 66.7 & 26.2 & 22.4 & 25.8 & 73.5 & 23.9 \\
\hline 26 & 86.1 & 35.9 & 23.5 & 28.1 & 79.4 & 25.3 \\
\hline 27 & 78.0 & 28.5 & 21.6 & 23.2 & 71.9 & 23.6 \\
\hline
\end{tabular}




\begin{tabular}{|c|c|c|c|}
\hline Anonymized & Sph Sin Vol & Rt $M \times \operatorname{Sin} \mathrm{Vol}$ & Lt $M \times \sin V o l$ \\
\hline 1 & 15143.3 & 12958.0 & 12852.3 \\
\hline 2 & 11252.1 & 10907.1 & 11145.7 \\
\hline 3 & 12092.5 & 16264.5 & 17083.3 \\
\hline 4 & 2216.2 & 10585.8 & 11777.5 \\
\hline 5 & 7760.9 & 10559.5 & 10488.4 \\
\hline 6 & 9136.9 & 15429.9 & 14704.9 \\
\hline 7 & 2455.0 & 6267.6 & 6956.7 \\
\hline 8 & 8501.4 & 10617.9 & 11246.7 \\
\hline 9 & 13311.2 & 15087.8 & 16403.9 \\
\hline 10 & 15172.7 & 16005.2 & 18545.9 \\
\hline 11 & 13477.1 & 24885.4 & 23047.7 \\
\hline 12 & 7831.5 & 8468.4 & 5893.4 \\
\hline 13 & 9333.4 & 15712.6 & 17063.0 \\
\hline 14 & 14044.1 & 20962.9 & 20376.7 \\
\hline 15 & 7117.1 & 11022.3 & 11974.3 \\
\hline 16 & 12134.5 & 14403.0 & 14832.4 \\
\hline 17 & 8102.4 & 28341.2 & 22346.1 \\
\hline 18 & 15249.4 & 14551.6 & 15210.4 \\
\hline 19 & 9090.2 & 12752.2 & 15694.3 \\
\hline 20 & 7656.5 & 6851.9 & 11244.8 \\
\hline 21 & 13075.4 & 14627.4 & 17685.8 \\
\hline 22 & 11687.3 & 22342.6 & 20964.0 \\
\hline 23 & 9220.2 & 15429.7 & 14967.8 \\
\hline 24 & 14015.5 & 2676.8 & 4139.6 \\
\hline 25 & 9206.6 & 13476.0 & 13785.1 \\
\hline 26 & 9521.0 & 12159.0 & 14685.8 \\
\hline 27 & 5498.8 & 10768.6 & 11805.4 \\
\hline 16 & 11537.4 & & \\
\hline 5 & 7695.2 & & \\
\hline 10 & 15389.9 & & \\
\hline 15 & 7145.4 & & \\
\hline 4 & 2067.8 & & \\
\hline 14 & 13777.0 & & \\
\hline 20 & 7832.6 & & \\
\hline 22 & 12034.5 & & \\
\hline 11 & 15825.9 & & \\
\hline
\end{tabular}




\section{CURRICULUM VITAE \\ Richard Halpern}

\section{EDUCATION}

$2009-2010$, Master of Science (M.Sc.)

School of Medicine, University of Louisville, KY

Department of Anatomical Sciences - Research Area: Cone-Beam CT

2007 - 2009, Pediatric Dental Training - General Practice Residency (G.P.R.)

Children's Hospital, Winnipeg, Canada

2003 - 2007, Doctor of Dental Medicine (D.M.D.)

College of Dentistry, University of Saskatchewan, Saskatoon, Canada 1999 - 2003, Bachelor of Science (B.Sc.)

Faculty of Arts and Science, Concordia University, Montréal, Canada

Exercise Science Department, Specialization: Athletic Therapy

\section{DENTAL EXPERIENCE}

2009 - Present, Dentist: Health Canada, Native Indian Reservations of Northern Manitoba, Canada

Spring 2008, 2009 and 2010, Volunteer Dentist: Society for Third World Dental Care / Dentistry for All, Guatemala

2007 - 2009, Dental Resident: Winnipeg Children's Hospital - University of Manitoba, Winnipeg, Canada

Summer 2006, Locum Dentist: Great Slave Dental Clinic, Yellowknife, Canada

Summer 2005, Orthodontic Assistant: Planète Ortho - Dr. Louis Fronenberg, Orthodontist, Montréal, Canada

2002 - 2003, Volunteer: McGill University Dental Outreach Program, Montréal, Canada 


\title{
PUBLICATIONS
}

Halpern R, Noble J. Location and Presence of Permanent Teeth in a Complete Bilateral Cleft Lip and Palate Population, The Angle Orthodontist. 80(3):591-6, May 2010

Halpern R, Rouleau T. The Effect of Air Abrasion Preparation on the Shear Bond Strength of an Orthodontic Bracket Bonded to Enamel, European Journal of Orthodontics. 32(2):224-7, April 2010

\section{POSTER PRESENTATIONS}

April 2009, Location and Presence of Permanent Teeth in a Complete Bilateral Cleft Lip and Palate Population, Halpern R*, Noble J, 2009 American Cleft Palate-Craniofacial Association Annual Meeting, Scottsdale, $A Z$

September 2008, Dental Anomalies in a Non-Syndromic Complete Bilateral Cleft Lip and Palate Population, Halpern R*, Noble J*2008 Annual Canadian Association of Orthodontists Scientific Session, Winnipeg, Canada

April 2006, The Effect of Air Abrasion Preparation on the Shear Bond Strength of an Orthodontic Bracket Bonded to Enamel, Halpern R*, Rouleau T*, University of Saskatchewan College of Dentistry Table Clinic Research Competition, Saskatoon, Canada

\section{TEACHING}

2007 - Present, Lecturer and Clinical Instructor: University of Manitoba - Faculty of Dentistry, Undergraduate Pediatric Dentistry, Winnipeg, Canada

2008 - 2009, Lecturer and Group Facilitator: University of Manitoba - Faculty of Medicine, Postgraduate Medical Education Teaching Improvement Programs (TIPs), Winnipeg, Canada

2006 - 2007, Senior Team Leader: University of Saskatchewan - College of Dentistry, Saskatoon, Canada

\begin{abstract}
AWARDS
January 2007 Pierre Fauchard Academy Annual Scholarship Award April $20062^{\text {nd }}$ Place Honors in Table Clinic Research Competition June 2003 Bachelor of Science with Distinction
\end{abstract}




\section{COMMUNITY AND CAMPUS INVOLVEMENT}

2010 - Present, Indian Journal of Dental Research, Peer Reviewer

2008 - Present, Society for Third World Dental Care / Dentistry for All, Chair of Corporate Relations Committee

2004 - Present, Alpha Omega International Dental Fraternity, Co-Chair Young Alumni Committee of International Body, Co-Chair Student Affairs Committee of International Body, Co-Founder and Past President of University of Saskatchewan Student Chapter Lambda

$2007-2009$, Professional Association of Residents and Interns of Manitoba (PARIM), Member of the Board

2003 - 2007, Canadian Dental Association, Committee on Student Affairs

2005 - 2007, Saskatchewan Dental Student Society, Executive Committee 